\title{
Mental health in elite athletes: International Olympic Committee consensus statement (2019)
}

\begin{tabular}{|c|}
\hline $\begin{array}{l}\mathrm{D} \\
25,26\end{array}$ \\
\hline
\end{tabular}

For numbered affiliations see end of article.

\section{Correspondence to} Dr Claudia L Reardon, Department of Psychiatry, University of Wisconsin School of Medicine and Public Health, Madison, WI 53719, USA; clreardon@wisc.edu

Received 14 February 2019 Revised 3 April 2019 Accepted 3 April 2019 Published Online First 15 May 2019
Check for updates

(C) Author(s) (or their employer(s)) 2019. No commercial re-use. See rights and permissions. Published by BMJ.

To cite: Reardon $\mathrm{CL}$ Hainline B, Aron CM, et al. Br J Sports Med 2019:53:667-699.

\section{ABSTRACT}

Mental health symptoms and disorders are common among elite athletes, may have sport related manifestations within this population and impair performance. Mental health cannot be separated from physical health, as evidenced by mental health symptoms and disorders increasing the risk of physical injury and delaying subsequent recovery. There are no evidence or consensus based guidelines for diagnosis and management of mental health symptoms and disorders in elite athletes. Diagnosis must differentiate character traits particular to elite athletes from psychosocial maladaptations.

Management strategies should address all contributors to mental health symptoms and consider biopsychosocial factors relevant to athletes to maximise benefit and minimise harm. Management must involve both treatment of affected individual athletes and optimising environments in which all elite athletes train and compete. To advance a more standardised, evidence based approach to mental health symptoms and disorders in elite athletes, an International Olympic Committee Consensus Work Group critically evaluated the current state of science and provided recommendations.

\section{BACKGROUND}

The International Olympic Committee (IOC) convened a consensus meeting on 12-14 November 2018 in Lausanne, Switzerland, at which experts reviewed the scientific literature addressing mental health symptoms and disorders in elite athletes. The participants analysed the current best evidence to provide a consensus statement for clinical practice and individual and systemic interventions to improve mental health among elite athletes. We define elite athletes as those competing at professional, Olympic or collegiate levels. Collegiate athletes often train and compete at levels similar to professional athletes, and including them expands the research we can draw on for this paper.

The group was charged with the following tasks:

- to review the literature describing prevalence, diagnosis and impact on athletic performance of mental health symptoms and disorders within elite athletes
- to review the literature describing and establishing recommendations for non-pharmacological and pharmacological management of mental health symptoms and disorders in elite athletes

- to provide recommendations on how to minimise negative impacts of the sport environment on mental health symptoms and disorders in elite athletes.

This consensus paper fulfils the IOC charge by addressing the multifaceted aspects of mental health symptoms and disorders in elite athletes. The intended audience includes sport and exercise medicine physicians and other clinicians (including physiotherapists and athletic trainers), psychiatrists and other licensed mental health providers, other mental health and performance professionals who work with elite athletes, researchers in the fields of elite athlete mental health and clinical or institutional leaders/ administrators who are stakeholders in sport.

\section{METHODS}

Planning for the consensus meeting began in June 2017 (figure 1). The initial organising group included IOC leadership (RB and LE) and the meeting co-chairs (CLR and $\mathrm{BH}$ ). They identified members of an expert panel, comprised of 23 individuals from 13 nations with expertise in the mental health of elite athletes. Panellists were identified based on their publications in the past 5 years, as determined by a literature search, and invited based on their clinical and/or scientific understanding of specific topics concerning mental health symptoms and disorders in elite athletes.

The meeting work group included the invited panel of experts, the organising committee members, four representatives from the IOC Medical and Scientific Department and two elite athlete representatives. Of the expert panel invited, one did not reply to the invitation and thus was not included, and one was removed after initial inclusion due to lack of follow-up. The final work group included psychiatrists, psychologists, primary care and orthopaedic sports medicine physicians, exercise scientists, a neurologist, a neurological surgeon and a social worker, and the work group represented Australia, Brazil, Canada, China, India, Italy, 


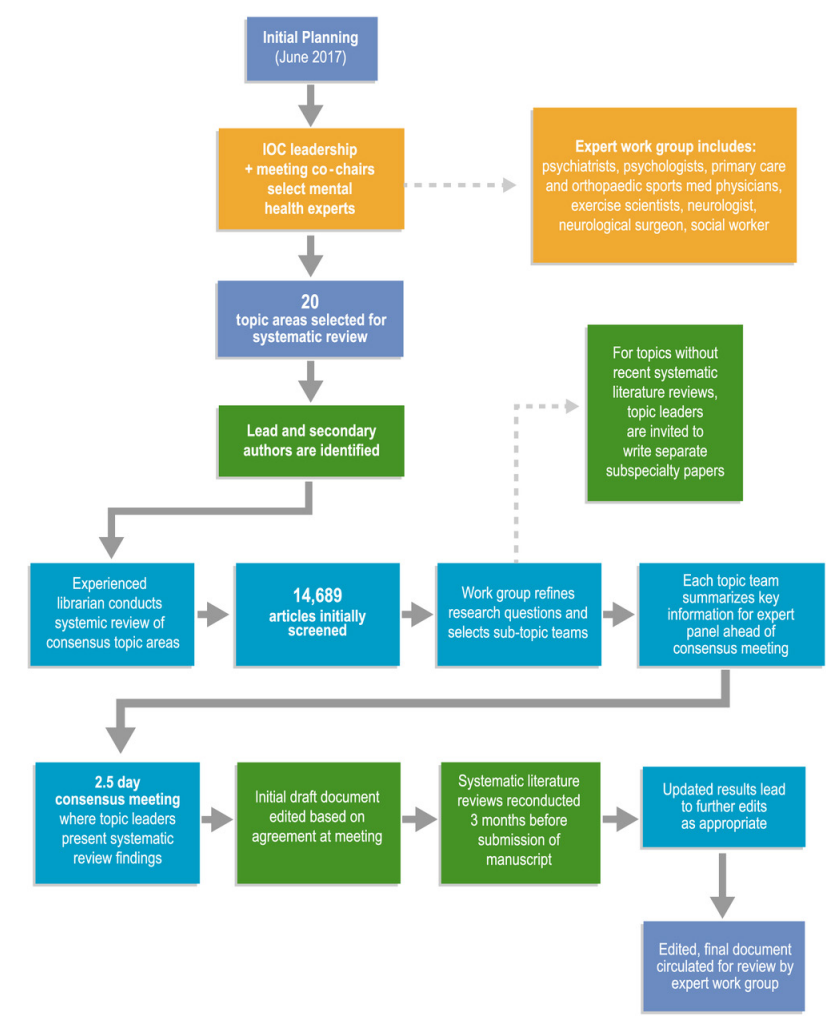

Figure 1 International Olympic Committee (IOC) consensus process for literature review, meeting and publication.

The Netherlands, Norway, South Africa, South Korea, Turkey, the UK and the USA.

The following methods sections describe the steps taken to plan and prepare for the meeting, the conduct of the meeting and the writing of the consensus statement.

\section{Systematic reviews}

The organising group initially identified 20 topic areas for the consensus statement (Figure 1). For each, a lead author and sometimes secondary author(s) were identified based on their scientific and clinical expertise.

An experienced librarian conducted a systematic review of each topic area using the PubMed, SportDiscus, PSycINFO, Scopus and Cochrane databases, and any additional databases felt relevant by individual topic leaders, for each topic. Searches were limited to the English language, and all study designs were included. An initial search strategy was developed with input from the expert panel to ensure that all relevant search terms were captured. Searches were revised by the librarian as needed. The expert panel screened 14689 published articles. Results and input from the expert panel led to revision of research questions asked within the 20 topic areas. Leaders of topics without a recent published systematic review were invited to write separate, more detailed, subspecialty papers on their topics; these will be published separately.

Each topic team was asked to summarise the key information from their review and share it with the expert panel before presenting it at the consensus meeting. A draft of these summaries was circulated to all participants prior to the meeting.

\section{Consensus meeting}

The consensus meeting was a 2.5 day series of presentations in which topic leaders presented their systematic review findings. Group discussion followed each presentation, and meeting co-chairs took notes during the discussions to capture all comments.

\section{Writing the consensus statement}

The initial draft systematic review summary document was edited based on agreement at the meeting. Key statements agreed on during the meeting were not changed during the drafting of the final document. To ensure inclusion of the most recent literature, the systematic literature reviews were re-conducted 3 months before submission of the manuscript, using the same search strategies as initially used. The updated search results were provided to topic leaders, and additional edits made accordingly. The edited final document was circulated for review and further editing by the full expert panel.

\section{GENERAL PREVALENCE OF MENTAL HEALTH SYMPTOMS AND DISORDERS IN ELITE ATHLETES}

Increasing numbers of epidemiological studies address mental health symptoms and disorders in elite athletes. Reporting prevalence compared with that in the general population is particularly difficult for the following reasons: (a) most studies in elite athletes have lacked reference groups from the general population; (b) different instruments have been used to assess mental health symptoms and disorders in athletes compared with the general population; (c) studies do not necessarily consider cross cultural differences in meanings and manifestations of mental health symptoms and disorders; and (d) studies vary in whether they describe self-reported specific mental health symptoms or physician diagnosed disorders. Regarding the latter, mental health disorders are typically defined as conditions causing clinically significant distress or impairment that meet certain diagnostic criteria, such as in the Diagnostic and Statistical Manual of Mental Disorders 5 (DSM-5) ${ }^{1}$ or the International Classification of Diseases, ${ }^{2}$ whereas mental health symptoms are more common, may be significant but do not occur in a pattern meeting specific diagnostic criteria and do not necessarily cause significant distress or functional impairment.

The reported prevalence of mental health symptoms and disorders among male elite athletes from team sports (cricket, football, handball, ice hockey and rugby) varies from $5 \%$ for burnout and adverse alcohol use to nearly $45 \%$ for anxiety and depression. ${ }^{3-13}$ Prospective studies have reported that mental health disorders occur in $5 \%$ to $35 \%$ of elite athletes over a follow-up period of up to 12 months. ${ }^{13-19}$ Among female elite athletes, mental health disorders-especially eating disorders-are also prevalent. ${ }^{20-23}$ Among collegiate athletes, the prevalence of mental health disorders ranges from $10 \%$ to $25 \%$ for depression and eating disorders. ${ }^{24-30}$

During an elite sport career, generic and sport specific factors may combine to increase the risk of mental health symptoms and disorders. ${ }^{3132}$ Elite athletes may experience a greater overall risk of mental health symptoms and disorders compared with their athletic counterparts if they suffer severe musculoskeletal injuries, undergo multiple surgeries, suffer from decreased sport performance or tend toward maladaptive perfectionism..$^{7162233-38}$ In other circumstances, sport participation might protect against mental health symptoms and disorders, ${ }^{39}$ since exercise has antidepressant effects. ${ }^{40}$ Finally, an athlete might have mental health symptoms or suffer with a mental health disorder with no apparent association between elite sport participation and the mental health condition. ${ }^{39}$

GENERAL APPROACHES TO MANAGEMENT OF MENTAL HEALTH SYMPTOMS AND DISORDERS IN ELITE ATHLETES

Management of mental health symptoms and disorders in elite athletes should take a comprehensive, integrative approach 
Box 1 Guidelines to overcome common obstacles that can interfere with psychotherapy with elite athletes

- Clinicians should:

- be flexible about timing of sessions (although without allowance of persistent cancelling of sessions) ${ }^{55}$

- urge couples or family therapy when relational issues impact functioning or performance ${ }^{55}$

- recommend psychotherapy plus pharmacological therapy when indicated for cases of moderate to severe mental health symptoms or disorders

- obtain collateral information from close informants, with appropriate consent, for athletes with severe mental health symptoms or disorders ${ }^{55}$

- insist that the athlete undergo substance use disorder treatment if needed ${ }^{55}$

- Clinicians should not:

- agree to see a surrogate (such as a coach or trainer) for psychotherapy sessions ${ }^{55}$

- provide experimental treatments, which may give false hope to athletes ${ }^{55}$

that puts the athlete at the centre and addresses the full range of emotional, mental, physical, social, spiritual and environmental influences that may affect a person's mental health. A personalised management strategy should be used to address mental health symptoms and disorders while striving to maintain optimum well being. The strategy should take into consideration the elite athlete's particular needs and circumstances, utilise the most appropriate consensus or evidence based interventions from a variety of scientific disciplines, and recognise differences across countries and cultures.

A core challenge in developing this consensus statement was that the evidence comes predominantly from high income countries, which have more health services compared with low and middle income countries ${ }^{41-43}$ where many athletes reside. There is debate concerning the range of ways in which mental health symptoms and disorders can be managed in culturally appropriate ways, drawing on resources from other health sectors and community carers, for example, ${ }^{4-46}$ with increasing evidence that intervening in ways that support existing community strengths may be of benefit to people with these conditions. ${ }^{478}$ It is important to consider this global context throughout this statement.

\section{Psychotherapy}

Psychotherapy is defined as the treatment of mental health symptoms or disorders or problems of living, and/or facilitation of personal growth, by psychological means; it is often based on therapeutic principles, structure and techniques. Psychotherapy, with or without pharmacologic therapy, is effective for the treatment of mental health symptoms and disorders but is commonly underprescribed. ${ }^{49}$ Moreover, studies on specific types of psychotherapy in elite athletes are lacking. Individual psychotherapy, especially cognitive behavioural therapy (CBT), is efficacious for treating depression and anxiety disorders in the general population. ${ }^{50}$ In many situations, psychoeducation and/ or counselling (broadly defined) are considered the treatment of choice for athletes. ${ }^{51}$ Depending on the sport, the athlete and the family dynamics, family therapy may be helpful. ${ }^{52}$ Further, although substance use may be problematic in elite athletes, little research exists on different psychotherapeutic treatments for substance use disorders in this population. ${ }^{534}$

Compared with non-athletes, elite athletes may present with sport related issues that may pose a challenge in psychotherapy and make it more difficult to tailor therapeutic interventions. These issues can include the following: diagnostic challenges (eg, overtraining syndrome vs major depression); aggression; narcissism; and entitlement. ${ }^{52}$ Insight oriented therapy, such as time limited psychodynamic psychotherapy, may be indicated for elite athletes with challenging personality and behavioural issues. ${ }^{55}$ In these situations, therapy should first focus on maladaptive behaviour patterns because personality traits tend to be more resistant to change. ${ }^{55}$

When engaging elite athletes in the psychotherapeutic process, the clinician must be mindful of how the athlete's characteristics may impact treatment. For instance, elite athletes may anticipate receiving preferential treatment from their healthcare providers. ${ }^{55}$ While a degree of flexibility may be needed to maintain patient privacy and accommodate travel schedules, perpetuating a pattern of preferential treatment may lead to unintended boundary violations. ${ }^{49}$ Box 1 guides clinicians as to how to overcome common obstacles that can interfere with treatment in elite athletes.

Clinicians should not compromise on delivering other appropriate treatment, including medications and hospitalisation as necessary, during psychotherapy with elite athletes. ${ }^{55}$ While barriers exist that may prevent elite athletes from seeking, accepting or effectively using psychotherapy, elite athletes also possess skills and personality characteristics-notably discipline and compliance with recommended regimens-that make them especially good candidates for psychotherapeutic interventions. ${ }^{49}$

\section{Pharmacological treatment}

Although psychotherapy is generally regarded as the firstline treatment for those with mild to moderate symptoms of mental illness, ${ }^{51}$ medications may be needed in those with more severe psychopathology ${ }^{56}$ Box 2 outlines four important considerations particular to elite athletes when prescribing psychiatric medications. Common side effects that may negatively impact athletic performance include: sedation; weight gain; cardiac side effects (including orthostatic hypotension, hypertension, tachycardia, palpitations, arrhythmias and electrocardiographic changes such as QTc prolongation); and tremor. ${ }^{567}$ Other relevant side effects include: impaired concentration; muscle rigidity; motor changes (including akathisia and bradykinesia); weight loss; blurred vision or dizziness; anxiety or agitation; and insomnia. ${ }^{56}$

The distinction between therapeutic and ergogenic performance enhancement that may result from a medication is important for all classes of medication. ${ }^{58}$ For example, an athlete who is performing poorly because of uncontrolled anxiety may gain a therapeutic performance enhancing effect by taking serotonin selective reuptake inhibitors (SSRIs). However, there is no evidence that they provide ergogenic performance enhancement, and thus they are not prohibited substances in elite sport. 575960 Indeed, stimulants are the only class of psychiatric drugs classified as prohibited substances, and they are prohibited only in competition; research suggest they could enhance performance beyond a pharmacological therapeutic effect. ${ }^{59}$

Finally, safety risks are paramount with certain psychiatric medications, as elite athletes commonly exercise at much higher intensity than the general population. ${ }^{61}$ For example, medications with blood levels that must be tightly regulated, such as 
Box 2 Four key considerations relevant for elite athletes when prescribing psychiatric medications ${ }^{57}$

- Potential negative impact on athletic performance

- Potential therapeutic performance enhancing effects (ie, based on improvement in the condition the medication is designed to treat)

- Potential non-therapeutic performance enhancement effects (ie, ergogenic effects)

- Potential safety risks

lithium, can be difficult to manage in elite athletes whose levels might be influenced by hydration status. ${ }^{5657}$

The four considerations of prescribing medications to elite athletes listed in Box 2 may vary by the particular sport and its demands, ${ }^{56}$ level of performance required, ${ }^{56}$ time frame within the athletic training/competition cycle and anticipated duration of treatment. Ultimately, medication choices must be informed by the need to provide effective clinical care for mental health symptoms and disorders. ${ }^{56}$ Although there are athlete specific considerations within each category of psychiatric medications, there is a paucity of applicable research on the topic. ${ }^{5660}$ Available studies have methodological flaws, including small sample sizes; medications are not used in real world dosages or time frames; populations studied are not representative of elite athletes; few female athletes are studied; performance measures used to determine if a medication has a negative impact on athletic performance may not represent actual performance impact; and study subjects often lack the mental health disorder that the medication is intended to treat. ${ }^{60-62}$ We acknowledge these limitations. Nevertheless, some research is available regarding psychiatric prescribing for athletes, and details are shared as relevant below.

\section{SPECIFIC MENTAL HEALTH SYMPTOMS AND DISORDERS IN ELITE ATHLETES}

In this section we detail the assessment and management of:

- sleep disorders and sleep concerns

- major depressive disorder and depression symptoms

- suicide

- anxiety and related disorders

- post-traumatic stress disorder and other trauma-related disorders

- eating disorders

- attention-deficit/hyperactivity disorder

- bipolar and psychotic disorders

- sport-related concussion

- substance use and substance use disorders

- gambling disorder and other behavioural addictions

Note that we have published separate review papers for several of these conditions.

\section{Sleep disorders and sleep concerns}

Insufficient sleep is defined as less than 7 hours of sleep for a healthy adult; ${ }^{63-68}$ adolescents and younger adults need 9-10 hours of sleep. ${ }^{67-70}$ National Collegiate Athletic Association (NCAA) surveys indicate that over half of collegiate athletes in the USA report regularly getting insufficient sleep; $50 \%$ report less than 7 hours of sleep per night in season and $79 \%$ report 8 hours or less. ${ }^{71}$ Data among large samples of elite athletes are sparse, although $49 \%$ of Olympic athletes would be classified as 'poor sleepers' (a term that includes multiple sleep problems). Elite athletes are particularly unlikely to get sufficient sleep the night prior to competition. ${ }^{72}$ Sleep deprivation impairs athletic performance across many sports ${ }^{73-96}$ and sleep improvement leads to improved performance. ${ }^{78} 8^{83} 97-100$ Sufficient sleep is important to avoid overtraining 828792101102 and maximise training gains by regulating adaptive release of hormones such as testosterone ${ }^{103-106}$ and growth hormone. ${ }^{107-111}$ Conversely, sleepiness and fatigue are associated with poor athletic outcomes. ${ }^{83} 85$

Circadian dysregulation - a misalignment between the individual's sleep-wake pattern and the desired pattern or the pattern regarded as the norm-is common in athletes, especially those who frequently travel across time zones. Circadian rhythms are important for metabolism, ${ }^{112-114}$ performance, ${ }^{91}{ }^{115-121}$ and psychological function. ${ }^{122-126}$ Disrupted circadian rhythms decrease athletic performance. ${ }^{127-129}$ The timing of sport training, especially in the early morning, can impair sleep ${ }^{72}$ and lead to suboptimal performance outcomes. Because of an athlete's chronotype (degree to which an individual is naturally a 'morning' or 'evening' person), timing of training or competition may not align with their personal time of peak performance. ${ }^{130-132}$ Persistent circadian dysregulation may contribute to neurodegeneration and mental health disorders. ${ }^{133-135}$

Insomnia disorder-a persistent difficulty initiating or maintaining sleep at least 3 nights per week for at least 3 months (in the context of adequate sleep opportunity and accompanied by daytime impairments) ${ }^{136}$ is a major risk factor for mood and other mental health disorders ${ }^{137-139}$ and impaired physical function. ${ }^{140}$ Insomnia disorder may be very common among athletes; approximately $64 \%$ of Olympic athletes reported significant insomnia symptoms. ${ }^{79}$ Insomnia is associated with impaired athletic performance. ${ }^{141}$

Sleep apnoea involves periodic reduction or cessation of breathing during sleep. ${ }^{136}$ Due to its relationship with higher body mass, sleep apnoea is especially common among American football players ${ }^{142-145}$ and many are at high risk for sleep apnoea. ${ }^{142} 146$ However, high body mass is not required for sleep apnoea, and many with the disorder remain undiagnosed. ${ }^{147}$ Additionally, training at altitude can produce central sleep apnoea. ${ }^{148}$ Untreated sleep apnoea, regardless of aetiology, increases fatigue and dramatically impairs athletic performance ${ }^{149-155}$ if untreated.

Addressing sleep problems in elite athletes requires screening for primary sleep disorders (such as circadian dysregulation, insomnia disorder or sleep apnoea), since solely treating comorbid mental health symptoms or disorders (such as depression or anxiety) will likely be unhelpful unless any primary sleep disorders are properly treated. ${ }^{156}$ A questionnaire validated for use in athletes may help identify athletes who need further sleep assessment. ${ }^{157}$ At the team level, the sports medicine team can promote healthy sleep by: (i) ensuring coaches model healthy sleep and schedule training around sleep and circadian rhythms; (ii) encouraging healthy sleep as part of the training protocol; (iii) promoting sleep health education; and (iv) engaging in proactive tracking and monitoring of sleep.

Non-pharmacological treatments are often recommended to treat sleep disorders in athletes because many medications are associated with increased injury risk and may cause side effects (eg, slowed reaction time, cognitive impairment) that may impair athletic performance. ${ }^{158} 159$ Non-pharmacological treatments (collectively described as 'behavioural sleep medicine') are available for many sleep disorders. ${ }^{160}$ The recommended treatment for insomnia is CBT for insomnia (CBTI); its effects are at least as good as those of medications, ${ }^{161} 162$ without the associated side effects. Further, CBTI is effective in the presence of comorbidities, such as chronic pain, depression and sleep apnoea. ${ }^{163}$ 
Table 1 Diagnostic and Statistical Manual of Mental Disorders-5 diagnostic criteria for a major depressive episode ${ }^{1}$

At least 5 symptoms must be present for at least 2 weeks (at least 1 of the symptoms must be depressed mood, or decreased interest or pleasure):

- Depressed mood or (in children) irritable most of the day, nearly every day, as indicated by either

Decreased interest or pleasure in most activities, most of each day subjective report (eg, feels sad or empty) or observation made by others (eg, appears tearful)

- Significant weight change or change in appetite

- Change in activity: psychomotor agitation or retardation

Feelings of worthlessness or excessive or inappropriate guilt

Recurrent thoughts of death or suicide
- Insomnia or hypersomnia

- Fatigue or loss of energy

Diminished ability to think or concentrate, or indecisiveness
Sleep hygiene alone is often insufficient for more complex problems. $^{83} 164$

Athletes taking any sleep aids should be advised of the importance of allowing a full night of restorative sleep. ${ }^{60}$ Melatonin, which may be prescribed or purchased over the counter, is a preferred choice of sports psychiatrists for insomnia. ${ }^{57}$ Additionally, it is the best studied sleep aid in athletes. ${ }^{57}$ Neither immediate release nor extended release melatonin adversely impact performance. 5660165166 Rarely, melatonin may cause hypotension. ${ }^{167}$ However, although melatonin often helps to ameliorate sleep problems, it may have limited utility for those with more extreme sleep difficulties, including insomnia disorder. ${ }^{168}$ Additionally, over the counter melatonin may contain impurities and unknown quantities of melatonin; athletes should purchase it only from a reputable company. ${ }^{60}$ If a supplement such as melatonin includes any prohibited substances, and an athlete ingests them unknowingly, the athlete will be held accountable if found to have an adverse analytical finding for a prohibited substance. Ignorance of ingredients or improper labelling of supplements is not excusable under the World Anti-Doping Agency (WADA) code. $^{60}$

If melatonin does not help an athlete with insomnia, trazodone and gabapentin are sometimes used, although they have not been studied specifically in athletes, ${ }^{57}$ and there is no evidence base to support their efficacy for insomnia disorder. ${ }^{168}$ Imidazopyridines (eg, zolpidem and zopiclone) may be options if needed ${ }^{57}$ and are effective medications for insomnia disorder. ${ }^{168}$ They have less of an impact on next day physical performance than benzodiazepines. ${ }^{169-173}$ Among the benzodiazepines, agents with longer half lives have a more detrimental impact on next day physical performance compared with shorter acting agents. ${ }^{174}$ This finding must be considered alongside the knowledge that benzodiazepines with shorter half lives are more likely to cause physical dependence and substance use disorders. ${ }^{175}$

For sleep apnoea, the recommended treatment is usually positive airway pressure therapy. ${ }^{176}$ Oral appliances are also recommended for some individuals, ${ }^{177}$ and in rare cases, airway surgery may be required. ${ }^{178}$ For circadian rhythm disturbances, melatonin is the treatment of choice and has established efficacy in many populations, ${ }^{179}$ although its dose and timing for schedule shifting are different than for sleep promotion. Typically, this involves lower doses timed earlier in the evening (for advancing sleep) or the end of the night (for delaying sleep). ${ }^{180} 181$ Timed bright light exposure is also routinely used to shift circadian rhythms. Bright light at night can delay sleep onset, and early morning light can advance sleep onset the next night. ${ }^{181} 182$

\section{Major depressive disorder and depression symptoms}

Individuals with major depressive disorder (MDD) experience depressed mood and/or little interest or pleasure from activities on most days over at least a 2 week period, in addition to associated physical, psychological and cognitive symptoms. ${ }^{1} \mathrm{~A}$ diagnosis requires at least five symptoms and a negative impact on functioning, but individuals may also experience depressive symptoms without meeting the criteria for MDD (table 1 ). ${ }^{1}$ An athlete specific screening tool for depression is reliable and valid (Box 3). ${ }^{183} 184$

The prevalence of depressive symptoms in elite athletes ranges from $4 \%{ }^{185}$ to $68 \%{ }^{35}$ When the research is considered in its entirety, the prevalence of depressive symptoms in elite athletes and the general population appears to be similar. ${ }^{186}$ However, elite athletes may not recognise or acknowledge depressive symptoms or may not seek support, ${ }^{187}$ in part related to stigma. ${ }^{188}$ Female athletes may be twice as likely to report depressive symptoms as male athletes. ${ }^{186}$ Rates of adjustment disorder with depressed mood (defined as experiencing more depressive symptoms than would normally be expected in response to a stressful life event, but not to the point of those symptoms meeting criteria for MDD) ${ }^{1}$ and persistent depressive disorder/dysthymic disorder (defined as a chronic course of depression lasting at least 2 years $)^{1}$ in elite athletes are unknown.

Different sports are associated with different risks for depressive symptoms and MDD. French athletes who took part in aesthetic or fine motor skills sports were at greater risk of experiencing depressive symptoms than those who took part in team ball sports. ${ }^{185}$ Among North American athletes, track and field athletes had the highest rates of MDD compared with those in other collegiate sports. ${ }^{29}$ Depressive symptoms may be more prevalent in individual sport athletes compared with team sport athletes. $^{12} 29189$

Risk factors associated with depressive symptoms and MDD in elite athletes include: genetic factors (eg, family history); environmental factors (eg, poor quality relationships, lack of social support) $;^{61190}$ injury; ${ }^{39}$ competitive failure $;^{39}$ retirement from sport; ${ }^{191}$ pain; ${ }^{192}$ and concussion. ${ }^{193}$ After athletes retire from elite sport, those with lower levels of physical activity have higher rates of MDD. ${ }^{194}$

Non-functional overreaching (NFO) and overtraining should be considered as possible relevant factors in athletes who present with depressive symptoms. There are no generally accepted diagnostic criteria for NFO and overtraining. NFO is often defined as the accumulation of training load without compensatory recovery, with resultant performance decrement and the need for more prolonged recovery. ${ }^{195} 196$ Overtraining is an extreme form of NFO that results in a prolonged performance decrement (usually longer than 2 months) and more severe psychological and/or neuroendocrinological manifestations. ${ }^{197} 198$ Both are associated with depressed mood. ${ }^{199}$ Symptoms that overlap with MDD may include fatigue, insomnia, appetite change, weight loss, amotivation and diminished concentration. ${ }^{200}$ In an 11 year study of 400 competitive collegiate swimmers, mood state disturbance increased with training stimulus during the season, and then fell to baseline as training load diminished. ${ }^{201}$ One possible difference between NFO/overtraining and MDD in some athletes may be the nature of the dysfunction-athletic performance in NFO/overtraining versus social, cognitive and 


\begin{tabular}{|c|c|c|}
\hline History of childhood trauma & $\triangleright$ & Anxiety \\
\hline - Agitation & 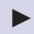 & Aggression \\
\hline - Impulsivity & 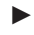 & Hopelessness \\
\hline - Interpersonal conflict & - & $\begin{array}{l}\text { Drug and alcohol } \\
\text { use }\end{array}$ \\
\hline - Physical illness/injury & - & $\begin{array}{l}\text { Prior suicide } \\
\text { attempts }\end{array}$ \\
\hline - Sleep disturbance & & \\
\hline
\end{tabular}

work performance in MDD. ${ }^{193}$ Cessation of training in athletes with NFO or overtraining often improves mood and associated symptoms, whereas depressed athletes who do not exercise may experience worsened mood and lose the antidepressant effect of exercise. $^{61}$

Depressive symptoms and MDD may result in decreased performance, adverse effects on personal life or an exit from sport. ${ }^{192}$ MDD is also highly associated with suicide and suicidal ideation. $^{202} 203$ Treatment of depressive symptoms and MDD depends on the severity of symptoms but usually consists of psychotherapy, often with medication.

In an international survey of sports psychiatrists, most of whom treat elite athletes, bupropion was described as a top choice for use in athletes with depression without comorbid anxiety. ${ }^{57}$ Bupropion's relatively energising properties and lack of weight gain as a side effect may have contributed to its top selection. ${ }^{57}$ However, it is not available worldwide, ${ }^{56}$ and should not be prescribed in athletes with an eating disorder because it increases the risk of seizure-a potential complication of eating disorders. ${ }^{204}$ Preliminary evidence suggests that bupropion potentially enhanced performance in endurance athletes who used a single, high dose $(600 \mathrm{mg})$ in warm climates. ${ }^{205}$ Performance enhancement was not observed with longer term therapeutic bupropion treatment. ${ }^{206}$ Performance enhancement has been noted with $300 \mathrm{mg}$ dosing the night before and morning of a cycling time trial in warm climates, but not at doses less than $300 \mathrm{mg}{ }^{207}$ The research on bupropion suggests that it may allow athletes to push themselves to higher core body temperatures and heart rates (thus improving performance) when used at higher doses and in acute rather than chronic doses. ${ }^{205}$ Bupropion is currently on WADA's Monitoring Programme list in competition. ${ }^{59}$ At present, however, it can be prescribed without a therapeutic use exemption (TUE), which is a process that allows athletes to request permission to take a medication that is on the WADA prohibited list.

SSRIs are also often prescribed to treat depression in athletes. $^{56} 57$ In particular, fluoxetine has no demonstrated negative impact on performance, ${ }^{208} 209$ and has emerged as an antidepressant of choice for athletes. ${ }^{56} 57210211$ Serotonin and norepinephrine reuptake inhibitors, tricyclic antidepressants (eg, nortriptyline, amitriptyline) and mirtazapine have not been studied in athletes. ${ }^{60}$ Serotonin and norepinephrine reuptake inhibitors are sometimes regarded as relatively energising, ${ }^{60}$ but one small study suggested that a norepinephrine reuptake inhibitor may be performance limiting. ${ }^{212}$ Tricyclic antidepressants and mirtazapine may cause sedation and weight gain. ${ }^{60}$ Furthermore, supraventricular and ventricular arrhythmias have been described in young, healthy people taking tricyclic antidepressants. ${ }^{213}$ Blood levels of tricyclic antidepressants could become toxic in athletes who sweat heavily, although this concern has not been confirmed in research among elite exercisers. ${ }^{214}$ In summary, the evidence suggests that tricyclic antidepressants should be avoided as firstline medications in athletes ${ }^{560}$ and, if prescribed, blood levels should be monitored. ${ }^{60}$

\section{Suicide}

In the largest study of suicide in elite collegiate student athletes in the USA, $7.3 \%$ of all deaths were attributed to suicide. ${ }^{215}$ Overall, the rate of suicide was $0.93 / 100000$ in collegiate athletes per year. The mean age of suicide was 20 years, and male collegiate athletes who participated in American football were at greatest risk. However, collegiate athletes still had a lower rate of suicide than individuals of the same age in the general US population (11.6/100 000 per year). ${ }^{216}$

Suicide prevention interventions should be multimodal, evidence based and range from interventions to manage stress and distress to addressing symptoms of MDD and overt suicidal ideation. ${ }^{202203}$ Risk factors (table 2) should be assessed and, where possible, mitigated..$^{27-219}$ To promote help seeking behaviours and to potentially reduce the risk of suicide, greater awareness of risk factors for suicide may be needed among coaches, medical professionals and others who work with athletes. ${ }^{2729} 215$ Strategies to understand and modify environmental stressors for elite athletes-such as improving social networks, athletic and personal life balance, team cohesion, and coach and team expectations-should be considered in conjunction with treatment for mental health symptoms and disorders. ${ }^{215}$ With retired athletes, careful consideration must be given to both mental and other medical aspects of health while addressing social isolation and other stressful aspects of transition from sport. ${ }^{217}$

\section{Anxiety and related disorders}

Individuals with generalised anxiety disorder (GAD) experience excessive anxiety and worry, with symptoms noted in table 3. GAD in elite athletes ranges in prevalence from $6.0 \%$ for a clinician confirmed diagnosis ${ }^{185}$ to $14.6 \%$ using self-report measures. ${ }^{14}$ Consistent with the general population, GAD symptom ratings tend to be higher for female athletes than male athletes. ${ }^{202430190220-222}$ Injured athletes appear to report more severe GAD symptoms than their non-injured counterparts. ${ }^{11} 2030223224$ From the limited data available regarding prevalence of other anxiety disorders and related disorders in elite athletes (table 4), self-reported estimates include $14.7 \%$ for social anxiety, ${ }^{11} 5.2 \%$ for obsessive-compulsive disorder ${ }^{225}$ and $4.5 \%$ for panic disorder. ${ }^{11}$ Rates of GAD and these other

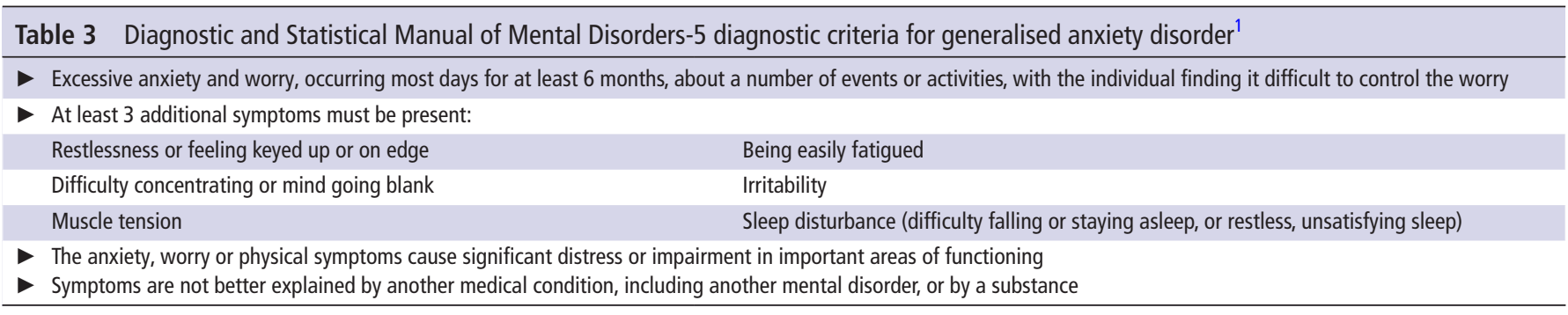


Table 4 Diagnostic and Statistical Manual of Mental Disorders-5 diagnostic criteria for selected other anxiety and related disorders ${ }^{1}$

\begin{tabular}{|c|c|c|}
\hline Social anxiety disorder & Obsessive-compulsive disorder & Panic disorder \\
\hline $\begin{array}{l}\text { Marked fear or anxiety about one or more social } \\
\text { situations in which the individual is exposed to } \\
\text { possible scrutiny by others }\end{array}$ & $\begin{array}{l}\text { Presence of obsessions, compulsions or both: } \\
\text { Obsessions: recurrent and persistent thoughts, urges or } \\
\text { impulses that are intrusive and unwanted, and that typically } \\
\text { cause marked anxiety or distress } \\
\text { Compulsions: repetitive behaviours or mental acts that } \\
\text { the individual feels driven to perform in response to an } \\
\text { obsession or according to rules that must be rigidly applied }\end{array}$ & $\begin{array}{l}\text { Recurrent unexpected panic attacks, which are } \\
\text { abrupt surges of intense fear or discomfort that } \\
\text { reach a peak within minutes, and during which } \\
\text { several accompanying symptoms occur }\end{array}$ \\
\hline $\begin{array}{l}\text { The individual fears that they will act in a way or } \\
\text { show anxiety symptoms that will be negatively } \\
\text { evaluated }\end{array}$ & $\begin{array}{l}\text { Obsessions or compulsions are time consuming or cause } \\
\text { clinically significant distress or impairment in important } \\
\text { areas of functioning }\end{array}$ & $\begin{array}{l}\text { At least one attack is followed by } 1 \text { month or } \\
\text { more of persistent concern about additional panic } \\
\text { attacks or their consequences, and/or a significant } \\
\text { maladaptive change in behaviour related to the } \\
\text { attacks (eg, avoidance of certain situations) }\end{array}$ \\
\hline $\begin{array}{l}\text { The social situations almost always provoke fear } \\
\text { or anxiety }\end{array}$ & $\begin{array}{l}\text { Symptoms are not better explained by another medical } \\
\text { condition, including another mental disorder, or by a } \\
\text { substance }\end{array}$ & $\begin{array}{l}\text { Symptoms are not better explained by another } \\
\text { medical condition, including another mental } \\
\text { disorder, or by a substance }\end{array}$ \\
\hline \multicolumn{3}{|c|}{ The fear or anxiety is out of proportion to the actual threat posed by the social situation and to the sociocultural context } \\
\hline \multicolumn{3}{|c|}{ Symptoms must be persistent, typically lasting 6 months or more } \\
\hline \multicolumn{3}{|c|}{ - The fear, anxiety or avoidance causes significant distress or impairment in important areas of functioning } \\
\hline \multicolumn{3}{|c|}{ - Symptoms are not better explained by another medical condition, including another mental disorder, or by a substance } \\
\hline
\end{tabular}

disorders in elite athletes do not appear to differ markedly from those in the general population. ${ }^{226}{ }^{227}$ Rates of specific phobia, agoraphobia, obsessive-compulsive personality disorder and adjustment disorder with anxiety (the latter defined as experiencing more anxiety symptoms than would normally be expected in response to a stressful life event, but not to the point that those symptoms meet the criteria for another specific anxiety disorder) ${ }^{1}$ in elite athletes are unknown. However, adjustment disorder with anxiety may be more common than other anxiety disorders in elite athletes. ${ }^{228}$

Among elite athletes, patterns of symptom onset, duration and severity should be used to differentiate anxiety disorders

Box 3 Baron Depression Screener for Athletes. The instrument is designed for athletes to self-report; if the athlete scores $>5$ they should be evaluated by a mental health professional ${ }^{183}$

Please respond to the following questions utilising the following scale:

0-Never

1-Some of the time (over a 2 week period)

2-Most of the time (over a 2 week period)

1. I feel sad even after a good practice session or successful competition.

2. I rarely get pleasure from competing anymore and have lost interest in my sport.

3. I get little or no pleasure from my athletic successes.

4. I am having problems with my appetite and weight.

5. I do not feel rested and refreshed when I wake up.

6. I am having problems maintaining my focus and concentration during training and competition.

7. I feel like a failure as an athlete and person.

8. I cannot stop thinking about being a failure and quitting sports.

9. I am drinking alcohol or taking supplements to improve my mood.

10. I have thoughts of ending my life. from competition performance anxiety, although state and trait anxiety domains can overlap. ${ }^{229} 230$ In addition, other mental health symptoms and disorders, most notably those of depression and/or eating disorders, may be coexisting. ${ }^{17} 2139185231232$ Pervasive worries or fears that accompany physiological symptoms may qualify for a diagnosis of GAD (if it persists for at least 6 months) or panic disorder (if accompanied by an abrupt surge in panic related symptoms). ${ }^{1}$ Agoraphobia, social anxiety and specific phobias occur in the context of specific stimuli, whereas obsessive-compulsive disorder is characterised by intrusive and unwanted obsessions and/or compulsions and obsessivecompulsive personality disorder by preoccupation with orderliness, perfectionism and control in the absence of obsessions and compulsions. ${ }^{1}$ Fear of negative evaluation by others may differentiate aspects of social anxiety from competitive performance anxiety. ${ }^{233}$ Panic attacks triggered by certain training or competitive situations may indicate a specific phobia; unexpected panic attacks not triggered by a specific fear more likely signal a panic disorder. $^{234}$ Because habitual behaviours are commonplace for elite athletes, ${ }^{235} 236$ idiosyncratic mannerisms or repetitive routines alone do not merit a diagnosis of obsessive-compulsive disorder in the absence of distress or impairment. ${ }^{1}$

Anxiety symptoms are reliably associated with both impaired cognitive performance and overall functioning in general populations, ${ }^{237} 238$ although scant research exists for elite athletes. ${ }^{39}$ Higher ratings of self-reported anxiety (relative to moderate ratings) are associated with negative performance outcomes and skill errors in elite athletes. ${ }^{230} 239240$ Pre-competitive (ie, state) anxiety is to be expected among elite athletes competing at major events, and the athlete's interpretation of pre-competitive anxiety may mediate the functional impact of symptoms. ${ }^{241}$ Facilitative, rather than debilitative, perceptions of anxiety symptoms appear associated with more adaptive coping and behavioural responses. $^{242} 243$

Anxiety disorders respond well to evidence based psychotherapy (eg, CBT), although treatment mechanisms necessarily vary by disorder. ${ }^{244}$ In addition to cognitive strategies addressing unhelpful thinking patterns or experiential avoidance, treatment frameworks should emphasise, as needed, graded exposure and 
behavioural experimentation for cases of social anxiety, response prevention for cases of obsessive-compulsive disorder and arousal reduction for those with GAD or panic disorder. ${ }^{245}$

Anxiolytic medications may be used to treat anxiety disorders in elite athletes, and there are important considerations, including side effects and performance impairment. ${ }^{61}$ SSRIs, specifically escitalopram, sertraline and fluoxetine, are sports psychiatrists' top choices for pharmacological treatment of anxiety in athletes. ${ }^{56}$ Buspirone, an antianxiety medication, has received little study in athletes; one small study suggested it impaired performance among recreational athletes, but only a single $45 \mathrm{mg}$ dose was tested. ${ }^{246}$

Short acting medications, such as benzodiazepines, are not usually recommended for performance (situational) anxiety because they may impair performance. ${ }^{56} 165174247$ Propranolol and other beta blockers, sometimes used for performance anxiety in non-sport settings, should typically be avoided in sport ${ }^{60}$ because they may lower blood pressure in athletes who already may have relatively low blood pressure. In endurance sports, beta blockers can problematically decrease cardiopulmonary capacity. ${ }^{248}$ Because of their effectiveness in reducing tremor and thereby improving fine motor control, beta blockers are prohibited at all times for archery and shooting, and are prohibited in competition for archery, automobile, billiards, darts, golf, shooting, some skiing/snowboarding and some underwater sports. ${ }^{59}$

\section{Post-traumatic stress disorder and other trauma-related disorders}

Trauma-related mental health disorders in elite athletes are common, with potentially serious consequences. ${ }^{249}$ These disorders include post-traumatic stress disorder (PTSD), defined as exposure to a trauma followed by at least 1 month of mental health symptoms; acute stress disorder (similar to PTSD, but less than 1 month in duration); and adjustment disorder (abnormal reaction to an identifiable life stressor). ${ }^{1}$ Athletes may encounter traumatic experiences from inside or outside of sport, and such experiences may range from sport injuries to life events independent of a sport injury. ${ }^{250} 251$

Research on the prevalence of trauma-related disorders in elite athletes is limited. This is particularly true regarding trauma-related disorders stemming from traumas other than sports injuries. Sport-related musculoskeletal injury is associated with elevated levels of PTSD symptomology. ${ }^{249}$ Athletes may also experience PTSD symptoms shortly after a sport-related concussion. ${ }^{252}$ Traumatic injuries may pose an even greater risk of progression to a chronic trauma-related mental health disorder in athletes with pre-existing exposure to trauma of any type. ${ }^{253}$

Diagnosing PTSD and other trauma-related disorders in athletes can be challenging. Trauma-related symptoms may manifest at any time, ${ }^{254}$ especially during situations reminiscent of a prior inciting event. ${ }^{249} 255$ Such symptoms include: hyperarousal (commonly experienced as anxiety); avoidance of physical and psychological reminders; re-experiencing symptoms (eg, intrusive thoughts, nightmares or flashbacks); dissociation (feeling detached from one's surroundings and/or emotions); and non-specific symptoms, including irritability and depressed mood. ${ }^{1250}$ Athletes may also develop comorbid substance use disorders or eating disorders. ${ }^{250}$ Trauma-related disorders may be associated with inconsistent athletic performance and somatic complaints without evident injury. ${ }^{250}$

Athletes may engage in behaviours that can obscure trauma-related symptoms. For example, elite athletes may compartmentalise to manage emotions, effectively concealing symptoms of trauma-related disorders. ${ }^{256}$ Further, dissociative strategies (eg, blocking of sensory input, as intentionally utilised by endurance athletes) ${ }^{257}$ may conceal trauma symptoms. Adaptive perfectionism, defined as deriving satisfaction from achievement from intense effort and tolerating imperfections without self-criticism, ${ }^{258}$ is a useful tool against symptom manifestation in many sports. ${ }^{259}$ However, it can evolve into maladaptive perfectionism, characterised by setting consistently unrealistic personal standards. ${ }^{258}$ This can include manifestations of obsessive-compulsive disorder, which can be a comorbid condition with trauma-related disorders. ${ }^{259}$

Symptoms of trauma-related disorders may negatively impact athletic performance. ${ }^{249} 260261$ Additionally, fear of re-injury increases the risk of subsequent injuries because of avoidance, inhibited effort or risk seeking behaviours. ${ }^{249} 262$ Injured athletes may hesitate to undergo physical therapy because of avoidance, thus interfering with recovery. ${ }^{260}$ Psychological distress, commonly seen in trauma-related disorders, reduces immune function and delays healing, thus impeding the athlete's ability to participate in rehabilitation following an injury. ${ }^{261}$

Early identification of and intervention for suspected trauma-related disorders may mitigate associated morbidity. ${ }^{263}$ Screening for mental health disorders following a sport-related traumatic musculoskeletal injury is recommended. ${ }^{264}$ Although evidence of impact on ultimate development of PTSD is mixed, careful, non-compulsory psychological debriefing with a qualified provider for an individual and/or team, with appropriate follow-up and support, may reduce distress and enhance group cohesion in the immediate aftermath of trauma. ${ }^{250}$ Trauma informed management of a traumatised athlete's team also can improve outcomes for the traumatised individual. ${ }^{265}$ Conversely, blaming the individual for the traumatic situation may perpetuate symptoms of trauma. ${ }^{250}$ Passive attitudes, non-intervention, denial and silence by those in power may also compound the initial trauma. ${ }^{266}$ Psychotherapeutic modalities recommended for the treatment of trauma-related disorders include CBT, cognitive processing therapy, cognitive therapy and prolonged exposure therapy. ${ }^{267}$ If medications are needed, SSRIs such as sertraline and fluoxetine are generally regarded as the agents of choice $^{268}$ and overall are reasonable choices for athletes. ${ }^{57}$

\section{Eating disorders}

Eating disorders (including anorexia nervosa, bulimia nervosa and binge eating disorder) and disordered eating (abnormal eating behaviours not meeting criteria for an eating disorder) (table 5) among elite male and female athletes are common. ${ }^{25} 269-272$ The estimated prevalence of eating disorders and/or disordered eating among athletes in general ranges from $0 \%$ to $19 \%$ in men and from $6 \%$ to $45 \%$ in women, ${ }^{273}$ considerably higher than in non-athletes. ${ }^{274}$ Data on elite athletes are sparser, but also show significantly greater risk in elite athletes than in non-athletes. ${ }^{23} 241$ Elite athletes more commonly meet criteria for disordered eating than for eating disorders. ${ }^{275}$ Data have largely relied on self-reports. However, athletes are prone to denial of symptoms, and are more apt to underreport disordered eating than are non-athletes. ${ }^{23}$

Athletes possess some of the same risk factors for eating disorders as the general population, and some that are sport specific risks (table 6) ${ }^{273}$ More than $60 \%$ of elite female athletes from both leanness focused and non-leanness focused sports have reported body shaming pressure from coaches. ${ }^{276}$ Eating disorders are common in athletes using performance and image enhancing 
Table 5 Characteristics of eating disorders versus disordered eating in elite athletes ${ }^{1274} 736$

\begin{tabular}{ll}
\hline Eating disorders & Disordered eating \\
\hline Restricting, bingeing or purging often occur multiple times per week & $\begin{array}{l}\text { Pathogenic behaviours used to control weight (eg, occasional restricting, use of diet pills, } \\
\text { bingeing, purging or use of saunas or 'sweat runs') may occur but not with regularity }\end{array}$ \\
& Obsessions with thoughts of food and eating occur much of the time
\end{tabular}

drugs, including anabolic androgenic steroids, amphetamine-like substances, coffee and caffeine derivatives, synthetic cathinones and ephedrine. ${ }^{277}$ Dissatisfaction with body image may be the strongest predictor of eating disorders in athletes. ${ }^{278}$

A diagnosis requires obtaining a detailed current and past history (including a corroborative history), a thorough physical examination and laboratory studies. ${ }^{274}$ Dual energy X-ray absorptiometry and electrocardiography are sometimes needed to assess possible adverse effects on bone and cardiac health. ${ }^{274}$ Rating scales that have been validated in athletes, such as the Athletic Milieu Direct Questionnaire version 2, the Brief Eating Disorders in Athletes Questionnaire version 2, and the Physiological Screening Test to Detect Eating Disorders Among Female Athletes, may be used. ${ }^{279}$ However, research suggests that personal interviews may be superior to rating scales in diagnosing eating disorders in athletes. ${ }^{280}$ The usual DSM-5 diagnostic criteria ${ }^{1}$ may be difficult to apply in athletes ${ }^{51}$ because the adaptive nature of a disciplined training diet and preoccupation with body shape and weight in sport may confuse the diagnosis. ${ }^{281}$ Additionally, athletes may present as normal weight, with very low body fat but high muscle mass. ${ }^{61}$ Finally, excessive exercise as an eating disorder behaviour often used to compensate for a perceived excess of calories consumed can be challenging to assess in athletes. ${ }^{282}$

In elite training, athletes may present with low energy availability (LEA), which can occur secondary to inadvertent inadequate intake or from disordered eating. The female athlete triad was historically denoted by LEA, menstrual dysfunction and low bone mineral density. ${ }^{51} 283284$ Male athletes may present with an analogous condition characterised by LEA, hypogonadotropic hypogonadism and low bone mineral density. ${ }^{285}$ The IOC convened and redefined these entities under a broader umbrella: relative energy deficiency in sport (RED-S), which addresses the more global impact of relative energy deficiency on physiological function and its psychological consequences and includes all genders. ${ }^{280} 286$

The fact that an eating disorder impairs athletic performance is a powerful motivator for treatment. ${ }^{278}$ While performance may not immediately suffer, typically performance decreases over time, related to factors such as dehydration, electrolyte disturbances, early glycogen depletion, loss of muscle mass and injuries such as stress fractures. 74278287288

Among the challenges in bringing an athlete to treatment are concerns about confidentiality, ${ }^{289}$ finding access to effective treatment, the athlete's acceptance that there is a problem to treat, the ability to relate-as an athlete-in treatment and the possible need to restrict activity on return to play. ${ }^{290}$ Just as team culture may engender disordered eating, there may be a role for teammates to encourage healthy eating behaviours. ${ }^{291}$

One of the first decision points in treatment is what level of care is required. Those who are severely nutritionally compromised may need hospitalisation. ${ }^{274}$ In any setting, an interdisciplinary team is ideal, and may include a psychiatrist, a sports nutritionist/dietitian, a primary care physician, another licensed mental health provider, an athletic trainer and a coach. ${ }^{274}$ Once a healthy nutritional status is attained, the psychological and sociocultural underpinnings of the disordered eating may be addressed through psychotherapeutic modalities in individual, group or family settings. ${ }^{292}$ A team may be viewed as a family structure, or a coach-athlete relationship may benefit from therapy. ${ }^{293}$

While there is little evidence that medication is helpful for anorexia nervosa, the primary pharmacologic treatments in bulimia nervosa are antidepressants, specifically fluoxetine, which has no evident adverse impact on performance. ${ }^{1208} 209294$ Lisdexamfetamine may be helpful for binge eating disorder ${ }^{295}$ but it is a stimulant and thus is prohibited in competition at elite levels of competition and requires a TUE. ${ }^{59}$

Although early detection and treatment are critical, prevention of eating disorders is also important. ${ }^{273296}$ Overall, the body of research on eating disorder prevention programmes with elite athletes is small but promising. ${ }^{296}$ Elements common to seemingly successful prevention programmes include involvement of multiple targets for systematic change (eg, athletes, coaches and sport administration), ${ }^{296-298}$ and utilisation of interactive programmes that encourage multiple modes of communication

Table 6 General and sport specific risk factors for eating disorders ${ }^{273} 296$

\begin{tabular}{|c|c|}
\hline General risk factors & Sport specific risk factors \\
\hline Low self esteem & $\begin{array}{l}\text { Weight sensitive sports (eg, weight class sports such as rowing, wrestling and judo; those that may be aesthetic judged such as } \\
\text { gymnastics, artistic swimming, diving, equestrian and figure skating; and gravitational sports in which lower body fat may be } \\
\text { advantageous, such as distance running, cycling and swimming) }\end{array}$ \\
\hline - Depression & - Team weigh-ins \\
\hline - Anxiety & $\begin{array}{l}\text { Sport specific training before the body is fully mature (which might hinder an athlete from choosing a suitable sport for their adult body } \\
\text { type) }\end{array}$ \\
\hline - Genetic vulnerability & - Performance pressure \\
\hline - Perfectionistic personality style & - Injury ${ }^{299}$ \\
\hline
\end{tabular}




Table 7 Diagnostic and Statistical Manual of Mental Disorders-5
diagnostic criteria for attention-deficit/hyperactivity disorder ${ }^{1}$

(eg, with athletes leading some of the session, use of practical skills assignments and provision of a safe space for athletes to express their experiences of body shape and weight). ${ }^{296-298}$ Athletes should be educated to recognise signs and behaviours that may be associated with eating disorders and RED-S, including overexercise, rigid eating patterns, amenorrhoea, a focus on thinness and a competitive comparison of physiques. ${ }^{299}$ A strong coach-athlete relationship may protect against eating disorders. $^{300}$ Coaches need to understand the physiologic importance of proper nutrition and weight management. ${ }^{301-303}$ Coaches should feel comfortable discussing eating disorders and RED-S with athletes. ${ }^{299}$ One strategy to decrease stigma is to reframe these disorders as a continuum of sport-related injury and illness. ${ }^{304}$

\section{Attention-deficit/hyperactivity disorder}

The essential features of attention-deficit/hyperactivity disorder (ADHD) are a persistent pattern of inattention and/or hyperactivity-impulsivity causing dysfunction and present in multiple spheres since prior to the age of 12 years (table 7). A formal diagnosis of ADHD may be made based on patient history, using DSM-5 diagnostic criteria. ${ }^{1}$ Other data, such as those obtained from neurocognitive testing, laboratory results and collateral information, may support a diagnosis, rule out other conditions or both. ${ }^{305}$

Using DSM-5 criteria, 30\% of those diagnosed with ADHD in childhood continue to meet ADHD criteria as adults. ${ }^{306} 307$
There are scant data regarding the prevalence of ADHD in elite athletes; however, ADHD may be more common than in the general population, since individuals with ADHD may be drawn to sport due to the positive reinforcing effects of physical activity. ${ }^{306} 308$ However, the sport-related hyperactivity manifest in some athletes must be distinguished from diagnosable ADHD. ${ }^{309}$

Athletes with ADHD who suffer concussions should be evaluated for comorbid or persistent concussion symptoms, since there is symptom overlap between concussion and ADHD. ${ }^{310-314}$ Both conditions affect similar neurocognitive domains, resulting in possible deficits in memory, attention and concentration. ${ }^{315} 316$ Collegiate athletes with ADHD are more likely to report a past history of concussions than those without ADHD, and ADHD may be associated with prolonged recovery following sport-related concussion in athletes. ${ }^{317} 318$

ADHD may negatively affect athletic performance. ${ }^{305}$ Lack of focus and concentration, oppositional behaviour, argumentative attitude, frustration, lowered self-esteem and labile mood may all interfere with performance. ${ }^{305}$ ADHD may cause academic difficulties that could threaten the academic eligibility of student athletes. ${ }^{305}$ Additionally, commonly described comorbid conditions such as anxiety, depression and substance use disorders may negatively impact performance. ${ }^{305}$ However, some individuals with ADHD naturally excel in sport because of quick and reactive decision making due to inherent impulsivity. ${ }^{319}$

In managing $\mathrm{ADHD}$ in elite athletes, psychosocial interventions should be used; ${ }^{57}$ these interventions may be as effective as-and should be considered an alternative to-stimulant medication in athletes with mild functional impairment. 306309 320-325 Depending on the age of the elite athlete, treatment may include: behaviour therapy or CBT; individual education plans; parent teaching/training and caregiver support; and education for athletes, families and coaches. ${ }^{308} 321326$

Stimulants are a primary pharmacological treatment for ADHD. ${ }^{62} 211306309321322324325327$ Such medications, including those in the methylphenidate and mixed amphetamine salts classes, may be ergogenic, ${ }^{328} 329$ and are misused because of the perception of performance enhancement. ${ }^{306322324325327330}$ Like classic stimulants, the psychostimulant modafinil reportedly may mask symptoms of fatigue. ${ }^{331}$ Stimulants may be misused for weight loss as a performance advantage in leanness sports (eg, distance running) or in sports with weight classes (eg, wrestling). ${ }^{309} 327$ Stimulants are prohibited by WADA in competition ${ }^{5932}$ so athletes taking them for legitimate medical reasons must receive a TUE. ${ }^{333}$

Athletes taking stimulants may be able to exercise to higher core body temperatures without perceived thermal stress, ${ }^{212}$ thereby raising concerns about both performance enhancement and safety. ${ }^{212}$ Stimulants may cause several side effects, including insomnia, anxiety, increased heart rate and blood pressure, and an undesired decrease in appetite, all of which can negatively impact performance and threaten athlete safety. 211306309322324325

Given these concerns, if medications are necessary for an athlete with ADHD, non-stimulant medications should be considered. $^{309324327334}$ The non-stimulant atomoxetine is a medication of choice for ADHD among sports psychiatrists, presumably owing to the regulatory and safety drawbacks of stimulants. ${ }^{57}$ However, it has not been studied in elite athletes. In addition, prescribers and athletes should be aware that it takes much longer to see full benefit from atomoxetine than from stimulants, ${ }^{309}$ and gastrointestinal discomfort and sedation are possible side effects. ${ }^{327}$ Bupropion, an antidepressant with some stimulant properties, is sometimes used off label for ADHD, ${ }^{306} 322335$ 
especially for individuals with comorbid depression. Clonidine and guanfacine in extended release formulations are approved in some countries for use in children under the age of 18 years with ADHD (which could include elite athletes). ${ }^{325} 336$ These latter two medications have not been studied in elite athletes, but sedation and cardiac side effects such as hypotension, bradycardia and QTc prolongation are possible side effects. ${ }^{336} 337$ Tricyclic antidepressants may also be used off label for ADHD, ${ }^{325}$ but side effects such as sedation, weight gain, cardiac arrhythmias and dry mouth may preclude their use in elite athletes. ${ }^{305}$

If stimulants are prescribed and a TUE is approved, it may be preferable to start with long acting formulations, which are more convenient and less likely to be abused. ${ }^{57324}$ An alternative potential stimulant prescribing strategy involves use of formulations and timing that allow use only during school, study and work times-not during practices and competition-thereby decreasing concerns about safety and impact on performance. ${ }^{57324327} \mathrm{~A}$ final important consideration is that prescribers must use caution in prescribing stimulant medication if the athlete is participating in endurance events in hot temperatures because of the possible increased risk of heat illness. ${ }^{60306322324}$

\section{Bipolar and psychotic disorders}

Bipolar disorders are characterised by major changes in mood with associated functional impairments (Box 4). Mood changes may be depressive, hypomanic, manic or occasionally with mixed symptoms. ${ }^{1}$ Psychotic symptoms need not be present, but if so are usually consistent with the individual's mood. ${ }^{1}$ Psychotic disorders such as schizophrenia and related conditions are usually characterised by hallucinations and delusions. In addition, schizophrenia may involve disturbances in speech, thought, behaviour, affect and cognition, in addition to social deficits and significant functional impairment. ${ }^{1}$

Bipolar and psychotic disorders have not been thoroughly studied in elite athletes; ${ }^{61}$ although prominent cases have been reported, ${ }^{338}$ the prevalence is unknown. Both disorders show a peak age of onset coincident with the usual age of peak sporting performance; ${ }^{339}$ thus it is important for clinicians and other key professionals in the world of sport to be aware of their symptoms. In cases of mania and hypomania, the diagnosis may be obscured if sport provides a functional outlet for excess energy, or if overactivity is normalised. ${ }^{340}$

It is important to distinguish primary mood and psychotic disorders from the impact of substance use (secondary disorders), as the latter may be self-limiting or require only short term treatment (table 8). ${ }^{341}$ For example, anabolic-androgenic steroid use may be associated with psychotic, hypomanic or depressive symptoms. ${ }^{342} 343$ Other substances used by athletes, including stimulants, cannabinoids and glucocorticoids, may also be associated with mood or psychotic symptoms. 344345

There are scant data on how bipolar and psychotic disorders affect athletic performance. The long term course of bipolar disorders is variable, and patients may spend a significant amount of time in a symptomatic (often depressed) state. ${ }^{346} 347$ However, some athletes have achieved sporting success despite this condition.

Cognitive and negative symptoms in schizophrenia cause significant impairment of function ${ }^{348} 349$ likely to interfere with the demands of elite sport. ${ }^{51}$ Conversely, physical activity may be beneficial for symptoms of bipolar and psychotic disorders, ${ }^{350-352}$ although some evidence suggests that vigorous exercise may exacerbate mania in patients with bipolar disorder. ${ }^{351}$ Supported strategies to exit from an elite sports level, perhaps to a lower level of participation, should be considered if this strategy would allow the individual to continue to benefit from physical activity.

There is limited evidence on the treatment of bipolar disorders and psychosis in athletes, ${ }^{61}$ and guidance is usually based on expert opinion and individualised prescribing. ${ }^{56}$ Long term medication is often needed alongside psychotherapy interventions, ${ }^{353-358}$ including family therapy, CBT and, for bipolar disorder, social rhythms therapy. ${ }^{359}$

Sports psychiatrists have reported preferences for lamotrigine and lithium in athletes with bipolar disorders ${ }^{60}$ Lamotrigine has a favourable side effect profile for elite athletes, but does not always prevent or treat mania. ${ }^{56}{ }^{57}$ Lithium is a full spectrum mood stabiliser, but its levels may fluctuate with intense exercise and hydration status, ${ }^{360361}$ so close monitoring is advised. ${ }^{56}$ Apart from lamotrigine, most medications for bipolar disorder can cause sedation, weight gain and tremor. ${ }^{5760}$ Among the atypical antipsychotics that may be used for bipolar or psychotic disorders, aripiprazole, lurasidone and ziprasidone may be relatively less likely to cause sedation and weight gain. ${ }^{5657}$ Ziprasidone may cause QTc prolongation ${ }^{362}$ and thus may not be a firstline choice within this class for athletes. ${ }^{57}$ Aripiprazole may cause akathisia, which could negatively impact motor performance in athletes. ${ }^{56}$ Typical antipsychotics are an infrequent choice for

Table 8 Features that may help distinguish between primary bipolar and psychotic disorders and those secondary to substance use ${ }^{341-343345508}$

\begin{tabular}{|c|c|c|}
\hline & Primary disorder & Secondary to substance use \\
\hline History & $\begin{array}{l}\text { Possible past history of episodes and } \\
\text { family history of disorder and no report of } \\
\text { substance use }\end{array}$ & $\begin{array}{l}\text { Use may be acknowledged with sensitive enquiry and corroborative reports (eg, from } \\
\text { family, friends, etc) }\end{array}$ \\
\hline Clinical features & $\begin{array}{l}\text { Symptoms may be similar } \\
\text { Longitudinal course is more likely to be } \\
\text { of episodes lasting weeks or more }\end{array}$ & $\begin{array}{l}\text { Symptoms may be similar } \\
\text { Episodes may self-limit after a few days } \\
\text { Irritability and aggression are more common } \\
\text { Sub-syndromal presentations are more likely than full syndromes } \\
\text { Close temporal relationship to use } \\
\text { Association with high dose and multiple substance use }\end{array}$ \\
\hline Physical exam & $\begin{array}{l}\text { Signs of increased arousal may be present } \\
\text { (eg, increased pulse and/or blood pressure) }\end{array}$ & $\begin{array}{l}\text { The following signs may be present: } \\
\text { AAS use - acne, needle marks, female hirsutism, jaundice, gynaecomastia (men), } \\
\text { breast atrophy (women), testicular atrophy or prostatic hypertrophy (men), } \\
\text { clitoromegaly (women) } \\
\text { Stimulant use - increased arousal, dilated pupils, tics } \\
\text { Cannabinoid use - characteristic smell, conjunctival injection, drowsy, slowed } \\
\text { responses, impaired short term memory }\end{array}$ \\
\hline
\end{tabular}


Box 4 Diagnostic and Statistical Manual of Mental Disorders 5 diagnostic criteria for bipolar I disorder and bipolar II disorder ${ }^{1}$

- Bipolar I disorder

- At least 1 manic episode, defined as a distinct period of abnormally and persistently elevated, expansive or irritable mood, and abnormally and persistently increased activity or energy, present most of each day for at least a week (or any duration if hospitalisation is necessary)

- 3 additional symptoms (4 if mood is only irritable) are present to a significant degree during the manic episode and represent a noticeable change from usual behaviour:

- inflated self-esteem or grandiosity

- decreased need for sleep

- more talkative than usual

- flight of ideas or subjective experience that thoughts are racing

- distractibility

- increased goal directed activity or psychomotor agitation

- excessive involvement in activities that have a high potential for painful consequences

- The mood disturbance is sufficiently severe to cause marked impairment in social or occupational functioning or to necessitate hospitalisation to prevent harm to self or others, or there are psychotic features

- The symptoms are not better explained by another medical condition, a psychotic disorder or a substance.

- Bipolar II disorder

- At least 1 hypomanic episode, defined as a distinct period of abnormally and persistently elevated, expansive or irritable mood, and abnormally and persistently increased activity or energy, present most of each day for at least 4 consecutive days

- Symptom criteria for a hypomanic episode are the same as for a manic episode (second bullet point above)

- The hypomanic episode is associated with an unequivocal change in functioning that is uncharacteristic of the individual when not symptomatic

- The disturbance in mood and change in functioning are observable by others

- The episode is not severe enough to cause marked impairment in functioning, hospitalisation or psychosis

- The symptoms are not better explained by another medical condition or a substance

- At least 1 major depressive episode has occurred (see criteria in table 1).

psychotic disorders in athletes because of sedation, motor side effects and cardiac concerns. ${ }^{57}$

\section{Sport-related concussion}

Sport related concussion (SRC) is a traumatic brain injury induced by biomechanical forces. It may be caused by a direct blow to the head, face or elsewhere in the body with a transmitted impulsive force to the head. ${ }^{363}$ SRC typically results in short lived impairment of neurological function, but signs and symptoms may evolve over minutes to hours. It largely reflects functional brain disturbances, but also may result in neuropathological changes. SRC manifests in a range of clinical signs and symptoms, with or without loss of consciousness; resolution of signs and symptoms usually follows a sequential course, but may be prolonged. ${ }^{363}$ Finally, the signs and symptoms cannot be explained by drugs, other injuries or comorbidities. ${ }^{317364365}$ Changes in mood, emotions and behaviour are common following SRC; indeed, in the Sport Concussion Assessment Tool, fifth edition, ${ }^{366}$ most symptoms overlap with those attributable to anxiety and depression. ${ }^{367-369}$ Thus SRC may be viewed as a neuropsychiatric syndrome.

Rice and colleagues ${ }^{365}$ performed a systematic review of mental health outcomes of SRC in elite athletes; of 103 studies, 27 met the inclusion criteria for the final analysis. The most common mental health symptoms following SRC reported in these studies were depression, anxiety and impulsivity, but studies were primarily in male athletes, and most were from North America. Only one paper was judged as meeting sufficient methodological rigour and lack of bias: Vargas et $a^{370}$ described depression symptoms in $20 \%$ of collegiate athletes following SRC. Vargas et al also reported that predictors of depression symptoms included baseline depression symptoms, baseline post-concussion symptoms, lower estimated premorbid intelligence, non-white ethnicity, increased number of games missed following injury and age of first participation in organised sport (more depression symptoms noted in athletes with fewer years of experience in organised sport).

Although acute mood and behavioural symptoms may be common following SRC, such symptoms must be differentiated from mental health disorders. For example, Kontos et al ${ }^{371}$ reported significantly worse depression symptoms following SRC, but not at the level of major depressive disorder. No high quality studies exist of other mental health outcomes, such as alcohol or other substance use disorders, personality disturbance or psychotic symptoms, after SRC in elite athletes. ${ }^{365}$

Most athletes recover from SRC within 7-10 days. ${ }^{372-374}$ However, up to $21 \%$ of athletes remain symptomatic after 30 days. ${ }^{374}$ Delayed recovery has often been diagnosed as 'post-concussion syndrome'. This label assumes the presence of common influencers of delayed recovery, but it lacks consensus criteria or clinical specificity, and subsumes varied presentations not clearly associated with the concussive injury. ${ }^{1363}{ }^{375-383}$ Since SRC is not a homogenous entity, persistent symptoms are increasingly described within specific, but often overlapping, post-concussion subtypes and should be managed as such. ${ }^{384}$

The development of depression, anxiety or other mental health symptoms or disorders following SRC may adversely impact recovery. ${ }^{385}{ }^{386}$ Further, pre-injury mood and/or other mental health disorder, family history of mental health disorder and high life stressors before injury all negatively impact SRC recovery. ${ }^{387}$ Multiple SRCs may predispose to the development of clinically significant depression. Kerr et al ${ }^{388}$ reported a 5.8-fold increased risk of depression after 5-9 concussions in retired professional football players, and Guskiewicz and colleagues ${ }^{389}$ described a 3-fold increased risk of depression following three or more SRCs among retired football players. Similarly, Kerr et $a^{390}$ reported a higher prevalence of moderate/severe depression among former collegiate football players with a history of three or more concussions. Although Fralick and colleagues ${ }^{391}$ found a twofold higher risk of suicide in individuals who experienced concussion and/or mild traumatic brain injury, this study was not athlete or sport specific, and included the general population. Of note, the risk of suicide in former professional football players is significantly lower than in the general population. ${ }^{392}$

Diagnosis of SRC and associated mental health symptoms or disorders can be challenging. ${ }^{365}$ For example, there are no objective imaging or blood biomarkers for SRC. ${ }^{373}$ Nonetheless, 
neuropsychological evaluation may help differentiate cognitive from other mental health manifestations. ${ }^{393-397}$

After an SRC, management of persistent mental health symptoms and/or disorders should first address factors that can contribute to delayed recovery, which may include several biopsychosocial issues. $^{365}$ 398-401 Because many athletes with prolonged concussive symptoms reduce their daily exercise markedly, a progressive increase in exercise often ameliorates mental health and somatic symptoms. ${ }^{399} 400402$ Additionally, social activity, including team activities, should not be restricted, as such a restriction has been associated with increased depression following an SRC. ${ }^{403}$ Psychotherapy may be helpful for both mental health and somatic symptoms. ${ }^{375} 404405$ Athletes with pre-existing or post-SRC substance use disorders may be more likely to report more SRC symptoms; ${ }^{406} 407$ thus ascertaining substance use patterns in elite athletes with SRC is important.

There are no approved pharmacological interventions specific to SRC and its sequelae, and evidence to support use of specific medications is minimal. ${ }^{408}$ While the majority of concussed athletes recover relatively quickly and thus will probably not need medications, ${ }^{374}$ when such an approach is warranted, targeted treatment beginning with a lower starting dose and a prolonged titration interval is generally indicated. ${ }^{409} 410$ Intervention for insomnia following SRC should focus on sleep hygiene; ${ }^{408}$ however, if a sleep aid is warranted, melatonin may be considered 408411412 with trazodone as a second option. 374408413414 Benzodiazepines should be avoided because of their negative effect on cognition. 408413414 SSRIs may be helpful to treat depressed mood following SRC, ${ }^{408410413415416}$ and may simultaneously improve cognition. ${ }^{415} 416$ Tricyclic antidepressants, for example amitriptyline, are sometimes used to treat headache, depression, anxiety and/or insomnia in the post-SRC setting ${ }^{374} 408417-419$ but side effects may limit their use in elite athletes. ${ }^{60}$ While some evidence exists for the use of stimulants to manage cognitive dysfunction such as deficits in attention and processing speed associated with SRC, $408413415420-423$ they carry risks ${ }^{415}$ and are prohibited in competition by WADA without an approved TUE. ${ }^{59}$

\section{Substance use and substance use disorders (ergogenic and recreational)}

Elite athletes use alcohol, caffeine, cannabis/cannabinoids, nicotine and other substances that can be misused for similar reasons as non-athletes. ${ }^{345} 424$ These reasons can include experimentation, socialisation, pleasure, boosting confidence and increasing alertness and energy. Elite athletes may also use substances for relief of stress, negative emotions, pain, cravings and withdrawal. ${ }^{345} 424$ Athletes may use ergogenic substances, ${ }^{425}$ doping methods such as gene doping ${ }^{426} 427$ and blood transfusions, ${ }^{428}$ and neuromodulation (eg, transcranial stimulation). ${ }^{429} \quad{ }^{430}$ Further, athletes may unwittingly ingest ergogenic substances by taking dietary substances that contain adulterants. ${ }^{431}$ These practices seek to enhance performance via hoped for increases in strength, power, endurance, aggression, concentration, oxygen carrying capacity of the blood and lean body mass; reductions in fatigue and percent body fat; and enhanced recovery from exercise and injury. ${ }^{345} 424$

The prevalence of substance use, misuse (defined as heavy, risky, harmful, hazardous or problem use) or full use disorders as defined in DSM- $5^{1}$ among elite athletes varies significantly by substance class, ${ }^{424} 432-439$ sport, ${ }^{5} 43-445$ in season versus out of season, ${ }^{434}$ age/level of competition, ${ }^{424} 432438445-448$ gender, ${ }^{438439445449450}$ country, ${ }^{433437445451-455}$ sexualorientation, ${ }^{456}$ ethnicity, ${ }^{439} 444457$ reasons for use ${ }^{424} 458$ and prevalence determination methods. ${ }^{433}$ 459-461 Although self-report surveys and competition day urine drug testing are the most common ways of determining use or misuse, these likely are underestimates. ${ }^{460} 461$ More reliable measures include: athlete biological passport baselines (obtaining an individual's profile of biological markers of doping over time); team urine surveillance and postgame testing; repeat testing; hair testing; early out of season testing; attitude scale administration; indirect questioning techniques; and interviews with athletes, teammates and parents or coaches. ${ }^{460-464}$

A few recent high quality studies have compared substance use among athletes and non-athletes. Using indirect comparisons among US collegiate athletes and non-athletes, athletes across all sports report annual use of alcohol, cigarettes, marijuana, amphetamines, anabolic-androgenic steroids, cocaine, ecstasy and lysergic acid diethylamide (LSD) at lower rates than their non-athlete peers. ${ }^{439} 465466$ However, in the recent NCAA study (2018) and older US studies that included comparison groups, ${ }^{432} 434448467-472$ collegiate athletes (especially white males) in lacrosse, ice hockey, swimming, baseball and wrestling use more spit tobacco ${ }^{473}$ and report higher rates of binge drinking and alcohol related problems than non-athletes. Female collegiate athletes in ice hockey, lacrosse and swimming binge drink at higher rates than non-athletes, while women ice hockey players use spit tobacco far more often than non-athletes. ${ }^{473}$ Male and female collegiate lacrosse players have higher rates of use for both cannabis and cocaine. ${ }^{439} 465466$ Recent studies of professional European football players from five countries ${ }^{6}$ and professional rugby players from eight countries ${ }^{19}$ showed rates of adverse alcohol behaviours (regular, heavy drinking and/ or binge drinking) ranging from $6 \%$ to $17 \%{ }^{6}$ and from $8 \%$ to $21 \%$, respectively, while a 2015 study of elite rugby players from Australasia using similar measures showed much higher rates of hazardous alcohol use both before (68.6\%) and during $(62.8 \%)$ the season. ${ }^{14}$ At the collegiate level, a 2017 study by Zanotti et al using the Psychiatric Diagnostic Survey Questionnaire $(\mathrm{N}=304)$ showed rates of DSM IV alcohol abuse/dependence of $7.2 \%$ to $10.3 \%,{ }^{474}$ confirming previous reports about collegiate athletes' relatively high rate of alcohol misuse. 432448468

The most commonly used substances by elite athletes across countries, sports and genders are alcohol, caffeine, nicotine, cannabis/cannabinoids, stimulants and anabolic-androgenic steroids. $^{425} 434435437444459$ 475-477 Marijuana (inhaled and/or ingested) has replaced nicotine as the second most widely used drug among some elite adolescent and collegiate athletes; it is more likely to be used in places where it is legal, which are becoming increasingly common. ${ }^{437} 439478$ Despite relatively low rates of use, synthetic cannabinoids ${ }^{479}$ and cocaine ${ }^{439}$ appear to be a growing problem among collegiate athletes, with uncertain year round trends for athletes worldwide.

The sports with the highest general substance use/misuse rates across all substances for men's elite sports are lacrosse, ice hockey, football, rugby, baseball, soccer, wrestling, weightlifting, skiing, biathlon, bobsleigh and swimming, and lowest for track, tennis and basketball. ${ }^{439} 443459480$ For women's elite sports, the highest rates occur in ice hockey, gymnastics, lacrosse, softball, swimming and rowing, and lowest in track, tennis, basketball and golf. 339443459480 In general, those who participate in team sports are more likely to use or misuse substances than athletes in individual sports. ${ }^{439442}$

Common risk factors for use include: sport context and culture (eg, normative beliefs about heavy peer drinking or illicit drug use); situational temptation (eg, drinking games); permissive 
attitudes among athletes, coaches and parents; male sex; use of performance enhancing substances or tobacco; identification as lesbian, gay, bisexual, transgender or queer; party lifestyle or drinking game participation; sensation seeking; overestimating peer use; achievement orientation; lower use of protective measures (eg, avoiding serious intoxication, using a designated driver); leadership position; fraternity/sorority membership; problem gambling; and injury. ${ }^{442} 443448450452458468$ 481-483 Intrinsic religiosity has been inversely associated with the use of alcohol, marijuana and other drugs. ${ }^{44}$

Substances most commonly used by elite athletes may cause performance enhancement, decrement or both, and the net impact may vary by sport and athlete. Some athletes may use alcohol before competition to reduce anxiety or tremor and improve subjective self-confidence. ${ }^{5442485}$ Alcohol is no longer a prohibited substance in competition in specified sports. ${ }^{59}$ Post-competition, alcohol is used by some athletes to reduce stress, boost self-esteem, increase social connectedness, improve team cohesion, strengthen athletic identity and raise subjective happiness. ${ }^{54} 442485$ Ergolytic effects of alcohol include dehydration, insomnia, higher injury rates, slower injury healing, impaired psychomotor skills, hangovers, accidents, lateness, missing important obligations, reduced metabolic recovery/ glycogen re-synthesis, impaired thermoregulation, weight gain and academic underperformance that can threaten athletic eligibility. ${ }^{424} 485486$

Although some elite athletes speculate that cannabis/cannabinoids increase the likelihood of obtaining restorative sleep before a competition, reduce pre-competition stress and anxiety to allow for optimal relaxation, or reduce physical pain, no studies have shown a beneficial effect on performance. ${ }^{486} 487$ In fact, since cannabis is likely to raise heart rate and blood pressure and impair reaction time and coordination, ${ }^{486}$ it might be expected to limit performance. Regular or heavy cannabis/ cannabinoid use may reduce motivation, activate anxiety, trigger psychosis ${ }^{488}$ or produce temporary disorientation, delirium or aggression. 489490

Ergogenic effects of anabolic-androgenic steroids include enhanced muscle mass, improved biomechanical efficiency and anti-catabolic effects. ${ }^{491}$ Potential ergolytic effects include cognitive impairment, ${ }^{492}$ negative mood symptoms, ${ }^{345}$ psychosis, ${ }^{345}$ aggression $^{345}$ and injury, especially tendon rupture. ${ }^{345}$ Some individuals who use anabolic-androgenic steroids have muscle dysmorphia, a preoccupation that one's body is not sufficiently lean and muscular, often with significant body image distortion. ${ }^{493-495}$ Cycles of using anabolic-androgenic steroids are usually interspersed with drug free periods and are sometimes associated with other drug use (eg, diuretics or benzodiazepines) to mitigate side effects. ${ }^{424} 491$ These other drugs themselves may have ergolytic effects. ${ }^{56165} 174247$

Stimulants may be attractive to elite athletes because they may improve reaction time and concentration, increase arousal, improve memory, boost energy, trigger relaxation and confidence, and improve energy when fatigued. ${ }^{309} 424475486496497$ Their negative effects, however, are more apparent in high doses or when combined ('stacked'), which may be relatively common among male athletes who use performance enhancing substances. ${ }^{424} 452$ Athletes may knowingly or unknowingly consume large amounts of caffeine in dietary supplements, and larger caffeine doses do not appear to increase performance and indeed are more likely to cause side effects. ${ }^{431}$ Ergolytic effects of high dose stimulant use or combination stacking may include anxiety, insomnia, gastric irritation, tachycardia and tremors. ${ }^{309} 424476486$
Nicotine, whether smoked (eg, via cigars, cigarettes or hookahs), used orally (eg, via moist snuff, snus or leaf tobacco) or vaped, is also widely used by elite athletes. ${ }^{439}$ Nicotine is currently being studied by WADA because of its potential ergogenic effects on performance and because it is so widely used in some sports, especially baseball, ice hockey and lacrosse. ${ }^{59} 486$ Athletes' perception of nicotine's ergogenic effects include improved alertness and concentration, increased energy and focus, increased muscular strength and power, enhanced endurance, relaxation/calmness, weight control and reduction of boredom, although the results of higher quality studies generally do not support ergogenesis. ${ }^{424} 475486$ Ergolytic effects may include elevated blood pressure, anxiety, insomnia and chronic respiratory infections. ${ }^{424} 475486$ Potential performance enhancement and decrement associated with other substances by elite athletes, not described in detail here, are documented elsewhere in the literature. ${ }^{345}$

Interventions for regular, risky or disordered use of substances in elite athletes are not well studied. Nonetheless, approaches to reducing spit tobacco use among baseball players ${ }^{424} 498499$ and newer approaches to service delivery models for mental health and substance use disorders in elite athletes provide some guidance. ${ }^{339500}$ For spit tobacco use, two approaches used the pre-season physical and dental examinations as an opportunity to screen for heavy nicotine use and examine players for oral lesions. If screening is positive, then a brief intervention by a dental technician or a substance counsellor experienced in tobacco cessation is delivered. In one study, ${ }^{498}$ after 10 years of annual oral examinations and dental technician interventions, spit tobacco use dropped from $41.1 \%$ to $25.6 \%$ of players. In more recent models of service delivery, experienced sports clinicians are onsite with teams to integrate substance screenings and brief interventions with other health screenings and interventions. ${ }^{339500}$ One model uses experienced mental health/ substance providers, who work with the team all year, to conduct screenings for substance use/misuse at the time of the pre-season physical and carry out follow-up evaluations and treatments for those who screen positive. This approach has led to increasing service utilisation rates and problem identification at earlier stages, when problems are easier to treat. ${ }^{424} 500$ Finally, drug testing is a known deterrent to substance use among athletes, ${ }^{501}$ and research suggests that increased frequency of drug testing, including during high risk time periods (eg, immediately after a game when athletes are socialising or early in the post-season), may diminish illicit drug use among elite athletes. ${ }^{462}$

Brief individual or group interventions delivered by clinicians, sometimes with key family members or members of the athlete's entourage in attendance, may successfully prevent or diminish binge drinking or other substance use in collegiate athletes. ${ }^{502-505}$ Similarly, binge drinking may be successfully diminished when athletic trainers and academic advisors screen for and deliver brief motivational interventions. ${ }^{506}$ Group therapy, as an adjunct to medication treatment, is effective when addressing substance use disorders among professional athletes. ${ }^{14478} 507$ No research on the use of self-help groups such as Alcoholics Anonymous or Narcotics Anonymous or intensive outpatient or residential treatment of elite athletes is available. While these treatments are evidence based in other populations, concerns about confidentiality may limit elite athletes' willingness to participate in self-help groups. ${ }^{508}$

There are no pharmacological studies on treatment of substance use disorders in elite athletes. Such treatment is generally grounded in psychosocial modalities, and pharmacotherapy is used to manage withdrawal and cravings and to treat comorbid 
mental health symptoms or disorders, such as insomnia, anxiety or depression. ${ }^{508}$ There are unique implications for treatment of opioid use disorder in elite athletes because treatment often involves use of opioid agonists (eg, methadone and buprenorphine). Since these are prohibited in competition by WADA, ${ }^{59}$ elite athletes falling under WADA's governance require a break from training and competition if such an approach is utilised. ${ }^{53}$ Because alcohol is the most commonly used substance among elite athletes, alcohol use disorder may occur in this population; naltrexone, acamprosate and disulfiram are treatment options for this disorder when cravings are strong or persistent and when the athlete is unable to stop use on their own. ${ }^{53}$ Since heavy oral nicotine use is also seen frequently in some sports and can be accompanied by tolerance, physiological dependence and cravings, pharmacological strategies for moderate to severe nicotine use disorders in elite athletes should be considered. These include nicotine replacement therapy with or without bupropion, varenicline or bupropion plus varenicline..$^{50-511}$ Electronic cigarettes or nicotine vaping devices are not recommended for use in elite athletes since their safety and effects on respiratory function have not been established. ${ }^{512513}$

\section{Gambling disorder and other behavioural addictions}

Many behavioural addictions may negatively impact an athlete's functioning, but most studies have focused on gambling disorder. ${ }^{514}$ Gambling disorder, as described by the DSM-5, ${ }^{1}$ involves at least 12 months of persistent and recurrent problematic gambling with resultant negative consequences. Individuals with gambling disorder report decreased athletic and academic performance, comorbid mental health symptoms and disorders (eg, anxiety, depression and substance use disorders), interpersonal difficulties and legal concerns (theft or embezzlement to support their gambling). ${ }^{514-516}$

Along with technological advances, attitudes toward gambling have changed. It is now a socially accepted, easily accessible form of entertainment. ${ }^{517}$ Gambling disorder is regarded as a 'hidden disorder', and mental health professionals have reported relative lack of awareness and concern about gambling as a potential problem. ${ }^{518}$ Relatively few studies have examined the impact of gambling disorder. Elite athletes may be particularly at risk for gambling disorder, given their overrepresentation of young males, which is a known high risk group. ${ }^{514}{ }^{519-521}$ Additional risk factors for elite athletes include their desire for competition and challenges, high levels of sensation seeking and impulsivity, and increased risk taking behaviours. ${ }^{522-525}$

Early studies that assessed North American collegiate athletes found prevalence rates of disordered gambling between 5.2\% $\%^{526}$ and 6.2\% ${ }^{527}$ Weiss and Loubier ${ }^{521}$ reported that both former and current athletes had the greatest likelihood of problem gambling
(13.0\% and $7.0 \%$, respectively) compared with non-athletes (3.0\%). In the NCAA's study of North American collegiate athletes between 2004 and 2016, over 84000 male collegiate athletes self-reported prevalence rates of disordered gambling of between $0.7 \%$ and $2.0 \%$. However, those athletes at risk (not meeting the clinical criteria for gambling disorder, but self-reporting serious gambling related problems) comprised between $1.1 \%$ and $2.9 \%$ of the sample. ${ }^{522}$ Thus the results suggest that between $1.8 \%$ and $4.0 \%$ of respondents have serious gambling related problems. Importantly, assessment measures have differed among studies, as have the availability and accessibility of gambling opportunities. Additionally, the NCAA study assessed athletes where gambling by collegiate athletes was prohibited. In a study among professional athletes from Spain, France, Greece, Ireland, Italy, Sweden and the UK, $56.6 \%$ participated in some form of gambling during the past year, and $8.2 \%$ had a gambling problem (either current or in the past). In particular, problem gambling was related to wagering on one's own team, betting online and gambling regularly. ${ }^{520}$

Several other behavioural disorders, including excessive gaming, Internet and social media use, may be of concern in athletes but are not DSM-5 diagnoses and have received little research attention. In one case study, a professional baseball pitcher experienced an injury after excessively playing a video game. ${ }^{528}$ Others have argued that Wii Sports software may be helpful for rehabilitation of athletic injuries. ${ }^{529}$ Some papers describing excessive professional gaming in electronic sports ('e-Sports') have questioned whether professional gamers who spend 10 hours or more a day practising and competing are 'addicted' to gaming or work. ${ }^{530-532}$

While also not included as a behavioural addiction in the DSM-5, excessive exercise shares behaviours with other addictive behaviours. ${ }^{533}$ Prevalence rates of 'exercise addiction' among athletes have varied considerably. Szabo and Griffiths ${ }^{534}$ reported that $6.9 \%$ of British sports science students were at risk for an exercise addiction. Blaydon and Linder ${ }^{535}$ reported that $30.5 \%$ of triathletes could be diagnosed with exercise addiction, with another $21.6 \%$ approaching an addiction. Allegre et al $l^{536}$ reported that $3.2 \%$ of ultra-marathoners displayed signs of an exercise addiction. Several studies have reported a significantly greater risk for exercise addiction in elite athletes compared with recreational exercisers. ${ }^{537}$ In the elite population, it may be challenging to distinguish exercise addiction from normative and adaptive high level training, but some characteristics may help with that distinction (table 9).

Eating disorders often are comorbid with exercise addiction in athletes. ${ }^{290} 539$ Some researchers distinguish primary exercise addiction, in which there is no accompanying eating disorder and exercise is the primary objective, from secondary exercise

Table 9 Features of 'exercise addiction' versus normative/adaptive exercise in elite athletes ${ }^{538738-741}$

\begin{tabular}{|c|c|}
\hline Exercise addiction & Normative/adaptive exercise in elite athletes \\
\hline $\begin{array}{l}\text { Tolerance: the need to increase the exercise duration, frequency and/or intensity to } \\
\text { perceive the desired benefit and to satisfy 'cravings' for it }\end{array}$ & $\begin{array}{l}\text { Fluctuation in amount of exercise as expected at various points in the training } \\
\text { cycle }\end{array}$ \\
\hline $\begin{array}{l}\text { Withdrawal: depressive or anxious symptoms or irritability when the individual suddenly } \\
\text { reduces or stops exercise, with possible difficulty performing professional or social } \\
\text { activities as a result of these symptoms }\end{array}$ & $\begin{array}{l}\text { Mild depressive or anxious symptoms or irritability are possible when the } \\
\text { individual suddenly reduces or stops exercise, but these symptoms do not cau } \\
\text { functional impairment }\end{array}$ \\
\hline $\begin{array}{l}\text { Continued exercise despite knowing that it is causing physical, psychological and/or } \\
\text { social problems }\end{array}$ & $\begin{array}{l}\text { Ability to stop or cut down on exercise as recommended (eg, if an injury or } \\
\text { illness could be worsened by continued exercise at the same level) }\end{array}$ \\
\hline - Inability to reduce or manage exercise, despite the desire to do so & - Feeling of control over exercise, which occurs according to planned training \\
\hline $\begin{array}{l}\text { Elimination of other life activities (eg, previously desired social, occupati } \\
\text { recreational activities) to accommodate increasingly time consuming exe }\end{array}$ & $\begin{array}{l}\text { While exercise may take a substantial amount of time, other life activities that } \\
\text { are important to the individual are not completely eliminated }\end{array}$ \\
\hline
\end{tabular}




\begin{tabular}{ll}
\hline Table 10 International Olympic Committee definitions: types of non-accidental violence in sport ${ }^{266}$ \\
\hline Psychological abuse & $\begin{array}{l}\text { A pattern of deliberate, prolonged repeated non-contact behaviours within a power differentiated relationship. This form of abuse is at the } \\
\text { core of all other forms }\end{array}$ \\
Physical abuse & $\begin{array}{l}\text { Non-accidental trauma or physical injury caused by punching, beating, kicking, biting, burning or otherwise harming an athlete. This could } \\
\text { include forced or mandated inappropriate physical activity (eg, age inappropriate or physique inappropriate training loads; when injured or } \\
\text { in pain), forced alcohol consumption or systematic doping practices }\end{array}$ \\
Sexual abuse & $\begin{array}{l}\text { Any conduct of a sexual nature, whether non-contact, contact or penetrative, where consent is coerced/manipulated or is not or cannot be } \\
\text { given }\end{array}$ \\
Neglect & $\begin{array}{l}\text { Failure of parents or caregivers to meet a child's physical and emotional needs or failure to protect a child from exposure to danger. This } \\
\text { definition equally applies to coaches and athlete entourages }\end{array}$ \\
\hline
\end{tabular}

addiction, in which weight loss is the objective, with excessive exercise being one of the primary means in achieving the objective. ${ }^{540-542}$

There is a growing body of clinical evidence that behavioural disorders can be successfully treated. ${ }^{514}$ The most common approaches include motivational interviewing and CBT. ${ }^{514} 543$ Coaches, trainers and team physicians are in a unique position to identify and address these concerns. 522544

\section{MAJOR STRESSORS AND KEY ENVIRONMENTAL FACTORS THAT INFLUENCE ELITE ATHLETE MENTAL HEALTH}

In addition to the specific mental health issues mentioned above, the IOC expert group also considered the larger social environment in which elite athletes operate. We share our consensus findings on: harassment and abuse; how injury, performance and mental health interesect; barriers to seeking care for mental health symptoms and disorders; the athete's transition out of sport; mental health emergencies; and how it may be possible to create an environment that promotes mental well-being and resilience.

Harassment and abuse (non-accidental violence)

The risk of non-accidental violence in elite sport environments-whether psychological, physical or sexual abuse, or neglect-requires policies and procedures to protect athletes (table 10). ${ }^{266}$ Non-accidental violence is the term used by the United Nations and the IOC to describe harms experienced by athletes because of an abuse of actual or perceived differentials in power, based in a cultural context of discrimination. ${ }^{266}$ Psychological abuse is considered the basis for all other forms of non-accidental violence and is the most prevalent in sport. ${ }^{545}$ The four types of non-accidental violence may occur in isolation or in combination, and may be a one time occurrence, continuous or repetitive. Non-accidental violence can manifest via different mechanisms, including contact, verbal or cyber mechanisms, negligence, bullying or hazing (figure 2).

Non-accidental violence occurs in all sports and at all levels, ${ }^{546-548}$ with a greater risk for psychological, physical and sexual abuse at the elite level. ${ }^{546549}$ High risk sport populations for non-accidental violence include: child athletes; ${ }^{550}$ athletes who identify as lesbian, gay, bisexual,transgender, or queer; ${ }^{551}$ and athletes with a disability. ${ }^{549}$ Underreporting is a significant concern and limits conclusions about the prevalence of non-accidental violence of any form among elite athletes. ${ }^{552}$ Stafford reports that the prevalence of psychological abuse approaches $75 \%$ in youth athletes. ${ }^{553}$ The reported prevalence of sexual abuse in sport ranges from $2 \%$ to $49 \% .{ }^{554}$ Although there are few robust prevalence studies on physical abuse and neglect

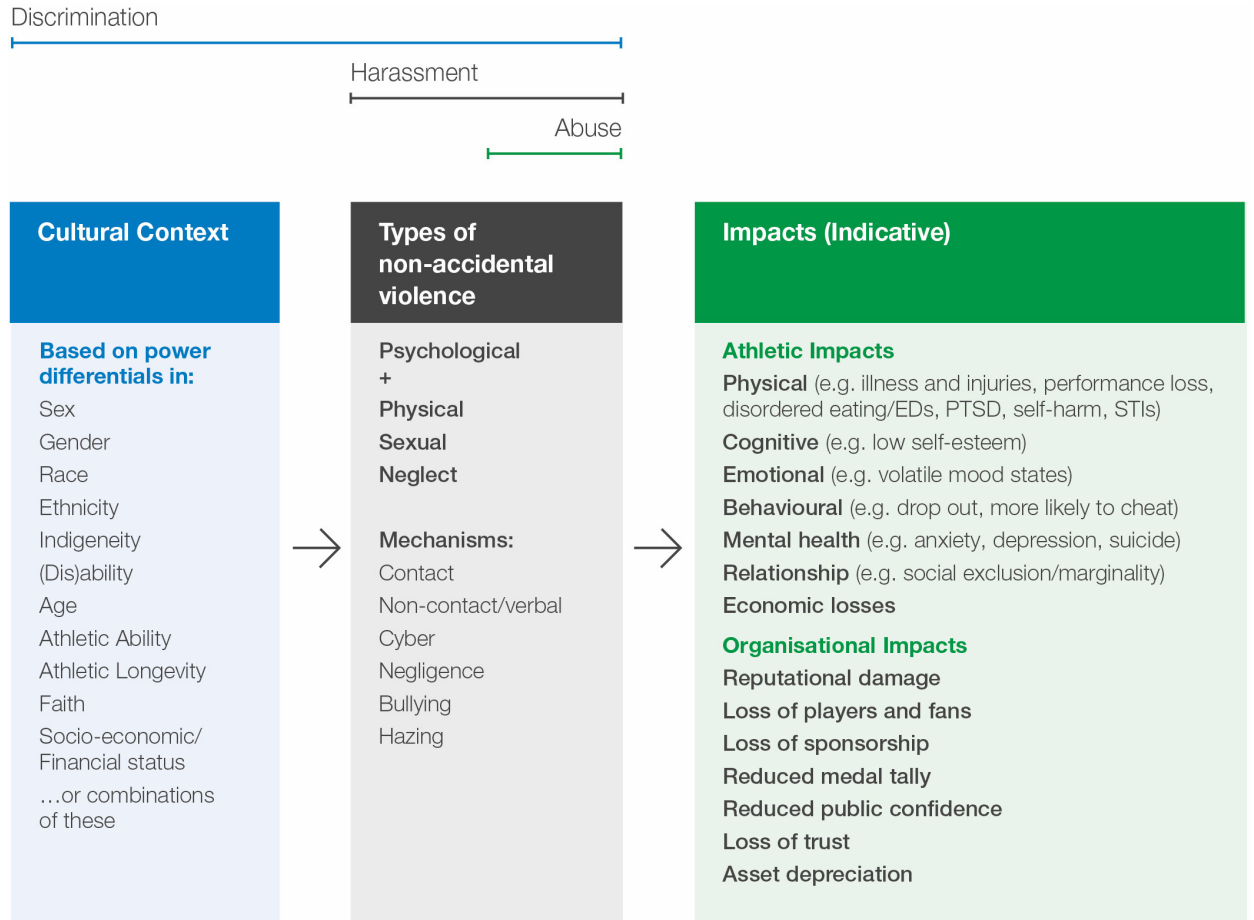

Figure 2 Framework of non-accidental violence in sport, as adapted from the International Olympic Committee. ${ }^{266}$ 
in sport, many public reports outline these forms of non-accidental violence in sport. Male perpetrators of sexual abuse are reportedly more common than female perpetrators, and female athletes are reportedly more often victims of sexual abuse than male athletes. ${ }^{55}$ Perpetrators of forms of non-accidental violence may be team physicians, ${ }^{556}$ coaches, other members of the athlete entourage, ${ }^{557}$ peers or team mates. ${ }^{558}$

The impact of non-accidental violence in sport can be devastating and long standing, ${ }^{559}$ including loss of self-esteem, poor academic performance, distorted body image, eating disorders, self-harm, depression, anxiety, substance use disorders and suicide. ${ }^{560}$ Non-accidental violence is correlated with willingness to cheat or dope in sport. ${ }^{561}$ Psychological abuse can lead to impaired athletic performance, reduced medal opportunities, loss of sponsorship and early sport dropout. ${ }^{560}$ Childhood psychological abuse is a correlate of long term post-traumatic and dissociative symptoms in athletes. ${ }^{562}$

Athletes can also suffer from indirect non-accidental violence when they witness such events experienced by others and not stopped by others, including those in authority ${ }^{563}$ This phenomenon compounds the psychological trauma of the victim, and deters disclosure by athletes. ${ }^{564}$ Non-accidental violence in sport may also affect the victim's family, and personal, social and work/school relationships outside of sport. ${ }^{565}$

An athlete presenting with mental health symptoms to a clinician should be asked about a history of non-accidental violence, either within or outside of sport. ${ }^{566}$ Sports medicine healthcare providers should develop the clinical competence to recognise non-accidental violence, manage athlete disclosures, report cases and treat victims, their families and their teams. ${ }^{556}$ It is imperative to ensure immediate athlete safety. Multidisciplinary support should be the cornerstone of management. ${ }^{556}$ Support for teammates, the athlete entourage and family members may also be appropriate. ${ }^{556}$ Depending on laws where the abuse occurred, reporting to legal authorities may be required, for example if a child has been sexually abused. ${ }^{556}$

\section{How injury, performance and mental health intersect}

The relationship of injury, performance and mental health in elite athletes is complex. ${ }^{322}{ }^{567-570}$ Elite sport has specific stressors that potentially increase the likelihood of injury or illness, including mental health disorders. ${ }^{222}{ }^{571-576}$ Injury also can potentially unmask or precipitate mental health disorders. ${ }^{574}$ Finally, mental health disorders can increase the likelihood of, or complicate recovery from, injury. ${ }^{222572573577}$ Nonetheless, there is minimal prospective research in this area.

\section{Injury risk factors}

Psychological and sociocultural factors are potential risk factors for injury in sport. ${ }^{569} 574575578$ Psychological risk factors include anxiety/worry, hypervigilance, poor body image or low self-esteem, perfectionism, limited coping resources, life event stress (ie, perceived strain associated with major life event stressors such as the death of a family member or starting at a new school), risk taking behaviours or low mood state. Sociocultural risk factors include limited social resources, a lifetime history of sexual or physical abuse, ${ }^{579}$ social pressures, organisational stress (ie, associated with an athlete's appraisal of the structure and function of their sports organisation), ${ }^{580}$ stress related to negative self-appraisal of athletic and academic performance, coaching quality (eg, poor athlete-coach relationship and communication) and the culture of sport and teams (eg, a mindset of 'winning at all costs' vs striving for continual improvement). ${ }^{223} 569574581$
Although there are limited prospective studies coupled with conflicting results regarding risk factors related to injury, life event stress and high stress response (ie, negative emotional responses after sport injury or other stressful events) consistently demonstrate a relationship with injury risk. ${ }^{223572574578581-585}$ Life event stress and high stress response can cause inattention, distraction and increased self-consciousness while increasing muscle tension and impaired coordination, all of which can impair performance and increase the risk for injury. $223572578581-585$ When team mates and coaches are sources of life event stress, there is an associated increased risk of both acute and overuse injuries. ${ }^{581}$ Emotional reactivity (involuntary and overly intense emotional reaction) is also associated with poor on field performance and injury. 222586587

\section{Response to and recovery from injury and illness}

Cognitive, emotional and behavioural responses are important factors associated with outcome following injury. ${ }^{57}$ The evidence for outcomes following illness is not well evaluated, but the same processes may occur as after injury. Cognitive responses to injury may include concerns about re-injury, doubts about competency, low self-efficacy, loss of identity and concerns about competency of the medical staff. ${ }^{588}$ Emotional responses to injury may include symptoms of sadness, depression, suicidal ideation, anxiety, isolation, lack of motivation, anger, irritation, frustration, changes in appetite and sleep, low vigour, disengagement and burnout. ${ }^{7574}$ Injured athletes report more symptoms of depression and of generalised anxiety disorder compared with non-injured athletes. ${ }^{11}$ Whereas emotional responses to injury and illness vary, problematic emotional responses are those that do not resolve, worsen over time or in which the symptoms seem excessive ${ }^{569}$ Injury (and possibly illness) may trigger or unmask other behavioural responses or underlying mental health disorders, including disordered gambling, disordered eating or eating disorders, and substance use disorders. ${ }^{26} 3035192241389483589-595$

Athletes with more positive cognitive, emotional and behavioural responses may have improved injury recovery. ${ }^{35} 573$ 596-606 Higher levels of optimism and self-efficacy and lower levels of depression and stress are associated with improved recovery from injury. ${ }^{35} 573$ 596-605 Examples of strategies that support positive return to sport experiences include: (a) reducing re-injury anxieties using modelling techniques, such as watching videos of formerly injured athletes discussing how they overcame their re-injury anxieties, or pairing an injured athlete with another athlete proficient in certain rehabilitation exercises so the less experienced athlete can learn how to execute the exercises correctly; (b) fostering athlete autonomy (eg, by explaining why they are performing rehabilitation exercises); (c) building confidence through functional tests and goal setting; (d) providing social support; (e) keeping athletes involved in their sport but avoiding premature return to sport; and (f) stress inoculation training when injury requires surgical intervention. ${ }^{604} 606$

\section{Barriers to seeking care for mental health symptoms and disorders}

Elite athletes may encounter many barriers to seeking mental healthcare, including stigma. ${ }^{188} 607-615$ Public stigma and selfstigma predict a significant detrimental impact on seeking treatment for mental health. ${ }^{616}$ Additionally, many athletes come from countries where there are few, if any, mental health services, and where there may also be ways of understanding and treating mental health symptoms and disorders outside of evidence and biomedically based ones. ${ }^{617} 618$ Other barriers can include lack 
of mental health literacy, negative past experiences with mental health help seeking and busy athlete schedules. 188290609610

Facilitators to seeking mental healthcare among athletes include: having an established relationship with a mental health provider; positive previous interactions with mental health providers; perception of benefits to seeking help; a sense of self-efficacy to seek treatment; and the positive attitudes of others, especially coaches, regarding seeking mental health treatment. ${ }^{188619620}$ Even for elite athletes with positive attitudes toward mental health help seeking who express a willingness to engage psychological services, many have concerns regarding how they will be perceived by their peers, coaches and sport managers. ${ }^{611612621}$ Brief mental health literacy and de-stigmatisation interventions improve knowledge and may decrease stigma but may not be enough to increase help seeking. ${ }^{289} 502505622-627$

Negative attitudes about mental health services are associated with several factors, including identification as male, younger age, Black (vs Caucasian) race, US (vs European) nationality, lower measures of openness, higher measures of conscientiousness, gender role conflicts and participation in physical contact sports. ${ }^{628-632}$ Conversely, coaches can be important advocates of promoting positive attitudes about mental health by being mindful of early identification and referral of athletes with possible mental health symptoms and disorders to mental health services. ${ }^{607}$ Moreover, athletes with stronger positive coping skills generally have attitudes more supportive of seeking mental health help. ${ }^{291}$ Finally, athletes have strong preferences for counsellor characteristics, such as familiarity with their sport, same gender, older but still close enough in age to understand their lives and geographic proximity to the sports facility. ${ }^{63-636}$

Cultural issues within sport have broad reaching effects that impact elite athletes differently, depending on their own cultural identities, including gender, gender identity, sex, sexual orientation, race, ethnicity, socioeconomic status and religion. ${ }^{55}$ Cultural influences and discrimination related to cultural factors may leave some athletes at a performance disadvantage and set the stage for mental health symptoms or disorders.

As women continue to engage in elite sport opportunities, their participation has led to varying degrees of cultural acceptance. ${ }^{637}$ Women competing in sports traditionally considered 'male' may face being marginalised and stereotyped ${ }^{638}$ and may experience unequal training opportunities and resources. ${ }^{639}$ Sexualisation, traditional gender roles, religion and ethnic beliefs all influence opportunities for women. ${ }^{640}$ For example, women of some religions may experience difficulty combining traditional roles with competition as an elite athlete, as related to religious rules about the body and presentation in public. ${ }^{640}$ Tension may also exist between what is functionally optimal for women elite athletes to be wearing and what is culturally deemed acceptable. ${ }^{641} 642$ Gender stereotyping in the media may influence how women athletes view themselves. ${ }^{641}$ Women athletes may be stereotyped as 'lesbian' to keep them from playing certain sports, or from playing for certain coaches or with certain teams. ${ }^{641}$ Some professional women athletes must train outside their native countries $^{643}$ and may struggle to find a support network and cultural understanding from team mates in their new location. ${ }^{644}$

Sexuality and cultural norms of masculinity in elite sport also impact elite athletes. ${ }^{645}$ Non-heterosexual athletes face various degrees of acceptance, ${ }^{646}$ and this may interfere with sports performance. ${ }^{646647}$ Transgender athletes often have negative experiences in sports and may struggle to be accepted, ${ }^{648}$ even after they meet criteria allowing them to participate. ${ }^{649}$

Racial disparities-including those involving exploitation, player-coach tension, prejudicial treatment and microaggressions-in addition to socioeconomic inequities, form barriers that may prevent equal opportunities. ${ }^{650-654}$ For example, access to wealth has predicted participation and success at the Olympic Games. ${ }^{655}$ Importantly, discrimination based on any aspect of cultural identity may come from several sources, including coaches, team mates, agents, universities, leagues, managers, healthcare providers or others.

\section{Transition out of sport}

Epidemiological evidence suggests that elite athletes transitioning out of sport are at risk of developing mental health symptoms and disorders. As in current athletes, most studies have relied on self-reported cross sectional data. These reports show that the prevalence of mental health symptoms and disorders in former elite athletes ranges from 5\% for adverse alcohol use to around 45\% for anxiety and depression. ${ }^{13} 162234590656-661$ Few studies have prospectively explored mental health disorders in former elite athletes; those that have done so reported incidence rates from $5 \%$ to $30 \%$ over a follow-up period of up to 12 months. 131618662

While transitioning out of elite sport, generic and sport specific factors are likely to interact and increase the risk of mental health symptoms and disorders among athletes. ${ }^{31} 32663$ Undesired and involuntary retirement from sport (eg, because of injury or deselection from sport) is especially associated with an increased risk of mental health symptoms and disorders among transitioning athletes. ${ }^{86164-668}$ Concussion in sport is associated with subsequent mental health symptoms and disorders among retired elite athletes; however, a causal relationship has not been established. ${ }^{16390594669-672}$ Other factors associated with adjustment difficulties and mental health symptoms and disorders among former elite athletes include high levels of athletic identity, lack of retirement planning, lower educational attainment, adverse life events, post-sport unemployment and chronic pain. 918662668673674

Stakeholders in elite sport have considered how to protect and promote the long term health of elite athletes beyond retirement. For example, an 'exit health examination' focusing on mental health indicators may promote sustainable health and quality of life. ${ }^{675676}$ This could be particularly important for former elite athletes at risk for mental health disorders, especially those retiring from sport involuntarily. Additionally, thorough preparation for post-sport life may help mitigate mental health disorders during transition out of sport. ${ }^{668}$ Accordingly, education programmes/seminars, practical resource centres, and mental and life skills training for career transition could be offered to elite athletes across their sport career. ${ }^{668} 677$ Finally, clinicians can help athletes to become aware of, develop and use transferable skills that may provide direction, meaning and motivation in their post-sport life. ${ }^{660}$

\section{Mental health emergencies}

A mental health emergency refers to immediate risk in the context of a disturbed mental state. ${ }^{678} 679$ Risks are typically to the health and/or safety of the athlete or others. ${ }^{678}$ Data on prevalence in elite athletes are sparse. Some circumstances within sport may carry an increased risk of mental health emergencies. For example, deselection is linked to acute adverse emotional reactions. ${ }^{60}$ Sporting injuries are associated with anger and depression, ${ }^{681}$ which are in turn associated with an increased suicide risk. ${ }^{682}$ Periods of injury may also necessitate time away from sport and a further increased risk of suicide. ${ }^{63}$ 
Substances misused by elite athletes may also contribute to a higher risk of mental health emergencies. Use of anabolic-androgenic steroids is linked to hypomanic or psychotic symptoms, aggression and even suicide. ${ }^{342}{ }^{343}$ Longitudinal studies lend support to these links, ${ }^{684} 685$ and symptoms are more likely with the high doses and multiple agents misused by athletes. ${ }^{341} 342$ Symptoms can emerge rapidly, ${ }^{686}$ but may be self-limiting or require only short term treatment. ${ }^{341}$ Current users may experience mood changes with suicidal thinking and impulsivity; discontinuation leads some to descend into depression with more planned suicidal ideation. ${ }^{687}$ Both scenarios carry significant risks, and death by suicide is $2-4$ times greater in male athletes who may have used anabolic-androgenic steroids compared with the general population. ${ }^{591}$ Stimulant use may lead to acute mood disturbance, aggression and psychosis. ${ }^{344} 345$ Marijuana and synthetic cannabinoids are associated with acute psychosis, ${ }^{688} 689$ but there are no athlete specific data.

Athletes' patterns of alcohol consumption tend more towards binge drinking; ${ }^{444}$ thus acute intoxication may be a more likely emergency presentation than physical dependence and/or withdrawal. Retired athletes may also be at greater risk for mental health emergencies associated with heavy alcohol use compared with their non-sporting peers. ${ }^{690}$ Acute concerns in eating disorders are often medical (eg, fracture risk, electrolyte abnormalities and electrocardiographic changes) and may be severe enough to warrant deselection. ${ }^{274} 286$ If so, then there is a risk of emotional decompensation, and urgent clinical evaluation may be needed. ${ }^{691}$ Limited data suggest that borderline (along with obsessive-compulsive) subtypes are the the most common personality disorders found in sport. ${ }^{692}$ Borderline personality disorder is associated with impulsivity, risk taking, frequent suicidal behaviours, an unstable affect and interpersonal difficulties. ${ }^{1}$ These features alone, or especially in combination, may promote an emergency mental health presentation.

There is little to guide the choice of pharmacological treatments for mental health emergencies in elite athletes. ${ }^{57}$ Benzodiazepines and/or antipsychotics by oral or parenteral routes are all used to tranquillise a person with an acutely, severely and dangerously disturbed mental state. ${ }^{679} 693$ Sports specific treatment concerns include the performance impact of motor symptoms, weight gain or sedation, ${ }^{5657}$ but these concerns may be less relevant when only short term treatment is required.

When conducting an emergency mental health assessment, the physical environment should be uncluttered and provide both containment and escape routes. ${ }^{678}$ However, such environments may be unavailable when assessing an athlete at a training or competition venue. ${ }^{694}$ Although pathways and available personnel may differ from country to country, ${ }^{339}$ it is best practice to develop and rehearse a mental health emergency action management plan for all relevant sport stakeholders. This plan should include clarity on what constitutes an emergency, who should be contacted and when, and familiarity with local emergency services and mental health legislation. Plans should be consistent with other emergencies in sport, such as cardiac arrest, heat illness and severe trauma. A review of procedures after any incident can be very helpful. ${ }^{567}$

\section{Creating an environment that supports mental well-being and resilience}

The diagnosis and management of mental health symptoms and disorders is a separate but related continuum with athlete wellbeing. ${ }^{695}{ }^{696}$ Within sport, coaches are often the primary interpersonal interface with the athlete. They can support diagnosis and management of mental health symptoms and disorders by creating a destigmatising environment wherein mental health help seeking is a core function of training and self-care. ${ }^{697} 698$ Coaches can attend to athlete stressors that may diminish wellbeing and predispose to mental health symptoms and disorders, including training load and recovery, ${ }^{699} 700$ injury, 22322700 burnout $^{701}$ and retirement. ${ }^{241}$ Coaches can ensure that training is age and developmentally appropriate. ${ }^{702-704}$ For younger elite athletes, coaches can communicate the importance of mental healthcare to parents, thereby managing expectations about avoiding stressors and seeking care when appropriate. ${ }^{705}$

Coaches can foster positive psychosocial development and well-being by helping athletes learn to respond to stressors in healthy ways. ${ }^{698} 706707$ This includes helping athletes learn skills that promote resilience, ${ }^{708}$ psychological flexibility, ${ }^{709}$ self-compassion $^{710}$ and adaptation to situational demands while staying consistent with one's values. ${ }^{709}$ In day to day training, coaches can de-emphasise achievements and outcomes and instead foster a process oriented mindset, in which effort and improvement are emphasised. ${ }^{711}$ Such an approach may help mitigate performance related anxiety ${ }^{712}$ and attrition from sport ${ }^{713}$ while optimising the positive psychological experiences of sport participation. ${ }^{714}$

Organisations can support athlete mental health by providing coaching education that is evidence based and efficacious. ${ }^{622} 698715-719$ Effective delivery of coaching education is more likely if it falls within the framework of coaching duties and expectations. ${ }^{705}$ Resource allocation, priorities and outcomes or behaviours that are rewarded (well-being vs win-loss record) show coaches whether mental health is viewed as an organisational priority. Intentional time allocation in the athlete's normal practice schedule for learning positive psychosocial skills is associated with better developmental outcomes. ${ }^{720}$ Sport governing bodies can further influence athlete mental health by requiring or recommending that coaches undergo mental health training. ${ }^{291}$ Ultimately, sport can positively influence society to promote well-being and de-stigmatise mental health help seeking. ${ }^{721}$

\section{SPECIAL CONSIDERATIONS: MENTAL HEALTH IN PARALYMPIC ATHLETES}

Paralympic sport is sport for people with disabilities. Paralympic athletes use adapted equipment or rules to make sport accessible to individuals with impairments. In general, sport is often heralded for its ability to promote mental health, and there is a largely unexamined assumption that participation in Paralympic sport improves an athlete's psychological well being. ${ }^{722}$ However, research concerning the mental health of athletes with disabilities is minimal..$^{723}$

Rates of mental health symptoms and disorders, specifically depression, among the general population of people with disabilities are reported to be higher than in non-disabled individuals. ${ }^{724}$ Nonetheless, a review of 12 studies of Olympic and Paralympic athletes demonstrated that most indices of wellbeing (eg, physical confidence, physical self-worth, self-regard, self-actualisation, self-acceptance, confidence and self-efficacy) were similar in the two groups. ${ }^{725}$ Emerging research suggests that athletes making a Paralympic team may have lower rates of depression and anxiety than those trying out for but not making a Paralympic team. ${ }^{723}$ While eating disorders in Paralympic athletes have received little research attention, those who restrict their food intake may be at greater risk for complications from low energy availability, especially low bone mineral density, because of factors such as altered skeletal loading. ${ }^{280}$ Finally, athletes with intellectual and physical impairments, as a subset 
of Paralympic competitors, may have unique mental health challenges, but specific research is particularly sparse. ${ }^{724}$

Elite athletes with disability experience both sport specific and disability specific stressors that may contribute to mental health symptoms and disorders. ${ }^{724}$ Stressors that disproportionately and commonly affect elite athletes with disabilities include: chronic pain; overtraining and injury in often complex medical situations (eg, with the need to distinguish sport fatigue, discomfort from the underlying disability and sport injuries); lack of sufficient adaptive sport facilities; logistical difficulties in getting to competition sites; challenging sleep conditions and inferior sleep quality in Paralympic villages; recent rapid escalation of Paralympic sport competitiveness and associated rapid increases in training demands; malfunctioning sports equipment; costs associated with new technology; negative coaching behaviours (eg, demeaning comments); and being 'misclassified' or assigned to the wrong disability category for competition. ${ }^{724726-729}$

There is little published work on the management of psychosocial stressors or mental health symptoms and disorders in Paralympic athletes. Studies that exist usually had very small sample sizes, did not use standardised measures of psychopathology and relied on unsophisticated statistical analysis. Some attention has been given to the use of psychological skills training to promote peak performance by Paralympic athletes, independent of a history of mental health disorders. ${ }^{724}$ Psychological skills training entails systematically training athletes to use mental skills-such as regulating anxiety, sustaining motivation, focusing attention and maintaining concentration-to enhance sport performance. ${ }^{724}$ Addressing insufficient sleep may be particularly relevant, as athletes with disabilities may be at high risk for sleep disorders. ${ }^{730}$

Given the relative prominence of research regarding social factors among athletes with disabilities, disability exclusion may be an important issue when working with these athletes. ${ }^{731}$ For example, Paralympic athletes may report feelings of powerlessness and invisibility; ${ }^{732}$ accordingly, athletes with disabilities benefit from coaches who are trained to be supportive of athletes' autonomy, ${ }^{733} 734$ and sport performance may improve as a result. ${ }^{735}$ Additionally, as with non-disabled athletes, retirement from sport is an important time of transition for Paralympic athletes. ${ }^{724}$ Many Paralympians start their careers shortly after the onset of disability. ${ }^{724}$ Consequently, with relatively short lived professional sport careers, some face the challenge of simultaneously needing to adjust to a relatively new disability and preparing for retirement from sport; providers should be aware of these dual transitions. ${ }^{723} 724$

\section{FUTURE DIRECTIONS}

The current state of the science of mental health in elite athletes suggests possible future direction for additional research, change in clinical practice and optimisation of environmental factors. These include:

1. The relative lack of access to mental health services in some countries and cultures must be considered as research is undertaken and clinical services developed. A rigorous, evidence based approach to mental healthcare should be utilised across countries, but nuanced approaches to provision of that care might be needed, for example by incorporating into the mental healthcare team people such as athletic trainers, physical therapists, coaches and others in the athlete's entourage and community. If mental healthcare for elite athletes is to be equitably available globally, researchers and practitioners must engage with any emerging evidence and lessons from the global mental health field.

2. More thorough and reliable mental health epidemiology in elite athletes is needed, with attention to cross cultural differences in manifestations of symptoms and disorders. There are particularly sparse data on bipolar and psychotic disorders, mental health emergencies and athletes with disabilities.

3. More robust data on pre-existing mental health symptoms and disorders as risk factors for subsequent concussion, and on mental health implications of sub-concussive impact, are needed.

4. While future research should be clear about whether mental health symptoms versus full disorders are being measured, athletes with symptoms and not full disorders must remain a focus of research attention, as symptoms themselves can be problematic for elite athletes. Increased understanding of risk factors for development of full disorders from earlier symptomatic stages needs clarification within elite athletes.

5. More research on and subsequent recommendations for expanded mental health screening of elite athletes is needed. Screening is often an important step to ensure that more affected elite athletes ultimately receive the treatment they need. Timing of screening must be carefully considered, given that risks, such as those that occur with injury, may increase at various times throughout an elite athlete's career. There may be benefit from athlete specific screening tools being developed across diagnostic categories where they do not yet exist, taking into consideration potential unique manifestations of these conditions in this population while also appreciating the limitations to sole reliance on rating scales in the absence of clinical interview. To be able to develop optimal assessment methodologies and screening tools, we need better understanding of the unique symptom manifestations in athletes, which may require both qualitative and quantitative study across countries and cultures.

6. A better understanding of physiological recovery and optimum readiness-including physical and psychological-to return to play after an injury or illness must be developed. The impact of sleep on recovery and on optimum readiness must be considered in this context.

7. Additional research is needed on treatments, including psychotherapy and pharmacological treatment, for mental health symptoms and disorders in elite athletes. Methodology should address the limitations that exist in the pharmacologic research to date. Cross cultural considerations include types of therapies and medications/supplements disproportionately used in some countries and cultures, but for which an evidence base may be relatively lacking. Pharmacological intervention for post-concussion mental health symptoms also needs further study, for example addressing duration of recommended treatment for apparent new onset depression and anxiety associated with concussion.

8. Additional prevention strategies for mental health symptoms and disorders are needed. For example, comprehensive strategies for preventing eating disorders and substance use disorders, especially within high risk elite sports, are needed. Furthermore, more widespread implementation of prevention strategies for non-accidental violence in elite sport is needed.

9. Strategies that more effectively overcome stigma for elite athlete populations must be developed, such that members 
of this population come to understand that the 'mental toughness' required for success in sport is compatible with mental health help seeking.

10. A better understanding of sport as a subculture within society is needed, including which elements of that subculture are particularly conducive to positive mental health outcomes. While much of the research in this area focuses on coaching interventions, roles for other members of the athlete entourage, including parents and other caregivers through their involvement in developmental factors that may lead to ultimate positive adjustment in elite sport, should be studied. Interventions need to distinguish between impact on mental well-being, and on actual mental health symptoms and disorders.

11. Olympic villages and similar areas should be designed and assessed with sleep hygiene in mind.

12. Researchers need to better understand the societal and sport specific impact of sport sponsorship by companies that promote alcohol, tobacco and other products associated with adverse mental health outcomes in elite athletes.

13. Coaches, athletes and stakeholders should be empowered with relevant information so that they recognise the importance of creating an environment that supports mental wellness and mental health help seeking.

\section{CONCLUSION}

The IOC has committed to improve the mental health of elite athletes, recognising that doing so will reduce suffering and improve quality of life in elite athletes and serve as a model for society at large. The IOC hopes that all involved in sport will increasingly recognise that mental health symptoms and disorders should be viewed in a similar light as other medical illnesses and musculoskeletal injuries; all can be severe and disabling, and nearly all can be managed properly by well informed medical providers, coaches and other stakeholders.

Mental health is an integral dimension of elite athlete wellbeing and performance and cannot be separated from physical health. Mental health assessment and management in elite athletes should be as commonplace and accessible as their other medical care; ideally elite athletes should have access to the best interdisciplinary care. To advance a more unified, evidence informed approach to mental health assessment and management in elite athletes, the IOC Consensus Group has critically evaluated the current state of the science and practice of mental health in elite athletes.

\section{Author affiliations}

'Department of Psychiatry, University of Wisconsin School of Medicine and Public Health, Madison, Wisconsin, USA

${ }^{2}$ National Collegiate Athletic Association, Indianapolis, Indiana, USA

${ }^{3}$ Department of Psychiatry, Samaritan Health Services, Corvallis, Oregon, USA ${ }^{4}$ Office of the President, Western University of Health Sciences, Pomona, California, USA

${ }^{5}$ Department of Psychiatry and Behavioral Sciences, George Washington University School of Medicine and Health Sciences, Washington, District of Columbia, USA

${ }^{6}$ Mohali, India

${ }^{7}$ Medical and Scientific Department, International Olympic Committee, Lausanne, Switzerland

${ }^{8}$ Sports Department, International Olympic Committee, Lausanne, Switzerland ${ }^{9}$ Department of Neuroscience, Faculdade de Medicina do ABC, Santo Andre, Brazil ${ }^{10}$ Universidade de Sao Paulo Faculdade de Medicina Hospital das Clinicas Instituto de Psiquiatria, Sao Paulo, Brazil

${ }^{11}$ Regional Affective Disorders Service, Northumberland Tyne and Wear NHS Foundation Trust, Newcastle, UK
${ }^{12}$ Department of Sport and Exercise Sciences, The University Of Sunderland, Sunderland, UK

${ }^{13}$ International Centre for Youth Gambling Problems and High Risk Behaviors, McGill University, Montreal, Quebec, Canada

${ }^{14}$ Department of Psychiatry and Behavioral Sciences, Stanford University School of Medicine, Stanford, California, USA

${ }^{15}$ Department of Sport and Exercise Science, University of Portsmouth, Portsmouth, , UK

${ }^{16}$ Department of Orthopaedic Surgery, Amsterdam UMC, University of Amsterdam, Amsterdam Movement Sciences, Meibergdreef 9, Amsterdam, The Netherlands

${ }^{17}$ Amsterdam Collaboration on Health and Safety in Sports (ACHSS), AMC/VUmc IOC Research Centre of Excellence, Amsterdam, The Netherlands

${ }^{18}$ Department of Psychiatry, University of Arizona, Tucson, Arizona, USA

${ }^{19}$ Department of Psychiatry, Chung Ang University Hospital, Seoul, Republic of Korea

${ }^{20}$ Department of Psychiatry, University of Maryland School of Medicine, Baltimore,

Maryland, USA

${ }^{21}$ Department of Family Medicine-Sport, McMaster University, Hamilton, Ontario, Canada

${ }^{22}$ FINA Bureau Liaison to Sport Medicine, Lausanne, Switzerland

${ }^{23}$ Department of Psychiatry, Kocaeli University, Faculty of Medicine, Kocaeli, Turkey

${ }^{24}$ Kocaeli University, Community Mental Health Centre, Kocaeli, Turkey

${ }^{25}$ Research and Translation, Orygen, The National Centre of Excellence in Youth

Mental Health, Melbourne, Victoria, Australia

${ }^{26}$ Centre for Youth Mental Health, University of Melbourne, Melbourne, Victoria,

Australia

${ }^{27}$ Athletic Medicine, University Health Services, Princeton University, Princeton, New Jersey, USA

${ }^{28}$ Department of Medicine, Rutgers-Robert Wood Johnson Medical School, New

Brunswick, New Jersey, USA

${ }^{29}$ Department of Research and Translation, Orygen, The National Centre of Excellence

in Youth Mental Health, Melbourne, Victoria, Australia

${ }^{30}$ Centre for Youth Mental Health, The University of Melbourne, Melbourne, Victoria,

Australia

${ }^{31}$ National Football League, New York, New York, USA

${ }^{32}$ Department of Neurological Surgery, Vanderbilt University Medical Center, Nashville, Tennessee, USA

${ }^{33}$ Athletic Department, University of Nebraska, Lincoln, Nebraska, USA

${ }^{34}$ Department of Psychology, Stellenbosch University, Stellenbosch, , South Africa

${ }^{35}$ Social Sport, Zheng Zhou University, Zheng Zhou, , China

${ }^{36}$ Social Aesthetic and Mental Health Institute, Vienna Sigmund Freud University, Vienna, Austria

${ }^{37}$ Orthopaedic Clinic, University of Oslo, Oslo, Norway

${ }^{38}$ Medical Sciences, International Olympic Committee, Lausanne, Switzerland

Acknowledgements The authors acknowledge Mary E Hitchcock, Senior Academic Librarian, Ebling Library for the Health Sciences, University of WisconsinMadison, for conducting systematic literature reviews for this manuscript; Sarah E Watkins from Raccoona Editing and Laura Arnett, NCAA Sport Science Institute Coordinator, for manuscript preparation; and Torbjorn Soligard, International Olympic Committee Medical and Scientific Department, for participation in the consensus meeting.

Contributors All authors meet criteria for authorship, as all have contributed in the following ways: substantial contributions to the conception or design of the work, or the acquisition, analysis or interpretation of the data; drafting the work or revising it critically for important intellectual content; final approval of the version published; and agreement to be accountable for all aspects of the work in ensuring that questions related to the accuracy or integrity of any part of the work are appropriately investigated and resolved. No one meeting the criteria for authorship has been excluded from authorship.

Disclaimer This consensus paper provides an overview of mental health symptoms and disorders in elite athletes that are important to physicians and other clinicians who treat elite athletes. It is not intended as a clinical practice guideline or legal standard of care and should not be interpreted as such. This consensus paper serves as a guide and, as such, is of a general nature, consistent with the reasonable practice of the healthcare professional. Individual treatment will depend on the facts and circumstances specific to each individual case.

Competing interests None declared.

Patient consent for publication Not required.

Provenance and peer review Not commissioned; externally peer reviewed.

\section{REFERENCES}

1. American Psychiatric Association. Diagnostic and statistical manual of mental disorders (DSM-5. Washington, DC: American Psychiatric Publishing, 2013. 
2. World Health Organization. International Classification of Diseases for mortality and morbidity statistics (ICD-11) 2018. Available: http://icd.who.int

3. Beable S, Fulcher M, Lee AC, et al. SHARPSports mental health awareness research project: prevalence and risk factors of depressive symptoms and life stress in elite athletes. I Sci Med Sport 2017;20:1047-52.

4. Drew M, Vlahovich $\mathrm{N}$, Hughes $\mathrm{D}$, et al. Prevalence of illness, poor mental health and sleep quality and low energy availability prior to the 2016 Summer Olympic Games. Br J Sports Med 2018:52:47-53.

5. Gouttebarge V, Aoki H, Kerkhoffs G. Symptoms of common mental disorders and adverse health behaviours in male professional soccer players. I Hum Kinet 2015;49:277-86.

6. Gouttebarge V, Backx FJG, Aoki H, et al. Symptoms of common mental disorders in professional football (soccer) across five European countries. J Sports Sci Med 2015;14.

7. Kiliç Ö, Aoki H, Goedhart E, et al. Severe musculoskeletal time-loss injuries and symptoms of common mental disorders in professional soccer: a longitudinal analysis of 12-month follow-up data. Knee Surg Sports Traumatol Arthrosc 2018;26:946-54

8. Brown J, Kerkhoffs G, Lambert M, et al. Forced retirement from professional rugby union is associated with symptoms of distress. Int I Sports Med 2017:38:582-7.

9. Gouttebarge $V$, Jonkers $R$, Moen $M$, et al. The prevalence and risk indicators of symptoms of common mental disorders among current and former Dutch elite athletes. J Sports Sci 2017:35:2148-56.

10. Gouttebarge V, Aoki H, Lambert M, et al. A history of concussions is associated with symptoms of common mental disorders in former male professional athletes across a range of sports. Phys Sportsmed 2017;45:443-9.

11. Gulliver A, Griffiths KM, Mackinnon A, et al. The mental health of Australian elite athletes. J Sci Med Sport 2015;18:255-61.

12. Nixdorf I, Frank R, Hautzinger $M$, et al. Prevalence of depressive symptoms and correlating variables among German elite athletes. I Clin Sport Psychol 2013;7:313-26.

13. Schuring N, Kerkhoffs G, Gray J, et al. The mental wellbeing of current and retired professional cricketers: an observational prospective cohort study. Phys Sportsmed 2017:45:463-9.

14. Du Preez EJ, Graham KS, Gan TY, et al. Depression, anxiety, and alcohol use in elite rugby league players over a competitive season. Clin I Sport Med 2017;27:530-5.

15. Foskett RL, Longstaff $F$. The mental health of elite athletes in the United Kingdom. J Sci Med Sport 2018;21:765-70.

16. Gouttebarge V, Jonkers R, Moen M, et al. A prospective cohort study on symptoms of common mental disorders among Dutch elite athletes. Phys Sportsmed 2017:45:426-32.

17. Gouttebarge V, Aoki H, Verhagen EALM, et al. A 12-month prospective cohort study of symptoms of common mental disorders among European professional footballers. Clin J Sport Med 2017;27:487-92.

18. Gouttebarge V, Kerkhoffs GMMJ. A prospective cohort study on symptoms of common mental disorders among current and retired professional ice hockey players. Phys Sportsmed 2017:45:252-8.

19. Gouttebarge V, Hopley P, Kerkhoffs G, et al. A 12-month prospective cohort study of symptoms of common mental disorders among professional rugby players. Eur $\mathrm{J}$ Sport Sci 2018;18:1004-12

20. Junge $A$, Feddermann-Demont N. Prevalence of depression and anxiety in top-level male and female football players. BMJ Open Sport Exerc Med 2016;2:e000087.

21. Hulley AJ, Hill AJ. Eating disorders and health in elite women distance runners. Int $\mathrm{J}$ Eat Disord. 2001:30:312-7.

22. Prinz B, Dvořák J, Junge A. Symptoms and risk factors of depression during and after the football career of elite female players. BMJ Open Sport Exerc Med 2016;2:e000124

23. Sundgot-Borgen J, Torstveit MK. Prevalence of eating disorders in elite athletes is higher than in the general population. Clin J Sport Med 2004;14:25-32

24. Brand R, Wolff W, Hoyer J. Psychological symptoms and chronic mood in representative samples of elite student-athletes, deselected student-athletes and comparison students. School Mental Health 2013:5:166-74.

25. Greenleaf C, Petrie TA, Carter J, et al. Female collegiate athletes: prevalence of eating disorders and disordered eating behaviors. J Am Coll Health 2009:57:489-96.

26. Proctor SL, Boan-Lenzo C. Prevalence of depressive symptoms in male intercollegiate student-athletes and nonathletes. J Clin Sport Psychol 2010;4:204-20.

27. Rao AL, Hong ES. Understanding depression and suicide in college athletes: emerging concepts and future directions. Br I Sports Med 2016;50:136-7.

28. Sarac N, Sarac B, Pedroza A, et al. Epidemiology of mental health conditions in incoming division I collegiate athletes. Phys Sportsmed 2018;46:242-8.

29. Wolanin A, Hong E, Marks D, et al. Prevalence of clinically elevated depressive symptoms in college athletes and differences by gender and sport. Br I Sports Med 2016;50:167-71

30. Yang J, Peek-Asa C, Corlette JD, et al. Prevalence of and risk factors associated with symptoms of depression in competitive collegiate student athletes. Clin I Sport Med 2007;17:481-7.
31. Arnold R, Fletcher D. A research synthesis and taxonomic classification of the organizational stressors encountered by sport performers. J Sport Exerc Psychol 2012;34:397-429

32. Engel G. The need for a new medical model: a challenge for biomedicine. Science 1977;196:129-36

33. Gouttebarge V, Aoki H, Ekstrand J, et al. Are severe musculoskeletal injuries associated with symptoms of common mental disorders among male European professional footballers? Knee Surg Sports Traumatol Arthrosc 2016:24:3934-42.

34. Gouttebarge V, Kerkhoffs G, Lambert M. Prevalence and determinants of symptoms of common mental disorders in retired professional rugby union players. Eur I Sport Sci 2016:16:595-602.

35. Hammond $\mathrm{T}$, Gialloreto $\mathrm{C}$, Kubas $\mathrm{H}$, et al. The prevalence of failure-based depression among elite athletes. Clin I Sport Med 2013:23:273-7.

36. Li H, Moreland JJ, Peek-Asa C, et al. Preseason anxiety and depressive symptoms and prospective injury risk in collegiate athletes. Am J Sports Med 2017:45:2148-55.

37. Rosenvinge J, Sundgot-Borgen J, Pettersen G, et al. Are adolescent elite athletes less psychologically distressed than controls? A cross-sectional study of 966 Norwegian adolescents. Open Access I Sports Med 2018;9:115-23.

38. Houltberg BJ, Wang KT, Qi W, et al. Self-narrative profiles of elite athletes and comparisons on psychological well-being. Res Q Exerc Sport 2018;89:354-60.

39. Reardon CL. Psychiatric comorbidities in sports. Neurol Clin 2017;35:537-46.

40. Cooney GM, Dwan K, Greig CA, et al. Exercise for depression. Cochrane Database Syst Rev 2013;12:CD004366.

41. Thornicroft G, Chatterii S, Evans-Lacko S, et al. Undertreatment of people with major depressive disorder in 21 countries. Br J Psychiatry 2017;210:119-24.

42. Patel V, Saxena $S$, Lund $C$, et al. The Lancet Commission on global mental health and sustainable development. Lancet 2018;392:1553-98.

43. Singla DR, Kohrt BA, Murray LK, et al. Psychological treatments for the world: lessons from low- and middle-income countries. Annu Rev Clin Psychol 2017:13:149-81.

44. Kohrt B, Asher L, Bhardwaj A, et al. The role of communities in mental health care in low- and middle-income countries: a meta-review of components and competencies. Int J Environ Res Public Health 2018:15:1279.

45. Kazdin AE. Innovations in psychosocial interventions and their delivery: Leveraging cutting-edge science to improve the world's mental health. New York, NY: Oxford University Press, 2018

46. Patel V, Hanlon C. Where there is no psychiatrist: a mental health care manual. New York: Cambridge University Press, 2018.

47. Breuer $E$, De Silva M, Lund C. Theory of change for complex mental health interventions: 10 lessons from The programme for improving mental healthcare. Glob Ment Health 2018:5:e24.

48. Munetsi E, Simms V, Dzapasi L, et al. Trained lay health workers reduce common mental disorder symptoms of adults with suicidal ideation in Zimbabwe: a cohort study. BMC Public Health 2018:18:227.

49. Stillman MA, Ritvo EC, Glick ID. Psychotherapeutic treatment of athletes and their significant others. In: Baron DA, Reardon C, Baron SH, eds. Clinical sports psychiatry: an international perspective. New York, NY: Wiley, 2013: 115-23.

50. Butler A, Chapman J, Forman E, et al. The empirical status of cognitive-behavioral therapy: a review of meta-analyses. Clin Psychol Rev 2006;26:17-31.

51. Ströhle A. Sports psychiatry: mental health and mental disorders in athletes and exercise treatment of mental disorders. Eur Arch Psychiatry Clin Neurosci 2018;3.doi: 10.1007/s00406-018-0891-5. [Epub ahead of print].

52. Stillman MA, Brown T, Ritvo EC, et al. Sport psychiatry and psychotherapeutic intervention, circa 2016. Int Rev Psychiatry 2016;28:614-22.

53. Gil F, de Andrade AG, Castaldelli-Maia JM, et al. Discussing prevalence, impacts, and treatment of substance use disorders in athletes. Int Rev Psychiatry 2016;28:572-8.

54. Zhou J, Heim D. Sports and spirits: a systematic qualitative review of emergent theories for student-athlete drinking. Alcohol Alcohol 2014;49:604-17.

55. Glick ID, Stillman MA, Reardon $\mathrm{CL}$, et al. Managing psychiatric issues in elite athletes. J Clin Psychiatry 2012;73:640-4.

56. Johnston A, McAllister-Williams RH. Psychotropic drug prescribing. In: Currie A, Owen B, eds. Sports psychiatry. Oxford: Oxford University Press, 2016: 133-43.

57. Reardon CL, Creado S. Psychiatric medication preferences of sports psychiatrists. Phys Sportsmed 2016;44:397-402.

58. Wagner JC. Enhancement of athletic performance with drugs. Sports Med 1991;12:250-65.

59. World Anti-Doping Agency (WADA). World anti-doping agency Prohibited list, 2019. Available: https://www.usada.org/substances/prohibited-list/

60. Reardon CL. The sports psychiatrist and psychiatric medication. Int Rev Psychiatry 2016;28:606-13

61. Reardon CL, Factor RM. Sport psychiatry: a systematic review of diagnosis and medical treatment of mental illness in athletes. Sports Med 2010;40:961-80.

62. Garner AA, Hansen AA, Baxley $C$, et al. The use of stimulant medication to treat attention-deficit/hyperactivity disorder in elite athletes: a performance and health perspective. Sports Med 2018:48:507-12.

63. Watson NF, Badr MS, Belenky G, et al. Recommended amount of sleep for a healthy adult: a joint consensus statement of the American Academy of Sleep Medicine and Sleep Research Society. Sleep 2015;38:843-4. 
64. Watson NF, Badr MS, Belenky G, et al. Joint consensus statement of the American Academy of Sleep Medicine and Sleep Research Society on the recommended amount of sleep for a healthy adult: methodology and discussion. Sleep 2015:38:1161-83.

65. St-Onge M-P, Grandner MA, Brown D, et al. Sleep duration and quality: impact on lifestyle behaviors and cardiometabolic health: a scientific statement from the American Heart Association. Circulation 2016;134:e367-86.

66. Mukherjee S, Patel SR, Kales SN, et al. An official American Thoracic Society statement: the importance of healthy sleep. recommendations and future priorities. Am J Respir Crit Care Med 2015;191:1450-8.

67. Hirshkowitz M, Whiton K, Albert SM, et al. National Sleep Foundation's updated sleep duration recommendations: final report. Sleep Health 2015;1:233-43.

68. Hirshkowitz M, Whiton K, Albert SM, et al. National Sleep Foundation's sleep time duration recommendations: methodology and results summary. Sleep Health 2015;1:40-3.

69. Paruthi S, Brooks LJ, D'Ambrosio C, et al. Consensus statement of the American Academy of Sleep Medicine on the recommended amount of sleep for healthy children: methodology and discussion. J Clin Sleep Med 2016;12:1549-61.

70. Paruthi S, Brooks LJ, D'Ambrosio C, et al. Recommended amount of sleep for pediatric populations: a consensus statement of the American Academy of Sleep Medicine. J Clin Sleep Med 2016;12:785-6.

71. NCAA. NCAA goals study 2015. Indianapolis, 2016.

72. Roberts SSH, Teo W-P, Warmington SA. Effects of training and competition on the sleep of elite athletes: a systematic review and meta-analysis. Br J Sports Med 2019;53:513-22.

73. Blumert PA, Crum AJ, Ernsting M, et al. The acute effects of twenty-four hours of sleep loss on the performance of national-caliber male collegiate weightlifters. J Strength Cond Res 2007;21:1146-54.

74. Calogiuri $G$, Weydahl A. Effects of sleep loss on the rest-activity circadian rhythm of helpers participating in continuous dogsled races. Biol Res Nurs 2014; 16:123-33

75. Dunican IC, Martin DT, Halson SL, et al. The effects of the removal of electronic devices for 48 hours on sleep in elite judo athletes. J Strength Cond Res 2017:31:2832-9.

76. Halson S, Martin DT, Gardner AS, et al. Persistent fatigue in a female sprint cyclist after a talent-transfer initiative. Int J Sports Physiol Perform 2006;1:65-9.

77. Halson SL. Stealing sleep: is sport or society to blame? Br J Sports Med 2016;50:381.

78. Halson SL. Sleep in elite athletes and nutritional interventions to enhance sleep. Sports Med 2014;44:13-23.

79. Juliff LE, Halson SL, Peiffer JJ. Understanding sleep disturbance in athletes prior to important competitions. J Sci Med Sport 2015;18:13-18.

80. Lalor BJ, Halson SL, Tran J, et al. No compromise of competition sleep compared with habitual sleep in elite Australian footballers. Int I Sports Physiol Perform 2018;13:29-36.

81. Lastella M, Roach GD, Halson SL, et al. Sleep/wake behaviours of elite athletes from individual and team sports. Eur J Sport Sci 2015;15:94-100.

82. Lastella M, Vincent $G E$, Duffield $R$, et al. Can sleep be used as an indicator of overreaching and overtraining in athletes? Front Physiol 2018;9:436.

83. Nédélec $M$, Halson $S, A$ baidia A-E, et al. Stress, sleep and recovery in elite soccer: a critical review of the literature. Sports Med 2015;45:1387-400.

84. Nédélec M, Halson S, Delecroix B, et al. Sleep hygiene and recovery strategies in elite soccer players. Sports Med 2015;45:1547-59.

85. Sargent C, Halson S, Roach GD. Sleep or swim? Early-morning training severely restricts the amount of sleep obtained by elite swimmers. Eur J Sport SCi 2014;14:S310-S315.

86. Erlacher D, Ehrlenspiel F, Adegbesan OA, et al. Sleep habits in German athletes before important competitions or games. J Sports Sci 2011;29:859-66.

87. Fullagar HHK, Skorski S, Duffield R, et al. Sleep and athletic performance: the effects of sleep loss on exercise performance, and physiological and cognitive responses to exercise. Sports Med 2015;45:161-86.

88. Oliver SJ, Costa RJS, Laing SJ, et al. One night of sleep deprivation decreases treadmill endurance performance. Eur J App/ Physiol 2009;107:155-61.

89. Rae DE, Chin T, Dikgomo K, et al. One night of partial sleep deprivation impairs recovery from a single exercise training session. Eur J Appl Physiol 2017:117:699-712.

90. Reilly T, Edwards B. Altered sleep-wake cycles and physical performance in athletes. Physiol Behav 2007;90:274-84.

91. Thun E, Bjorvatn B, Flo E, et al. Sleep, circadian rhythms, and athletic performance. Sleep Med Rev 2015;23:1-9.

92. Watson AM. Sleep and athletic performance. Curr Sports Med Rep 2017;16:413-8.

93. Reyner LA, Horne JA. Sleep restriction and serving accuracy in performance tennis players, and effects of caffeine. Physiol Behav 2013;120:93-6.

94. Andrade A, Bevilacqua GG, Coimbra DR, et al. Sleep quality, mood and performance: a study of elite Brazilian volleyball athletes. J Sports Sci Med 2016;15:601-5.

95. Ben Cheikh R, Latiri I, Dogui M, et al. Effects of one-night sleep deprivation on selective attention and isometric force in adolescent karate athletes. J Sports Med Phys Fitness 2017;57:752-9.
96. Biggins M, Cahalan R, Comyns T, et al. Poor sleep is related to lower general health, increased stress and increased confusion in elite Gaelic athletes. Phys Ther Sport 2018;46:14-20.

97. Simpson NS, Gibbs EL, Matheson GO. Optimizing sleep to maximize performance: implications and recommendations for elite athletes. Scand J Med Sci Sports 2017:27:266-74.

98. Benton ML, Friedman NS. Treatment of obstructive sleep apnea syndrome with nasal positive airway pressure improves golf performance. J Clin Sleep Med 2013;9:1237-42.

99. Schwartz J, Simon RD. Sleep extension improves serving accuracy: a study with College varsity tennis players. Physiol Behav 2015;151:541-4.

100. Mah CD, Mah KE, Kezirian EJ, et al. The effects of sleep extension on the athletic performance of collegiate basketball players. Sleep 2011;34:943-50.

101. Brenner JS, Kelly AW. Overuse and overtraining injuries in teenage athletes. Adolesc Med State Art Rev 2015;26:79-99.

102. Urhausen A, Kindermann W. Diagnosis of overtraining: what tools do we have? Sports Med 2002;32:95-102.

103. Cote KA, McCormick CM, Geniole SN, et al. Sleep deprivation lowers reactive aggression and testosterone in men. Biol Psychol 2013;92:249-56.

104. Reynolds AC, Dorrian J, Liu PY, et al. Impact of five nights of sleep restriction on glucose metabolism, leptin and testosterone in young adult men. PLoS One 2012;7:e41218-e18.

105. Schmid SM, Hallschmid M, Jauch-Chara K, et al. Sleep timing may modulate the effect of sleep loss on testosterone. Clin Endocrinol 2012;77:749-54.

106. Leproult $R$, Van Cauter $E$. Effect of 1 week of sleep restriction on testosterone levels in young healthy men. JAMA 2011;305:2173-4.

107. Besedovsky L, Lange T, Born J. Sleep and immune function. Pflügers Archiv - Eur J Physiol 2012;463:121-37.

108. Morris CJ, Aeschbach D, Scheer FAJL. Circadian system, sleep and endocrinology. Mol Cell Endocrinol 2012;349:91-104.

109. Frenette E, Lui A, Cao M. Neurohormones and sleep. Vitam Horm 2012:89:1-18.

110. Van Cauter $E$, Spiegel $K$, Tasali E, et al. Metabolic consequences of sleep and sleep loss. Sleep Med 2008;9(Suppl 1):S23-S28.

111. Rasmussen $M H$, Wildschiødtz $G$, Juul $A$, et al. Polysomnographic sleep, growth hormone insulin-like growth factor-I axis, leptin, and weight loss. Obesity 2008;16:1516-21.

112. Perelis M, Ramsey KM, Marcheva B, et al. Circadian transcription from beta cell function to diabetes pathophysiology. J Biol Rhythms 2016;31:323-36.

113. Grandner MA, Seixas A, Shetty $S$, et al. Sleep duration and diabetes risk: population trends and potential mechanisms. Curr Diab Rep 2016;16:106.

114. Dashti HS, Scheer FAJL, Jacques PF, et al. Short sleep duration and dietary intake: epidemiologic evidence, mechanisms, and health implications. Adv Nutr 2015;6:648-59

115. Smith RS, Efron B, Mah CD, et al. The impact of circadian misalignment on athletic performance in professional football players. Sleep 2013;36:1999-2001.

116. Reilly $T$, Atkinson G, Gregson W, et al. Some chronobiological considerations related to physical exercise. Clin Ter 2006;157:249-64.

117. Racinais $S$, Connes $P$, Bishop D, et al. Morning versus evening power output and repeated-sprint ability. Chronobiol Int 2005;22:1029-39.

118. Edwards BJ, Waterhouse J. Effects of one night of partial sleep deprivation upon diurnal rhythms of accuracy and consistency in throwing darts. Chronobio/ Int 2009;26:756-68

119. Edwards BJ, Edwards W, Waterhouse J, et al. Can cycling performance in an early morning, laboratory-based cycle time-trial be improved by morning exercise the day before? Int J Sports Med 2005;26:651-6.

120. Kantermann T, Forstner $S$, Halle $M$, et al. The stimulating effect of bright light on physical performance depends on internal time. PLoS One 2012;7:e40655.

121. Cook CJ, Kilduff LP, Crewther BT, et al. Morning based strength training improves afternoon physical performance in rugby union players. I Sci Med Sport 2014; 17:317-21

122. Robillard R, Naismith SL, Rogers NL, et al. Delayed sleep phase in young people with unipolar or bipolar affective disorders. J Affect Disord 2013;145:260-3.

123. Okawa M. Delayed sleep phase syndrome and depression. Sleep Med 2011;12:621-2

124. Abe $T$, Inoue $Y$, Komada $Y$, et al. Relation between morningness-eveningness score and depressive symptoms among patients with delayed sleep phase syndrome. Sleep Med 2011;12:680-4.

125. Kripke DF, Rex KM, Ancoli-Israel S, et al. Delayed sleep phase cases and controls. J Circadian Rhythms 2008;6:6-14.

126. Tuunainen Aet al. Depression and endogenous melatonin in postmenopausal women. J Affect Disord 2002;69:149-58.

127. Song A, Severini T, Allada R. How jet lag impairs major league baseball performance Proc Natl Acad Sci 2017;114:1407-12.

128. Pace A, Carron AV. Travel and the home advantage. Can J Sport Sci 1992;17:60-4.

129. Winter WC, Hammond WR, Green NH, et al. Measuring circadian advantage in major league baseball: a 10-year retrospective study. Int I Sports Physiol Perform 2009;4:394-401 
130. Nédélec M, Aloulou A, Duforez F, et al. The variability of sleep among elite athletes. Sports Med Open 2018;4:34.

131. Laborde S, Guillén F, Dosseville F, et al. Chronotype, sport participation, and positive personality-trait-like individual differences. Chronobiol Int 2015;32:942-51.

132. Lastella M, Roach GD, Halson SL, et al. The chronotype of elite athletes. J Hum Kinet 2016:54:219-25.

133. Porcu A, Riddle M, Dulcis D, et al. Photoperiod-induced neuroplasticity in the circadian system. Neural Plast 2018:2018:1-13.

134. Dmitrzak-Weglarz M, Reszka E. Pathophysiology of depression: Molecular regulation of melatonin homeostasis - current status. Neuropsychobiology 2018;76:117-29.

135. Brzecka A, Leszek J, Ashraf GM, et al. Sleep disorders associated with Alzheimer's disease: a perspective. Front Neurosci 2018;12:330.

136. American Academy of Sleep Medicine. International Classification of sleep disorders. Darien, IL: American ACademy of Sleep Medicine, 2014.

137. Spiegelhalder K, Regen W, Nanovska S, et al. Comorbid sleep disorders in neuropsychiatric disorders across the life cycle. Curr Psychiatry Rep 2013;15:364.

138. Baglioni C, Riemann D. Is chronic insomnia a precursor to major depression? epidemiological and biological findings. Curr Psychiatry Rep 2012;14:511-8.

139. Baglioni C, Battagliese G, Feige B, et al. Insomnia as a predictor of depression: a meta-analytic evaluation of longitudinal epidemiological studies. J Affect Disord 2011;135:10-19.

140. Matteson-Rusby SE, Pigeon WR, Gehrman P, et al. Why treat insomnia? Prim Care Companion J Clin Psychiatry 2010;12:PCC.08r00743.

141. Strand LB, Laugsand LE, Wisløff U, et al. Insomnia symptoms and cardiorespiratory fitness in healthy individuals: the Nord-Trøndelag health study (HUNT). Sleep 2013;36:99-108

142. George Cet al. Sleep and breathing in professional football players. Sleep Med 2003;4:317-25.

143. George CFP, Kab V. Sleep-disordered breathing in the National Football League is not a trivial matter. Sleep 2011:34:245.

144. Rice TB, Dunn RE, Lincoln AE, et al. Sleep-disordered breathing in the National Football League. Sleep 2010;33:819-24.

145. Albuquerque FN, Sert Kuniyoshi FH, Calvin AD, et al. Sleep-disordered breathing, hypertension, and obesity in retired National Football League players. J Am Coll Cardiol 2010:56:1432-3.

146. Rogers A, Xia K, Soe K, et al. Obstructive sleep apnea among players in the National Football League: a scoping review. J Sleep Disord Ther 2017:06:278.

147. American Academy of Sleep Medicine. Underdiagnosing and undertreating obstructive sleep apnea draining healthcare system. Mountain View, CA: Frost \& Sullivan, 2016.

148. Eckert DJ, Jordan AS, Merchia P, et al. Central sleep apnea: pathophysiology and treatment. Chest 2007;131:595-607.

149. Jackson ML, Stough C, Howard ME, et al. The contribution of fatigue and sleepiness to depression in patients attending the sleep laboratory for evaluation of obstructive sleep apnea. Sleep Breath 2011;15:439-45.

150. Godderis L, Dours G, Laire G, et al. Sleep apnoeas and neurobehavioral effects in solvent exposed workers. Int J Hyg Environ Health 2011;214:66-70.

151. Smolensky MH, Di Milia L, Ohayon MM, et al. Sleep disorders, medical conditions, and road accident risk. Accid Anal Prev 2011;43:533-48.

152. Lurie A. Obstructive sleep apnea in adults: epidemiology, clinical presentation, and treatment options. Adv Cardiol 2011;46:1-42.

153. Rajaratnam SMW, Barger LK, Lockley SW, et al. Sleep disorders, health, and safety in police officers. JAMA 2011;306:2567-78.

154. Lee I-S, Bardwell WA, Ancoli-Israel S, et al. Number of lapses during the psychomotor vigilance task as an objective measure of fatigue. J Clin Sleep Med 2010;6:163-8.

155. McMahon JP, Foresman BH, Chisholm RC. The influence of CPAP on the neurobehavioral performance of patients with obstructive sleep apnea hypopnea syndrome: a systematic review. WMJ 2003;102:36-43.

156. Lichstein KL. Secondary insomnia: a myth dismissed. Sleep Med Rev 2006;10:3-5.

157. Bender AM, Lawson D, Werthner P, et al. The clinical validation of the athlete sleep screening questionnaire: an instrument to identify athletes that need further sleep assessment. Sports Med Open 2018;4:1-8.

158. Perlis M, Gehrman P, Riemann D. Intermittent and long-term use of sedative hypnotics. Curr Pharm Des 2008;14:3456-65.

159. Riemann D, Perlis ML. The treatments of chronic insomnia: a review of benzodiazepine receptor agonists and psychological and behavioral therapies. Sleep Med Rev 2009;13:205-14

160. Perlis ML, Aloia M, Kuhn BR. Behavioral treatments for sleep disorders: a comprehensive primer of behavioral sleep medicine interventions. London: Elsevier, 2011.

161. Smith MT, Perlis ML, Park A, et al. Comparative meta-analysis of pharmacotherapy and behavior therapy for persistent insomnia. Am J Psychiatry 2002;159:5-11.

162. Perlis ML, Smith MT, Cacialli DO, et al. On the comparability of pharmacotherapy and behavior therapy for chronic insomnia. commentary and implications. J Psychosom Res 2003:54:51-9.

163. Wu JQ, Appleman ER, Salazar RD, et al. Cognitive behavioral therapy for insomnia comorbid with psychiatric and medical conditions: a meta-analysis. JAMA Intern Med 2015;175:1461-72.
164. Irish $L A$, Kline $C E$, Gunn $H E$, et al. The role of sleep hygiene in promoting public health: a review of empirical evidence. Sleep Med Rev 2015;22:23-36.

165. Paul MA, Gray G, Kenny G, et al. Impact of melatonin, zaleplon, zopiclone, and temazepam on psychomotor performance. Aviat Space Environ Med 2003;74:1263-70

166. Atkinson G, Drust B, Reilly $T$, et al. The relevance of melatonin to sports medicine and science. Sports Med 2003;33:809-31.

167. Herman D, MacKnight JM, Stromwall AE, et al. The International Athlete-Advances in management of jet lag disorder and anti-doping policy. Clin Sports Med 2011;30:641-59.

168. SateiaMJ, BuysseDJ, KrystalAD, et al. Clinical practice guideline for the pharmacologic treatment of chronic insomnia in adults: an American Academy of Sleep Medicine clinical practice guideline. J Clin Sleep Med 2017:13:307-49.

169. Ito S-U, Kanbayashi T, Takemura T, et al. Acute effects of zolpidem on daytime alertness, psychomotor and physical performance. Neurosci Res 2007:59:309-13.

170. Grobler LA, Schwellnus MP, Trichard C, et al. Comparative effects of zopiclone and loprazolam on psychomotor and physical performance in active individuals. Clin J Sport Med 2000;10:123-8.

171. Tafti M, Besset A, Billiard M. Effects of zopiclone on subjective evaluation of sleep and daytime alertness and on psychomotor and physical performance tests in athletes. Prog Neuropsychopharmacol Biol Psychiatry 1992;16:55-63.

172. Holmberg G. The effects of anxiolytics on CFF. Pharmacopsychiatry 1982;15:49-53.

173. Maddock RJ, Casson EJ, Lott LA, et al. Benzodiazepine effects on flicker sensitivity: role of stimulus frequency and size. Prog Neuropsychopharmacol Biol Psychiatry 1993; 17:955-70.

174. Charles RB, Kirkham AJ, Guyatt AR, et al. Psychomotor, pulmonary and exercise responses to sleep medication. Br J Clin Pharmacol 1987:24:191-7.

175. Longo LP, Johnson B. Addiction: Part I. Benzodiazepines--side effects, abuse risk and alternatives. Am Fam Physician 2000;61:2121-30.

176. Kushida CA, Littner MR, Hirshkowitz M, et al. Practice parameters for the use of continuous and bilevel positive airway pressure devices to treat adult patients with sleep-related breathing disorders. Sleep 2006;29:375-80.

177. Ramar K, Dort LC, Katz SG, et al. Clinical practice guideline for the treatment of obstructive sleep apnea and snoring with oral appliance therapy: an update for 2015. J Clin Sleep Med 2015;11:773-827.

178. Aurora RN, Casey KR, Kristo D, et al. Practice parameters for the surgical modifications of the upper airway for obstructive sleep apnea in adults. Sleep 2010:33:1408-13.

179. Burgess HJ, Emens JS, Emens JS. Drugs used in circadian sleep-wake rhythm disturbances. Sleep Med Clin 2018;13:231-41.

180. Burgess HJ, Revell VL, Molina TA, et al. Human phase response curves to three days of daily melatonin: $0.5 \mathrm{mg}$ versus $3.0 \mathrm{mg}$. J Clin Endocrinol Metab 2010:95:3325-31.

181. Sack RL. Clinical practice. Jet lag. N Eng/ J Med 2010;362:440-7.

182. Reid K, Zee P. Circadian rhythm disorders. Semin Neurol 2009;29:393-405.

183. Baron DA, Baron SH, Tompkins J, et al. Assessing and treating depression in athletes. In: Baron DA, Reardon C, Baron SH, et al, eds. Clinical sports psychiatry: an international perspective. Chichester. West Sussex: Wiley, 2013: 65-78.

184. Polat A, Cakir U, Karabulut U, et al. Reliability and validity of Turkish form of baron depression screener for athletes. Bull Clini Pharmacol 2015;25:S134.

185. Schaal K, Tafflet M, Nassif H, et al. Psychological balance in high level athletes: gender-based differences and sport-specific patterns. PLoS One 2011;6:e19007.

186. Gorczynski PF, Coyle M, Gibson K. Depressive symptoms in high-performance athletes and non-athletes: a comparative meta-analysis. Br I Sports Med 2017;51:1348-54.

187. Coyle M, Gorczynski P, Gibson K. "You have to be mental to jump off a board any way": Elite divers' conceptualizations and perceptions of mental health. Psychol Sport Exerc 2017:29:10-18.

188. Gulliver A, Griffiths KM, Christensen H. Barriers and facilitators to mental health help-seeking for young elite athletes: a qualitative study. BMC Psychiatry 2012;12:157.

189. Nixdorf I, Frank R, Beckmann J. Comparison of athletes' proneness to depressive symptoms in individual and team sports: research on psychological mediators in junior elite athletes. Front Psychol 2016;7:893.

190. Lancaster MA, McCrea MA, Nelson LD. Psychometric properties and normative data for the brief symptom Inventory-18 (BSI-18) in high school and collegiate athletes. Clin Neuropsychol 2016;30:321-33.

191. Parham WD. The Intercollegiate athlete: a 1990s profile. The Counseling Psychologist 1993:21:411-29.

192. Wolanin A, Gross M, Hong E. Depression in athletes: prevalence and risk factors, Curr Sports Med Rep 2015;14:56-60.

193. Schwenk TL. The stigmatisation and denial of mental illness in athletes. Br I Sports Med 2000:34:4-5

194. Bäckmand H, Kaprio J, Kujala U, et al. Influence of physical activity on depression and anxiety of former elite athletes. Int I Sports Med 2003;24:609-19.

195. Halson SL, Jeukendrup AE. Does overtraining exist? An analysis of overreaching and overtraining research. Sports Med 2004;34:967-81. 
196. Meeusen R, Duclos M, Foster C, et al. Prevention, diagnosis and treatment of the overtraining syndrome: joint consensus statement of the European College of Sport Science (ECSS) and the American College of Sports Medicine (ACSM). Eur J Sport SC 2013;13:1-24.

197. Doherty S, Hannigan B, Campbell MJ. The experience of depression during the careers of elite male athletes. Front Psychol 2016;7:1069.

198. Roy BA. Overreaching/overtraining: more is not always better. ACSM Health Fitness J 2015:19:4-5.

199. Kreher JB, Schwartz JB. Overtraining syndrome: a practical guide. Sports Health 2012:4:128-38.

200. Armstrong LE, VanHeest JL. The unknown mechanism of the overtraining syndrome: clues from depression and psychoneuroimmunology. Sports Med 2002;32:185-209.

201. Morgan WP, Brown DR, Raglin JS, et al. Psychological monitoring of overtraining and staleness. Br J Sports Med 1987;21:107-14.

202. Patel V. Talking sensibly about depression. PLoS Med 2017;14:e1002257.

203. Mann JJ, Apter A, Bertolote J, et al. Suicide prevention strategies: a systematic review. JAMA 2005;294:2064-74.

204. Davidson J. Seizures and bupropion: a review. J Clin Psychiatry 1989;50:256-61.

205. Watson $\mathrm{P}$, Hasegawa $\mathrm{H}$, Roelands B, et al. Acute dopamine/noradrenaline reuptake inhibition enhances human exercise performance in warm, but not temperate conditions. J Physiol 2005;565:873-83.

206. Roelands $B$, Hasegawa $H$, Watson $P$, et al. Performance and thermoregulatory effects of chronic bupropion administration in the heat. Eur J Appl Physiol 2009;105:493-8.

207. Roelands B, Watson P, Cordery P, et al. A dopamine/noradrenaline reuptake inhibitor improves performance in the heat, but only at the maximum therapeutic dose. Scand J Med Sci Sports 2012;22:e93-8.

208. Parise G, Bosman MJ, Boecker DR, et al. Selective serotonin reuptake inhibitors: their effect on high-intensity exercise performance. Arch Phys Med Rehabil 2001;82:867-71.

209. Meeusen R, Piacentini M, Van Den Eynde $S$, et al. Exercise performance is not influenced by a 5-HT reuptake inhibitor. Int J Sports Med 2001;22:329-36.

210. Baum AL. Psychopharmacology in athletes. In: Begel D, Burton RW, eds. Sport psychiatry. New York: WW Norton \& Company, 2000: 249-59.

211. Ciocca M, Stafford H, Laney R. The athlete's pharmacy. Clin Sports Med 2011;30:629-39.

212. Roelands B, Goekint M, Heyman E, et al. Acute norepinephrine reuptake inhibition decreases performance in normal and high ambient temperature. J Appl Physiol 2008;105:206-12.

213. Fowler NO, McCall D, Chou T-C, et al. Electrocardiographic changes and cardiac arrhythmias in patients receiving psychotropic drugs. Am J Cardiol 1976;37:223-30.

214. de Zwaan M. Exercise and antidepressant serum levels. Biol Psychiatry 1992;32:210-1.

215. Rao AL, Asif IM, Drezner JA, et al. Suicide in National Collegiate Athletic Association (NCAA) athletes: a 9-year analysis of the NCAA resolutions database. Sports Health 2015;7:452-7.

216. Silverman MM, Meyer PM, Sloane F, et al. The big ten student suicide study: a 10year study of suicides on midwestern university campuses. Suicide Life Threat Behav 1997;27:285-303.

217. Iverson GL. Chronic traumatic encephalopathy and risk of suicide in former athletes. Br J Sports Med 2014;48:162-4.

218. Pigeon WR, Pinquart M, Conner K. Meta-analysis of sleep disturbance and suicidal thoughts and behaviors. J Clin Psychiatry 2012;73:e1160-7.

219. Perlis ML, Grandner MA, Brown GK, et al. Nocturnal wakefulness as a previously unrecognized risk factor for suicide. J Clin Psychiatry 2016;77:e726-33.

220. Weber S, Puta C, Lesinski M, et al. Symptoms of anxiety and depression in young athletes using the hospital anxiety and depression scale. Front Physiol 2018;9:1-12.

221. Gerber $M$, Holsboer-Trachsler $E$, Pühse $U$, et al. Elite sport is not an additional source of distress for adolescents with high stress levels. Percept Mot Skills 2011;112:581-99.

222. Ivarsson A, Johnson U, Podlog L. Psychological predictors of injury occurrence: a prospective investigation of professional Swedish soccer players. J Sport Rehabil 2013;22:19-26.

223. Johnson U, Ivarsson A. Psychological predictors of sport injuries among junior socce players. Scand J Med Sci Sports 2011;21:129-36.

224. Gomez-Piqueras P, González-Víllora S, Grassi A, et al. Are we making smart decisions regarding return to training of injured football players? preliminary results from a pilot study. IES 2018;26:115-23.

225. Cromer L, Kaier E, Davis J, et al. OCD in college athletes. AJP 2017;174:595-7.

226. Bandelow B, Michaelis S. Epidemiology of anxiety disorders in the 21 st century. Dialogues Clin Neurosci 2015;17:327-35.

227. Goodman WK, Grice DE, Lapidus KAB, et al. Obsessive-compulsive disorder. Psychiatr Clin North Am 2014;37:257-67.

228. McDuff DR. Adjustment and anxiety disorders. In: Currie A, Owen B, eds. Sports psychiatry. Oxford, United Kingdom: Oxford University Press, 2016: 1-16.

229. Guillén F, Sánchez R. Competitive anxiety in expert female athletes: sources and intensity of anxiety in national team and first division Spanish basketball players. Percept Mot Skills 2009;109:407-19.
230. Halvari H, Gjesme T. Trait and state anxiety before and after competitive performance. Percept Mot Skills 1995;81(3_suppl):1059-74.

231. Kerr ZY, DeFreese JD, Marshall SW. Current physical and mental health of former collegiate athletes. Orthop J Sports Med 2014:2:232596711454410-9.

232. Junge A, Prinz B. Depression and anxiety symptoms in 17 teams of female football players including 10 German first league teams. Br J Sports Med 2019;53:471-7.

233. Mesagno C, Harvey JT, Janelle CM. Choking under pressure: the role of fear of negative evaluation. Psychol Sport Exerc 2012;13:60-8.

234. Barlow DH, Brown TA, Craske MG. Definitions of panic attacks and panic disorder in the DSM-IV: implications for research. J Abnorm Psychol 1994;103:553-64.

235. Bleak JL, Frederick CM. Superstitious behavior in sport: levels of effectiveness and determinants of use in three collegiate sports. J Sport Behav 1998;21:1-15.

236. Dömötör Z, Ruíz-Barquín R, Szabo A. Superstitious behavior in sport: a literature review. Scand J Psychol 2016:57:368-82.

237. Moran TP. Anxiety and working memory capacity: a meta-analysis and narrative review. Psychol Bull 2016:142:831-64.

238. McKnight PE, Monfort SS, Kashdan TB, et al. Anxiety symptoms and functional impairment: a systematic review of the correlation between the two measures. Clin Psychol Rev 2016;45:115-30

239. Morgan WP, O'Connor PJ, Ellickson KA, et al. Personality structure, mood states, and performance in elite male distance runners. Int J Sport Psychol 1988;19:247-63.

240. Turner PE, Raglin JS. Variability in precompetition anxiety and performance in college track and field athletes. Med Sci Sports Exerc 1996:28:378-85.

241. Rice SM, Purcell R, De Silva $S$, et al. The mental health of elite athletes: a narrative systematic review. Sports Med 2016;46:1333-53.

242. Hatzigeorgiadis A, Chroni S. Pre-competition anxiety and in-competition coping in experienced male swimmers. Int J Sports Sci Coach 2007;2:181-9.

243. Jones $G$, Hanton $S$, Swain A. Intensity and interpretation of anxiety symptoms in elite and non-elite sports performers. Pers Individ Dif 1994;17:657-63.

244. Craske MG. Anxiety disorders: psychological approaches to theory and treatment. Boulder, CO: Westview Press, 1999.

245. Clark DA, Beck AT. Cognitive therapy of anxiety disorders: science and practice. New York: Guilford Press, 2010.

246. Marvin G, Sharma A, Aston W, et al. The effects of buspirone on perceived exertion and time to fatigue in man. Exp Physiol 1997;82:1057-60

247. Patel DR, Omar H, Terry M. Sport-related performance anxiety in young female athletes. J Pediatr Adolesc Gynecol 2010;23:325-35.

248. Cowan DA, abuse D, Harries M, et al. Oxford textbook of sports medicine. New York: Oxford University Press, 1994: 314-29.

249. Bateman A, Morgan KAD. The postinjury psychological sequelae of high-level Jamaican athletes: exploration of a posttraumatic stress disorder-self-efficacy conceptualization. J Sport Rehabil 2019;28:144-52.

250. Wenzel T, Zhu LJ. Posttraumatic stress in athletes. In: Baron DA, Reardon C, Baron SH, eds. Clinical sports psychiatry: an international perspective. New York: Wiley, 2013: 102-14.

251. Breslau N, Peterson EL, Schultz LR. A second look at prior trauma and the posttraumatic stress disorder effects of subsequent trauma: a prospective epidemiological study. Arch Gen Psychiatry 2008;65:431-7.

252. Brassil HE, Salvatore AP. The frequency of post-traumatic stress disorder symptoms in athletes with and without sports related concussion. Clin Trans/ Med 2018;7:25.

253. Cloitre M, Stolbach BC, Herman JL, et al. A developmental approach to complex PTSD: childhood and adult cumulative trauma as predictors of symptom complexity. J Traum Stress 2009;22:399-408

254. Carty J, O'Donnell ML, Creamer M. Delayed-onset PTSD: a prospective study of injury survivors. J Affect Disord 2006;90:257-61.

255. Appaneal RN, Perna FM, Larkin KT. Psychophysiological response to severe sport injury among competitive male athletes: a preliminary investigation. J Clin Sport Psychol 2007;1:68-88.

256. Lanius RA, Vermetten E, Loewenstein RJ, et al. Emotion modulation in PTSD: clinical and neurobiological evidence for a dissociative subtype. AJP 2010;167:640-7.

257. Scott LM, Scott D, Bedic SP, et al. The effect of associative and dissociative strategies on rowing ergometer performance. Sport Psychol 1999;13:57-68.

258. Stoltz K, Ashby JS. Perfectionism and lifestyle: personality differences among adaptive perfectionists, maladaptive perfectionists, and nonperfectionists. J Individ Psychol 2007:63:414-23.

259. Chen LH, Chen M-Y, Kee YH, et al. Relation of perfectionism with athletes' burnout: further examination. Percept Mot Skills 2008;106:811-20.

260. Brewer BW, Van Raalte JL, Cornelius AE, et al. Psychological factors, rehabilitation adherence, and rehabilitation outcome after anterior cruciate ligament reconstruction. Rehabil Psychol 2000;45:20-37.

261. Putukian M, Echemendia RJ. Psychological aspects of serious head injury in the competitive athlete. Clin Sports Med 2003;22:617-30.

262. James LM, Strom TQ, Leskela J. Risk-taking behaviors and impulsivity among Veterans with and without PTSD and mild TBI. Mil Med 2014;179:357-63.

263. Rothbaum BO, Kearns MC, Price M, et al. Early intervention may prevent the development of posttraumatic stress disorder: a randomized pilot civilian study with modified prolonged exposure. Biol Psychiatry 2012;72:957-63. 
264. Wiseman T, Foster K, Curtis K. Mental health following traumatic physical injury: an integrative literature review. Injury 2013;44:1383-90.

265. O'Neill DF. Injury contagion in alpine ski racing: The effect of injury on teammates' performance. J Clin Sport Psychol 2008;2:278-92.

266. Mountjoy M, Brackenridge C, Arrington M, et al. International Olympic Committee consensus statement: harassment and abuse (non-accidental violence) in sport. $\mathrm{Br}$ Sports Med 2016;50:1019-29.

267. American Psychological Association. Guideline development panel for the treatment of posttraumatic stress disorder in adults. Clinical practice guideline for the treatment of PTSD, 2017. Available: https://www.apa.org/ptsd-guideline/ptsd.pdf

268. Department of Veterans Affairs, Department of Defense. VA/DOD clinical practice guideline for the management of posttraumatic stress disorder and acute stress disorder. Washington, D.C.: Department of Veterans Affairs, 2017.

269. Walsh JM, Wheat ME, Freund K. Detection, evaluation, and treatment of eating disorders the role of the primary care physician. J Gen Intern Med 2000;15:577-90.

270. Rousselet M, Guérineau B, Paruit MC, et al. Disordered eating in French high-level athletes: association with type of sport, doping behavior, and psychological features. Eat Weight Disord 2017;22:61-8.

271. Anderson C, Petrie TA. Prevalence of disordered eating and pathogenic weight control behaviors among NCAA division I female collegiate gymnasts and swimmers. Res Q Exerc Sport 2012;83:120-4.

272. Giel KE, Hermann-Werner A, Mayer J, et al. Eating disorder pathology in elite adolescent athletes. Int J Eat Disord 2016:49:553-62.

273. Bratland-Sanda S, Sundgot-Borgen J. Eating disorders in athletes: overview of prevalence, risk factors and recommendations for prevention and treatment. Eur $\mathrm{J}$ Sport Sci 2013;13:499-508.

274. Joy E, Kussman A, Nattiv A. 2016 update on eating disorders in athletes: a comprehensive narrative review with a focus on clinical assessment and management. Br J Sports Med 2016;50:154-62.

275. Thompson A, Petrie T, Anderson C. Eating disorders and weight control behaviors change over a collegiate sport season. J Sci Med Sport 2017;20:808-13.

276. Kong P, Harris LM. The sporting body: body image and eating disorder symptomatology among female athletes from leanness focused and nonleanness focused sports. J Psychol 2015;149:141-60.

277. Piacentino D, Kotzalidis GD, Longo L, et al. Body image and eating disorders are common among professional and amateur athletes using performance and image enhancing drugs: a cross-sectional study. J Psychoactive Drugs 2017:49:373-84.

278. Torstveit MK, Sundgot-Borgen J. Disordered eating and eating disorders in female athletes. In: Mountjoy M, ed. The female athlete. Hoboken, NJ: Wiley \& Sons, Inc, 2015: 42-55.

279. Wagner AJ, Erickson CD, Tierney DK, et al. The diagnostic accuracy of screening tools to detect eating disorders in female athletes. J Sport Rehabil 2016;25:395-8.

280. Mountjoy M, Sundgot-Borgen J, Burke L, et al. International Olympic Committee (IOC) consensus statement on relative energy deficiency in sport (RED-S): 2018 update. Int I Sport Nutr Exerc Metab 2018;28:316-31.

281. Tan JOA, Calitri R, Bloodworth A, et al. Understanding eating disorders in elite gymnastics: ethical and conceptual challenges. Clin Sports Med 2016;35:275-92.

282. Chapa DAN, Hagan KE, Forbush KT, et al. The Athletes' Relationships with Training scale (ART): A self-report measure of unhealthy training behaviors associated with eating disorders. Int J Eat Disord 2018:51:1080-9.

283. De Souza MJ, Nattiv A, Joy E, et al. 2014 female athlete triad coalition consensus statement on treatment and return to play of the female athlete triad: $1 \mathrm{st}$ International Conference held in San Francisco, Ca, May 2012, and 2nd International Conference held in Indianapolis, May 2013. Clin J Sport Med 2014:24:96-119.

284. VanBaak K, Olson D. The female athlete triad. Curr Sports Med Rep 2016;15:7-8.

285. Tenforde AS, Carlson JL, Chang A, et al. Association of the female athlete triad risk assessment stratification to the development of bone stress injuries in collegiate athletes. Am J Sports Med 2017;45:302-10.

286. Mountjoy M, Sundgot-Borgen J, Burke L, et al. The IOC consensus statement: beyond the female athlete triad—relative energy deficiency in sport (RED-S). Br I Sports Med 2014:48:491-7.

287. El Ghoch M, Soave F, Calugi S, et al. Eating disorders, physical fitness and sport performance: a systematic review. Nutrients 2013;5:5140-60.

288. VanHeest JL, Rodgers CD, Mahoney CE, et al. Ovarian suppression impairs sport performance in junior elite female swimmers. Med Sci Sports Exerc 2014;46:156-66.

289. McArdle S, Meade MM, Moore P. Exploring attitudes toward eating disorders among elite athlete support personnel. Scand J Med Sci Sports 2016;26:1117-27.

290. Plateau CR, Arcelus J, Leung N, et al. Female athlete experiences of seeking and receiving treatment for an eating disorder. Eat Disord 2017;25:273-7.

291. Kroshus E. Stigma, coping skills, and psychological help seeking among collegiate athletes. Athletic Training \& Sports Health Care 2017;9:254-62.

292. Baum A. Eating disorders in the male athlete. Sports Med 2006:36:1-6.

293. Baum AL. Sports psychiatry: an outpatient consultation-liaison model. Psychosomatics 1998;39:395-6.

294. Davis H, Attia E. Pharmacotherapy of eating disorders. Curr Opin Psychiatry 2017:30:452-7.

295. Citrome L. Lisdexamfetamine for binge eating disorder in adults: a systematic review of the efficacy and safety profile for this newly approved indication - what is the number needed to treat, number needed to harm and likelihood to be helped or harmed? Int J Clin Pract 2015:69:410-21.

296. Bar RJ, Cassin SE, Dionne MM. Eating disorder prevention initiatives for athletes: a review. Eur J Sport Sci 2016:16:325-35.

297. Piran N. Eating disorders: a trial of prevention in a high risk school setting. J Prim Prev 1999:20:75-90.

298. Martinsen M, Bahr R, Børresen R, et al. Preventing eating disorders among young elite athletes: a randomized controlled trial. Med Sci Sports Exerc 2014;46:435-47.

299. Arthur-Cameselle JN, Baltzell A. Learning from collegiate athletes who have recovered from eating disorders: advice to coaches, parents, and other athletes with eating disorders. J App/ Sport Psychol 2012;24:1-9.

300. Coker-Cranney A, Reel JJ. Coach pressure and disordered eating in female collegiate athletes: is the coach-athlete relationship a mediating factor? I Clin Sport Psychol 2015;9:213-31

301. Knox C, Love P, Mosby T. Review and commentary of the nutritional recommendations, weight management regulations, weight management practices, and the potential of disordered eating patterns in high school age wrestlers. Sport $\rfloor$ 2017. http://thesportjournal.org/article/review-and-commentary-of-the-nutritionalrecommendations-weight-management-regulations-weight-management-practicesand-the-potential-of-disordered-eating-patterns-in-high-school-age-wrestlers/ [Accessed 05 May 2019].

302. Martinsen M, Sherman RT, Thompson RA, et al. Coaches' knowledge and management of eating disorders: a randomized controlled trial. Med Sci Sports Exerc 2015;47:1070-8.

303. Whitson E, Cordova ML, Demchak T, et al. Certified athletic trainers' knowledge and perception of professional preparation involving eating disorders among athletes. J Allied Health 2006;35:18-29.

304. Quatromoni PA. A tale of two runners: a case report of athletes' experiences with eating disorders in college. J Acad Nutr Diet 2017;117:21-31.

305. White RD, Harris GD, Gibson ME. Attention deficit hyperactivity disorder and athletes. Sports Health 2014;6:149-56

306. Putukian M, Kreher JB, Coppel DB, et al. Attention deficit hyperactivity disorder and the athlete: an American Medical Society for Sports Medicine position statement. Clin J Sport Med 2011;21:392-400

307. Kessler RC, Adler LA, Barkley R, et al. Patterns and predictors of attention-deficit/ hyperactivity disorder persistence into adulthood: results from the national comorbidity survey replication. Biol Psychiatry 2005;57:1442-51.

308. Wolraich M, Brown L, Brown RT, et al. ADHD: clinical practice guideline for the diagnosis, evaluation, and treatment of attention-deficit/hyperactivity disorder in children and adolescents. Pediatrics 2011;128:1007-22.

309. Reardon CL, Factor RM. Considerations in the use of stimulants in sport. Sports Med 2016:46:611-7

310. Dooley JJ, Anderson V, Hemphill SA, et al. Aggression after paediatric traumatic brain injury: a theoretical approach. Brain Inj 2008;22:836-46.

311. Jorge RE, Robinson RG, Moser D, et al. Major depression following traumatic brain injury. Arch Gen Psychiatry 2004;61:42-50.

312. Laird RD, Pettit GS, Dodge KA, et al. Peer relationship antecedents of delinquent behavior in late adolescence: is there evidence of demographic group differences in developmental processes? Dev Psychopathol 2005;17:127-44.

313. Sharp NL, Bye RA, Llewellyn GM, et al. Fitting back in: adolescents returning to school after severe acquired brain injury. Disabil Rehabil 2006;28:767-78.

314. Huw Williams W, Cordan G, Mewse AJ, et al. Self-reported traumatic brain injury in male young offenders: a risk factor for re-offending, poor mental health and violence? Neuropsychol Rehabil 2010;20:801-12.

315. Harmon KG, Drezner J, Gammons M, et al. American Medical Society for Sports Medicine position statement. Clin J Sport Med 2013;23:1-18.

316. Nelson LD, Guskiewicz KM, Marshall SW, et al. Multiple self-reported concussions are more prevalent in athletes with ADHD and learning disability. Clin I Sport Med 2016:26:120-7.

317. McCrory P, Meeuwisse W, Johnston K, et al. Consensus statement on concussion in sport: the 3rd international Conference on Concussion in Sport, Zurich, November 2008. Br J Sports Med 2009;43(Suppl_1):i76-84.

318. Esfandiari A, Broshek DK, Freeman JR. Psychiatric and neuropsychological issues in sports medicine. Clin Sports Med 2011;30:611-27.

319. Parr JW. Attention-deficit hyperactivity disorder and the athlete: new advances and understanding. Clin Sports Med 2011:30:591-610.

320. Pelham WE, Burrows-MacLean L, Gnagy EM, et al. Transdermal methylphenidate, behavioral, and combined treatment for children with ADHD. Exp Clin Psychopharmacol 2005;13:111-26.

321. Stewman CG, Liebman C, Fink L, et al. Attention deficit hyperactivity disorder: unique considerations in athletes. Sports Health 2018;10:40-6.

322. Putukian M. The psychological response to injury in student athletes: a narrative review with a focus on mental health. Br J Sports Med 2016;50:145-8.

323. Wolfe ES, Madden KJ. Evidence-based considerations and recommendations for athletic trainers caring for patients with attention-deficit/hyperactivity disorder. J Athl Train 2016;51:813-20.

324. Perrin AE, Jotwani VM. Addressing the unique issues of student athletes with ADHD. J Fam Pract 2014;63:E1-9. 
325. Pujalte GGA, Maynard JR, Thurston MJ, et al. Considerations in the care of athletes with attention deficit hyperactivity disorder. Clin J Sport Med 2017;00:1-12.

326. Seixas M, Weiss M, Müller U. Systematic review of national and international guidelines on attention-deficit hyperactivity disorder. J Psychopharmacol 2012;26:753-65

327. Conant-Norville DO, Tofler IR. Attention deficit/hyperactivity disorder and psychopharmacologic treatments in the athlete. Clin Sports Med 2005;24:829-43.

328. Smith GM, BEECHER HK. Amphetamine sulfate and athletic performance. I. objective effects. J Am Med Assoc 1959;170:542-57.

329. Chandler JOEV, Blair SN. The effect of amphetamines on selected physiological components related to athletic success. Med Sci Sports Exerc 1980;12:65-9.

330. Corrigan B. Attention deficit hyperactivity disorder in sport: a review. Int J Sports Med 2003;24:535-40.

331. Jacobs IRA, Bell DG. Effects of acute modafinil ingestion on exercise time to exhaustion. Med Sci Sports Exerc 2004;36:1078-82.

332. World Anti-Doping Agency (WADA). Medical information to support the decisions of TUECs-ADHD, 2017. Available: https://www.wada-am.org/en/resources/therapeuticuse-exemption-tue/medical-information-to-support-the-decisions-of-tuecs-adhd

333. WADA. Therapeutic use Exemptions (TUE) n.d. Available: https://www.wadaama.org/en/what-we-do/science-medical/therapeutic-use-exemptions [Accessed November 17 2018].

334. NCAA. Medical exceptions procedures, 2018. Available: http://www.ncaa.org/sportscience-institute/medical-exceptions-procedures [Accessed November 17 2018]

335. Verbeeck W, Bekkering GE, Van den Noortgate W, et al. Bupropion for attention deficit hyperactivity disorder (ADHD) in adults. Cochrane Database Syst Rev 2017; 10:CD009504.

336. Hirota T, Schwartz S, Correll CU. Alpha-2 agonists for attention-deficit/hyperactivity disorder in youth: a systematic review and meta-analysis of monotherapy and addon trials to stimulant therapy. J Am Acad Child Adolesc Psychiatry 2014;53:153-73.

337. Joo SW, Kim H-W. Treatment of children and adolescents with attention deficit hyperactivity disorder and/or Tourette's disorder with clonidine extended release. Psychiatry Investig 2018;15:90-3.

338. Favor Hamilton S, Tomlinson S. Fast girl: a life spent running from madness. New York: HarperCollins, 2015.

339. Moesch K, Kenttä G, Kleinert J, et al. FEPSAC position statement: mental health disorders in elite athletes and models of service provision. Psychol Sport Exerc 2018;38:61-71.

340. Markser VZ. Sport psychiatry and psychotherapy. Mental strains and disorders in professional sports. challenge and answer to societal changes. Eur Arch Psychiatry Clin Neurosci 2011;261:182-5.

341. Trenton AJ, Currier GW. Behavioural manifestations of anabolic steroid use. CNS Drugs 2005;19:571-95.

342. Bahrke MS, Yesalis CE, Wright JE. Psychological and behavioural effects of endogenous testosterone and anabolic-androgenic steroids an update. Sports Med 1996;22:367-90.

343. Piacentino D, Kotzalidis G, Casale A, et al. Anabolic-androgenic steroid use and psychopathology in athletes. A systematic review. Curr Neuropharmacol 2015;13:101-21.

344. Baron DA, Reardon CL, Baron SH. Clinical sports psychiatry: an international perspective. London: John Wiley \& Sons, 2013.

345. Reardon C, Creado S. Drug abuse in athletes. Subst Abuse Rehabil 2014;5:95-105.

346. Judd LL, Akiskal HS, Schettler PJ, et al. A prospective investigation of the natural history of the long-term weekly symptomatic status of bipolar II disorder. Arch Gen Psychiatry 2003:60:261-9.

347. Judd LL, Akiskal HS, Schettler PJ, et al. The long-term natural history of the weekly symptomatic status of bipolar I disorder. Arch Gen Psychiatry 2002;59:530-7.

348. Green MF. What are the functional consequences of neurocognitive deficits in schizophrenia? Am J Psychiatry 1996;153:321-30.

349. Rabinowitz J, Levine SZ, Garibaldi G, et al. Negative symptoms have greater impact on functioning than positive symptoms in schizophrenia: analysis of CATIE data. Schizophr Res 2012;137:147-50.

350. Firth J, Cotter J, Elliott R, et al. A systematic review and meta-analysis of exercise interventions in schizophrenia patients. Psychol Med 2015;45:1343-61.

351. Melo MCA, Daher EDF, Albuquerque SGC, et al. Exercise in bipolar patients: a systematic review. J Affect Disord 2016;198:32-8.

352. Dauwan M, Begemann MJH, Heringa SM, et al. Exercise improves clinical symptoms, quality of life, global functioning, and depression in schizophrenia: a systematic review and meta-analysis. Schizophr Bull 2016;42:588-99.

353. National Institute for Health and Care Excellence. Psychosis and schizophrenia in adults: Prevention and management, 2014. Available: https://www.nice.org.uk/ guidance/cg178 [Accessed November 17 2018].

354. Goodwin GM, Consensus Group of the British Association for Psychopharmacology. Evidence-based guidelines for treating bipolar disorder: revised second editionrecommendations from the British Association for Psychopharmacology. J Psychopharmacol 2009;23:346-88.

355. Hirschfeld RMA, Bowden CL, et al, American Psychiatric Association. Practice guideline for treatment of patients with bipolar disorder. 2th edn. Washington DC, 2010.
356. National Institute for Health and Care Excellence (NICE). Bipolar disorder: assessment and management, 2014. Available: https://www.nice.org.uk/guidance/ cg185 [Accessed 18 Dec 2018].

357. Lehman AF, Lieberman JA, et al, American Psychiatric Association. Practice quideline for the treatment of patients with schizophrenia. 2th edn. Washington DC, 2010.

358. Barnes TRE, Schizophrenia Consensus Group of British Association for Psychopharmacology. Evidence-based guidelines for the pharmacological treatment of schizophrenia: recommendations from the British Association for Psychopharmacology. J Psychopharmacol 2011;25:567-620.

359. Frank E, Soreca I, Swartz HA, et al. The role of interpersonal and social rhythm therapy in improving occupational functioning in patients with bipolar I disorder. Am J Psychiatry 2008;165:1559-65.

360. Jefferson JW, Greist JH, Clagnaz PJ, et al. Effect of strenuous exercise on serum lithium level in man. Am J Psychiatry 1982;139:1593-5.

361. Miller EB, Pain RW, Skripal PJ. Sweat lithium in manic-depression. Br J Psychiatry 1978;133:477b-8

362. Beach SR, Celano CM, Noseworthy PA, et al. QTc prolongation, torsades de pointes, and psychotropic medications. Psychosomatics 2013;54:1-13.

363. McCrory P, Meeuwisse W, Dvorák J, et al. Consensus statement on concussion in sport-the 5 th $^{\text {th }}$ International Conference on concussion in sport held in Berlin, October 2016. Br J Sports Med 2017;51:838-47.

364. King D, Brughelli $M$, Hume $P$, et al. Assessment, management and knowledge of sport-related concussion: systematic review. Sports Med 2014;44:449-71.

365. Rice SM, Parker AG, Rosenbaum S, et al. Sport-related concussion and mental health outcomes in elite athletes: a systematic review. Sports Med 2018;48:447-65.

366. Echemendia RJ, Meeuwisse W, McCrory P, et al. The sport concussion assessment tool 5th edition (SCAT5): background and rationale. Br J Sports Med 2017:51:848-50

367. Beck ATet al. An inventory for measuring depression. Arch Gen Psychiatry 1961:4:561-71

368. Potter $\mathrm{S}$, Leigh $\mathrm{E}$, Wade $\mathrm{D}$, et al. The Rivermead post concussion symptoms questionnaire: a confirmatory factor analysis. J Neurol 2006;253:1603-14.

369. Thompson E. Hamilton rating scale for anxiety (HAM-A). Occup Med 2015;65:601.

370. Vargas G, Rabinowitz A, Meyer J, et al. Predictors and prevalence of postconcussion depression symptoms in collegiate athletes. J Athl Train 2015;50:250-5.

371. Kontos AP, Covassin T, Elbin RJ, et al. Depression and neurocognitive performance after concussion among male and female high school and collegiate athletes. Arch Phys Med Rehabil 2012;93:1751-6.

372. McCrea M, Guskiewicz KM, Marshall SW, et al. Acute effects and recovery time following concussion in collegiate football players. JAMA 2003;290:2556-63.

373. McCrea M, Meier T, Huber D, et al. Role of advanced neuroimaging, fluid biomarkers and genetic testing in the assessment of sport-related concussion: a systematic review. Br J Sports Med 2017;51:919-29.

374. Broglio SP, Collins MW, Williams RM, Broglio SP, et al. Current and emerging rehabilitation for concussion: a review of the evidence. Clin Sports Med 2015:34:213-31.

375. Al Sayegh A, Sandford D, Carson AJ. Psychological approaches to treatment of postconcussion syndrome: a systematic review. J Neurol Neurosurg Psychiatry 2010;81:1128-34.

376. Alves W, Macciocchi SN, Barth JT. Postconcussive symptoms after uncomplicated mild head injury. J Head Trauma Rehabil 1993;8:48-59.

377. Boake C, McCauley SR, Levin HS, et al. Limited agreement between criteriabased diagnoses of postconcussional syndrome. J Neuropsychiatry Clin Neurosci 2004; 16:493-9.

378. Hadanny A, Efrati S. Treatment of persistent post-concussion syndrome due to mild traumatic brain injury: current status and future directions. Exp Rev Neurother 2016;16:875-87.

379. Hou R, Moss-Morris R, Peveler R, et al. When a minor head injury results in enduring symptoms: a prospective investigation of risk factors for postconcussional syndrome after mild traumatic brain injury. J Neurol Neurosurg Psychiatry 2012:83:217-23.

380. Iverson G. Misdiagnosis of the persistent postconcussion syndrome in patients with depression. Arch Clin Neuropsychol 2006;21:303-10.

381. Rose SC, Fischer AN, Heyer GL. How long is too long? The lack of consensus regarding the post-concussion syndrome diagnosis. Brain Inj 2015;29:798-803.

382. Katz DI, Cohen SI, Alexander MP. Mild traumatic brain injury. In: Grafman J, Salaza AM, eds. Traumatic brain injury, Part I. San Diego: Elsevier BV, 2015: 131-56.

383. Iverson GL, Lange RT. Examination of "postconcussion-like" symptoms in a healthy sample. App/ Neuropsychol 2003;10:137-44.

384. Collins MW, Kontos AP, Okonkwo DO, et al. Statements of agreement from the targeted evaluation and active management (team) approaches to treating concussion Meeting held in Pittsburgh, October 15-16, 2015. Neurosurgery 2016;79:912-29.

385. Corwin DJ, Zonfrillo MR, Master CL, et al. Characteristics of prolonged concussion recovery in a pediatric subspecialty referral population. J Pediatr 2014;165:1207-15.

386. Lange RT, Iverson GL, Rose A. Depression strongly influences postconcussion symptom reporting following mild traumatic brain injury. J Head Trauma Rehabil 2011;26:127-37 
387. Morgan CD, Zuckerman SL, Lee YM, et al. Predictors of postconcussion syndrome after sports-related concussion in young athletes: a matched case-control study. $J$ Neurosurg Pediatr 2015;15:589-98

388. Kerr GA, Stirling AE. Parents' reflections on their child's experiences of emotionally abusive coaching practices. J App/ Sport Psychol 2012;24:191-206.

389. Guskiewicz KM, Marshall SW, Bailes J, et al. Recurrent concussion and risk of depression in retired professional football players. Med Sci Sports Exerc 2007:39:903-9.

390. Kerr ZY, Thomas LC, Simon JE, et al. Association between history of multiple concussions and health outcomes among former college football players: 15-year follow-up from the NCAA concussion study (1999-2001). Am J Sports Med 2018;46:1733-41.

391. Fralick M, Sy E, Hassan A, et al. Association of concussion with the risk of suicide: a systematic review and meta-analysis. JAMA Neuro/ 2018. doi:10.1001/ jamaneurol.2018.3487. [Epub ahead of print: 12 Nov 2018].

392. Lehman EJ, Hein MJ, Gersic CM. Suicide mortality among retired National Football League players who played 5 or more seasons. Am J Sports Med 2016:44:2486-91.

393. Collie A, Darby D, Maruff P. Computerised cognitive assessment of athletes with sports related head injury. Br J Sports Med 2001;35:297-302.

394. Collie Aet al. Psychometric issues associated with computerised neuropsychological assessment of concussed athletes. Br J Sports Med 2003;37:556-9.

395. Collins MWet al. Relationship between concussion and neuropsychological performance in college football players. JAMA 1999;282:964-70.

396. Lovell MR. The relevance of neuropsychologic testing for sports-related head injuries Curr Sports Med Rep 2002:1:7-11.

397. Broglio SP, Macciocchi SN, Ferrara MS. Neurocognitive performance of concussed athletes when symptom free. J Athl Train 2007;42:504-8.

398. McAllister TW, Arciniegas D. Evaluation and treatment of postconcussive symptoms. NeuroRehabilitation 2002;17:265-83.

399. Leddy JJ, Baker JG, Merchant A, et al. Brain or strain? symptoms alone do not distinguish physiologic concussion from cervical/vestibular injury. Clin I Sport Med 2015;25:237-42.

400. Leddy JJ, Sandhu H, Sodhi V, et al. Rehabilitation of concussion and post-concussion syndrome. Sports Health 2012:4:147-54.

401. Arciniegas DB, Topkoff J, Silver JM. Neuropsychiatric aspects of traumatic brain injury. Curr Treat Options Neurol 2000;2:169-86.

402. Leddy JJ, Cox JL, Baker JG, et al. Exercise treatment for postconcussion syndrome: a pilot study of changes in functional magnetic resonance imaging activation, physiology, and symptoms. J Head Trauma Rehabil 2013;28:241-9.

403. Schneider KJ, Iverson GL, Emery CA, et al. The effects of rest and treatment following sport-related concussion: a systematic review of the literature. Br J Sports Med 2013;47:304-7.

404. Todd R, Bhalerao S, Vu MT, et al. Understanding the psychiatric effects of concussion on constructed identity in hockey players: implications for health professionals. PLOS One 2018;13:e0192125.

405. Potter S, Brown RG. Cognitive behavioural therapy and persistent post-concussional symptoms: integrating conceptual issues and practical aspects in treatment. Neuropsychol Rehabil 2012;22:1-25.

406. Iverson GL, Silverberg ND, Mannix R, et al. Factors associated with concussion-like symptom reporting in high school athletes. JAMA Pediatr 2015;169:1132-40.

407. Gaetz M. The multi-factorial origins of chronic traumatic encephalopathy (CTE) symptomology in post-career athletes: the athlete post-career adjustment (AP-CA) model. Med Hypotheses 2017;102:130-43.

408. Meehan WP. Medical therapies for concussion. Clin Sports Med 2011;30:115-24.

409. Arciniegas DB, Silver JM, McAllister TW. Stimulants and acetylcholinesterase inhibitors for the treatment of cognitive impairment after traumatic brain injury. Psychopharm Review 2008;43:91-7.

410. Warden DL, Gordon B, McAllister TW, et al. Guidelines for the pharmacologic treatment of neurobehavioral sequelae of traumatic brain injury. J Neurotrauma 2006;23:1468-501.

411. Maldonado MD, Murillo-Cabezas F, Terron MP, et al. The potential of melatonin in reducing morbidity/mortality after craniocerebral trauma. J Pineal Res 2007;42:1-11.

412. Samantaray S, Das A, Thakore NP, et al. Therapeutic potential of melatonin in traumatic central nervous system injury. J Pineal Res 2009;47:134-42.

413. Arciniegas DB, Anderson CA, Topkoff J, et al. Mild traumatic brain injury: a neuropsychiatric approach to diagnosis, evaluation, and treatment. Neuropsychiatr Dis Treat 2005:1:311-28.

414. Rao V, Rollings P. Sleep disturbances following traumatic brain injury. Curr Treat Options Neurol 2002:4:77-87.

415. Chew E, Zafonte RD. Pharmacological management of neurobehavioral disorders following traumatic brain injury. A state-of the-art review. J Rehabil Res Dev 2009;46:851-79

416. Fann JR, Uomoto JM, Katon WJ. Cognitive improvement with treatment of depression following mild traumatic brain injury. Psychosomatics 2001;42:48-54.

417. Minen MT, Boubour A, Walia $H$, et al. Post-concussive syndrome: a focus on posttraumatic headache and related cognitive, psychiatric, and sleep issues. Curr Neurol Neurosci Rep 2016;16:1-12.
418. Comper $P$, Bisschop SM, Carnide $N$, et al. A systematic review of treatments for mild traumatic brain injury. Brain Inj 2005;19:863-80.

419. Lew HL, Lin P-H, Fuh J-L, et al. Characteristics and treatment of headache after traumatic brain injury. Am J Phys Med Rehabil 2006:85:619-27.

420. Plenger PM, Dixon CE, Castillo RM, et al. Subacute methylphenidate treatment for moderate to moderately severe traumatic brain injury: a preliminary double-blind placebo-controlled study. Arch Phys Med Rehabil 1996;77:536-40.

421. Whyte J, Hart T, Schuster K, et al. Effects of methylphenidate on attentional function after traumatic brain injury. A randomized, placebo-controlled trial. Am J Phys Med Rehabil 1997;76:440-50.

422. Williams JM, Andersen MB. Psychosocial antecedents of sport injury: review and critique of the stress and injury model'. J App/ Sport Psychol 1998;10:5-25.

423. Sivan M, Neumann V, Kent $R$, et al. Pharmacotherapy for treatment of attention deficits after non-progressive acquired brain injury. A systematic review. Clin Rehabil 2010;24:110-21.

424. McDuff DR, Baron D. Substance use in athletics: a sports psychiatry perspective. Clin Sports Med 2005:24:885-97.

425. Drobnic F, Galilea PA. Doping control adverse results prevalence worldwide for 13 consecutive years. Apunts Medicina de l'Esport 2018:53:11-18.

426. van der Gronde T, de Hon O, Haisma HJ, et al. Gene doping: an overview and current implications for athletes. Br J Sports Med 2013;47:670-8.

427. Mazzeo F, Monda V, Santamaria S, et al. Antidoping program: an important factor in the promotion and protection of the integrity of sport and athlete's health. J Sports Med Phys Fitness 2018;58:1135-45.

428. Hughes D. The world anti-doping code in sport: update for 2015. Aust Prescr 2015:38:167-70.

429. Davis NJ. Neurodoping: brain stimulation as a performance-enhancing measure. Sports Med 2013:43:649-53.

430. Borducchi DMM, Gomes JS, Akiba H, et al. Transcranial direct current stimulation effects on athletes' cognitive performance: an exploratory proof of concept trial. Front Psychiatry 2016;7:183.

431. Maughan RJ, Burke LM, Dvorak J, et al. IOC consensus statement: dietary supplements and the high-performance athlete. Br J Sports Med 2018;52:439-55

432. Lisha NE, Sussman S. Relationship of high school and college sports participation with alcohol, tobacco, and illicit drug use: a review. Addict Behav 2010:35:399-407.

433. Dunn M, Thomas JO, Swift W, et al. Elite athletes' estimates of the prevalence of illicit drug use: evidence for the false consensus effect. Drug Alcohol Rev 2012;31:27-32.

434. Yusko DA, Buckman JF, White HR, et al. Risk for excessive alcohol use and drinkingrelated problems in college student athletes. Addict Behav 2008;33:1546-56.

435. Momaya A, Fawal M, Estes R. Performance-enhancing substances in sports: a review of the literature. Sports Med 2015:45:517-31.

436. Heather N, Partington S, Partington E, et al. Alcohol use disorders and hazardous drinking among undergraduates at English universities. Alcohol Alcohol 2011;46:270-7

437. Diehl K, Thiel A, Zipfel S, et al. Substance use among elite adolescent athletes: findings from the goal study. Scand J Med Sci Sports 2014;24:250-8.

438. Lisha NE, Crano WD, Delucchi KL. Participation in team sports and alcohol and marijuana use initiation trajectories. J Drug Issues 2014;44:83-93.

439. NCAA. National study on substance abuse habits of college student-athletes, 2018. Available: http://www.ncaa.org/sites/default/files/2018RES_Substance_Use_Final_ Report_FINAL_20180611.pdf [Accessed 17 Nov 2018].

440. Ford JA. Alcohol use among college students: a comparison of athletes and nonathletes. Subst Use Misuse 2007;42:1367-77.

441. Ford JA. Nonmedical prescription drug use among college students: a comparison between athletes and nonathletes. J Am Coll Health 2008;57:211-20.

442. Zhou J, Heim D, O'Brien K. Alcohol consumption, athlete identity, and happiness among student sportspeople as a function of Sport-Type. Alcohol Alcohol 2015:50:617-23

443. Veliz PT, Boyd CJ, McCabe SE. Competitive sport involvement and substance use among adolescents: a nationwide study. Subst Use Misuse 2015;50:156-65.

444. Green GA, Uryasz FD, Petr TA, et al. NCAA study of substance use and abuse habits of college student-athletes. Clin J Sport Med 2001;11:51-6.

445. Kondric M, Sekulic D, Mandic GF. Substance use and misuse among Slovenian table tennis players. Subst Use Misuse 2010;45:543-53.

446. O'Brien KS, Ali A, Cotter JD, et al. Hazardous drinking in New Zealand sportspeople: level of sporting participation and drinking motives. Alcohol Alcohol 2007;42:376-82.

447. Hoyte CO, Albert D, Heard KJ. The use of energy drinks, dietary supplements, and prescription medications by United States college students to enhance athletic performance. J Community Health 2013;38:575-80.

448. Green K, Nelson TF, Hartmann D. Binge drinking and sports participation in college: patterns among athletes and former athletes. Int Rev Socio/ Sport 2014:49:417-34

449. Sagoe D, Molde H, Andreassen CS, et al. The global epidemiology of anabolicandrogenic steroid use: a meta-analysis and meta-regression analysis. Ann Epidemiol 2014;24:383-98. 
450. Ford JA, Pomykacz C, Veliz P, et al. Sports involvement, injury history, and nonmedical use of prescription opioids among college students: an analysis with a national sample. Am J Addict 2018;27:15-22.

451. Al Ghobain M, Konbaz MS, Almassad A, et al. Prevalence, knowledge and attitude of prohibited substances use (doping) among Saudi sport players. Subst Abuse Treat Prev Policy 2016;11:14.

452. Buckman JF, Farris SG, Yusko DA. A national study of substance use behaviors among NCAA male athletes who use banned performance enhancing substances. Drug Alcohol Depend 2013;131:50-5.

453. Peretti-Watel $P$, Guagliardo V, Verger $P$, et al. Sporting activity and drug use: alcohol, cigarette and cannabis use among elite student athletes. Addiction 2003;98:1249-56.

454. Lindqvist AS, Moberg T, Eriksson BO, et al. A retrospective 30-year follow-up study of former Swedish-elite male athletes in power sports with a past anabolic androgenic steroids use: a focus on mental health. Br J Sports Med 2013:47:965-9.

455. Pereira HMG, Sardela VF. Stimulant doping agents used in Brazil: prevalence, detectability, analytical implications, and challenges. Subst Use Misuse 2014;49:1098-114

456. Veliz PT, Boyd CJ, Epstein-Ngo Q, et al. Substance use among sexual minority collegiate athletes: a national study. Drug Alcohol Depend 2015;156:e230.

457. Denham BE. Alcohol and marijuana use among American high school seniors: empirical associations with competitive sports participation. Socio/ Sport J 2011;28:362-79.

458. Blank C, Kopp M, Niedermeier M, et al. Predictors of doping intentions, susceptibility, and behaviour of elite athletes: a meta-analytic review. Springerplus 2016;5:1-14.

459. Marclay F, Grata E, Perrenoud L, et al. A one-year monitoring of nicotine use in sport: frontier between potential performance enhancement and addiction issues. Forensic Sci Int 2011:213:73-84.

460. Dimeo P, Taylor J. Monitoring drug use in sport: the contrast between official statistics and other evidence. Drugs: Education, Prevention and Policy 2013;20:40-7.

461. Druckman JN, Gilli M, Klar S, et al. Measuring drug and alcohol use among college student-athletes*. Soc Sci Q 2015;96:369-80.

462. Harcourt PR, Unglik H, Cook JL. A strategy to reduce illicit drug use is effective in elite Australian football. Br J Sports Med 2012;46:943-5.

463. Simon $P$, Neuberger EW, Wang G, et al. Antidoping science: important lessons from the medical sciences. Curr Sports Med Rep 2018;17:326-31.

464. Alquraini $H$, Auchus RJ. Strategies that athletes use to avoid detection of androgenicanabolic steroid doping and sanctions. Mol Cell Endocrinol 2018;464:28-33.

465. Schulenberg JE, Johnston LD, O'Malley PM. Monitoring the future national survey results on drug use, 1975-2016. Volume II, College Students \& Adults Ages 19-55: Institute for Social Research. University of Michigan, 2017.

466. SIUC/Core Institute. 2013 Annual Data. Core Alcohol and Drug Survey Long Form Form 194. Executive Summary. Carbondale, IL: SIUC/Core Institute, 2013. Available: https://core.siu.edu/_common/documents/2013.pdf

467. Nelson TF, Wechsler $\bar{H}$. Alcohol and college athletes. Med Sci Sports Exerc 2001:43-7.

468. Grossbard J, Geisner IM, Neighbors C, et al. Are drinking games sports? College athlete participation in drinking games and alcohol-related problems. J Stud Alcohol Drugs 2007;68:97-105.

469. Barry AE, Howell SM, Riplinger A, et al. Alcohol use among college athletes: do intercollegiate, club, or intramural student athletes drink differently? Subst Use Misuse 2015:50:302-7.

470. Leichliter JS, Meilman PW, Presley CA, et al. Alcohol use and related consequences among students with varying levels of involvement in college athletics. J Am Coll Health 1998:46:257-62.

471. Wilson GS, Pritchard ME, Schaffer J. Athletic status and drinking behavior in college students: the influence of gender and coping styles. J Am Coll Health 2004;52:269-75

472. Wechsler $H$, Davenport AE, Dowdall GW, et al. Binge drinking, tobacco, and illicit drug use and involvement in college athletics. J Am Coll Health 1997;45:195-200.

473. Rigotti NA, Lee JE, Wechsler H. Us college students' use of tobacco products: results of a national survey. JAMA 2000;284:699-705.

474. Zanotti D, Kaier E, Strunk K. Prevalence of mental health symptoms in college athletes. Washington, D C: American Psychological Association, 2017.

475. Mündel T. Nicotine: sporting friend or foe? A review of athlete use, performance consequences and other considerations. Sports Med 2017;47:2497-506.

476. Cappelletti S, Daria P, Sani G, et al. Caffeine: cognitive and physical performance enhancer or psychoactive drug? Curr Neuropharmacol 2015;13:71-88.

477. Kabiri S, Cochran JK, Stewart BJ, et al. Doping among professional athletes in Iran: A test of Akers's social learning theory. Int J Offender Ther Comp Criminol 2018:62:1384-410.

478. Brisola-Santos MB, Gallinaro JGdeMe, Gil F, et al. Prevalence and correlates of cannabis use among athletes-A systematic review. Am J Addict 2016;25:518-28.

479. Egan KL, Erausquin JT, Milroy JJ, et al. Synthetic cannabinoid use and descriptive norms among collegiate student-athletes. J Psychoactive Drugs 2016:48:166-72.

480. Bents RT, Tokish JM, Goldberg L, Ephedrine GL. Ephedrine, pseudoephedrine, and amphetamine prevalence in college hockey players: most report performanceenhancing use. Phys Sportsmed 2004;32:30-4.
481. Weaver CC, Martens MP, Cadigan JM, et al. Sport-related achievement motivation and alcohol outcomes: an athlete-specific risk factor among intercollegiate athletes. Addict Behav 2013;38:2930-6.

482. Zhou J, Heim D, Levy A. Sports participation and alcohol use: associations with sports-related identities and well-being. J Stud Alcohol Drugs 2016;77:170-9.

483. Huang J-H, Jacobs DF, Derevensky JL, et al. Gambling and health risk behaviors among U.S. college student-athletes: findings from a national study. J Adolesc Health 2007:40:390-7.

484. Storch EA, Kolsky AR, Silvestri SM, et al. Religiosity of elite college athletes. Sport Psychol 2001;15:346-51.

485. Barnes MJ. Alcohol: impact on sports performance and recovery in male athletes. Sports Med 2014;44:909-19.

486. Pesta DH, Angadi SS, Burtscher $\mathrm{M}$, et al. The effects of caffeine, nicotine, ethanol, and tetrahydrocannabinol on exercise performance. Nutr Metab 2013;10:71.

487. Ware MA, Jensen D, Barrette A, et al. Cannabis and the health and performance of the elite athlete. Clin J Sport Med 2018;28:480-4

488. LaBrie JW, Grossbard JR, Hummer JF. Normative misperceptions and marijuana use among male and female college athletes. J App/ Sport Psychol 2009;21:S77-S85.

489. Castaneto MS, Gorelick DA, Desrosiers NA, et al. Synthetic cannabinoids: epidemiology, pharmacodynamics, and clinical implications. Drug Alcohol Depend 2014;144:12-41

490. Heltsley R, Shelby MK, Crouch DJ, et al. Prevalence of synthetic cannabinoids in U.S. athletes: Initial findings. J Anal Toxicol 2012;36:588-93.

491. Cohen J, Collins R, Darkes J, et al. A league of their own: demographics, motivations and patterns of use of 1,955 male adult non-medical anabolic steroid users in the United States. J Int Soc Sports Nutr 2007;4:12-14

492. Kanayama G, Kean J, Hudson Jl, et al. Cognitive deficits in long-term anabolicandrogenic steroid users. Drug Alcohol Depend 2013;130:208-14

493. Choi PYL, Pope HG, Olivardia R. Muscle dysmorphia: a new syndrome in weightlifters * commentary. Br J Sports Med 2002;36:375-6.

494. Esco MR, Olson MS, Williford HN. Muscle Dysmorphia: an emerging body image concern in men. Strength Cond J 2005;27:76-9.

495. Leone JE, Sedory EJ, Gray KA. Recognition and treatment of muscle dysmorphia and related body image disorders. J Athl Train 2005;40:352-35.

496. Kaufman KR. Modafinil in sports: ethical considerations. Br J Sports Med 2005;39:241-4.

497. Trinh KV, Kim J, Ritsma A. Effect of pseudoephedrine in sport: a systematic review. BMJ Open Sport Exerc Med 2015;1:e000066.

498. Conrad AK, Hutton SB, Munnelly M, et al. Screening for smokeless tobacco use and presence of oral lesions in major league baseball athletes. J Calif Dent Assoc 2015:43:14-20.

499. Cooper J, Ellison JA, Walsh MM. Spit (Smokeless)-tobacco use by baseball players entering the professional ranks. J Ath/ Train 2003;38:126-32.

500. McDuff DR, Garvin M. Working with sports organizations and teams. Int Rev Psychiatry 2016:28:595-605.

501. Martens MP. Alcohol abuse and drug use in sport and performance. Oxford Research Encyclopedia of Psychology, 2017. Available: http://psychology.oxfordre.com/ abstract/10.193/acrefore/9780190236557.001.0001/acrefore978019236557-e168

502. Donohue B, Loughran T, Pitts M, et al. Preliminary development of a brief intervention to prevent alcohol misuse and enhance sport performance in collegiate athletes. J Drug Abuse 2016;2:3.

503. Cimini MD, Monserrat JM, Sokolowski KL, et al. Reducing high-risk drinking among student-athletes: the effects of a targeted athlete-specific brief intervention. J Am Coll Health 2015;63:343-52.

504. Gross M, Moore ZE, Gardner FL, et al. An empirical examination comparing the Mindfulness-Acceptance-Commitment approach and psychological skills training for the mental health and sport performance of female student athletes. Int I Sport Exerc Psychol 2018;16:431-51

505. Donohue B, Gavrilova Y, Galante M, et al. Controlled evaluation of an optimization approach to mental health and sport performance. J Clin Sport Psychol 2018;12:234-67.

506. Agley J, Walker BB, Gassman RA. Adaptation of alcohol and drug screening, brief intervention and referral to treatment (SBIRT) to a department of intercollegiate athletics: the COMPASS project. Health Educ J 2013:72:647-59.

507. Weiss RD, Jaffee WB, de Menil VP, et al. Group therapy for substance use disorders: what do we know? Harv Rev Psychiatry 2004;12:339-50.

508. Morse ED. Substance use in athletes. In: Baron DA, Reardon CL, Baron SH, eds. Clinical sports psychiatry: an international perspective. Oxford, UK: Wiley, 2013.

509. Ebbert JO, Hatsukami DK, Croghan IT, et al. Combination varenicline and bupropion SR for tobacco-dependence treatment in cigarette smokers. JAMA 2014;311:155-63.

510. Malas M, van der Tempel J, Schwartz R, et al. Electronic cigarettes for smoking cessation: a systematic review. Nicotine Tob Res 2016:18:1926-36.

511. Canadian Agency for Drugs and Technologies in Health (CADTH). Nicotine replacement therapy, bupropion and varenicline for tobacco cessation: a review of clinical effectiveness: CADTH, 2016. Available: https://www.cadth.ca/nicotine- 
replacement-therapy-bupropion-and-varenicline-tobacco-cessation-review-clinical [Accessed 8 Mar 2016].

512. Gaznick NV, Anthenelli RM. E-cigarettes and vapes: do they work for smoking cessation and should we be recommending their use? Curr Psychiatry 2017; 16:36-9

513. Brose LS, Brown J, Hitchman SC, et al. Perceived relative harm of electronic cigarettes over time and impact on subsequent use. A survey with 1-year and 2-year followups. Drug Alcohol Depend 2015;157:106-11.

514. Derevensky JL. Teen gambling: understanding a growing epidemic. New York: Rowman \& Littlefield Publishers, 2012

515. Bischof A, Meyer C, Bischof $G$, et al. Comorbid axis I-disorders among subjects with pathological, problem, or at-risk gambling recruited from the general population in Germany: results of the page study. Psychiatry Res 2013;210:1065-70.

516. Black DW, Coryell WH, Crowe RR, et al. Personality disorders, impulsiveness, and novelty seeking in persons with DSM-IV pathological gambling and their first-degree relatives. J Gambl Stud 2015;31:1201-14.

517. Messerlian C, Derevensky J, Gupta R. Youth gambling problems: a public health perspective. Health Promot Int 2005;20:69-79.

518. Temcheff CE, Derevensky JL, St-Pierre RA, et al. Beliefs and attitudes of mental health professionals with respect to gambling and other high risk behaviors in schools. Int J Ment Health Addict 2014:12:716-29.

519. Volberg RA, Gupta R, Griffiths MD, et al. An international perspective on youth gambling prevalence studies. Int J Adolesc Med Health 2010;22:3-38.

520. Grall-Bronnec M, Caillon J, Humeau E, et al. Gambling among European professional athletes. Prevalence and associated factors. J Addict Dis 2016;35:278-90.

521. Weiss SM, Loubier SL. Gambling behaviors of former athletes: the delayed competitive effect. UNLV Gaming Research \& Review Journal 2008;12:53-60

522. Derevensky J, Paskus T, Gambling behaviors of college student athletes: Cause for concern. In: Brown GT, Hainline B, Kroshus E, et al, eds. Mind, body and sport: understanding and supporting student-athlete mental wellness. Indianapolis: NCAA Press, 2014: 52-7.

523. Mastroleo NR, Scaglione N, Mallett KA, et al. Can personality account for differences in drinking between college athletes and non-athletes? explaining the role of sensation seeking, risk-taking, and impulsivity. J Drug Educ 2013:43:81-95.

524. Seznec J-C, Lépine J-P, Pélissolo A. [Dimensional personality assessment of the members of the French junior national team of road cycling]. Encephale 2003;29:29-33.

525. Shead NW, Derevensky JL, Gupta R. Risk and protective factors associated with youth problem gambling. Int J Adolesc Med Health 2010;22:39-58.

526. Kerber CS, Sullivan Kerber C. Problem and pathological gambling among college athletes. Ann Clin Psychiatry 2005;17:243-7.

527. Rockey DL, Beason KR, Gilbert JD. Gambling by college athletes: an association between problem gambling and athletes. J Gambl IssuesJGI 2002;12.

528. Etkowicz JM. Professional athletes playing video games-The next prohibited other activity. Villanova Sports and Entertainment Law Journal 2008:15:65-101.

529. Middlemas DA, Basilicato J, Prybicien M, et al. Incorporating gaming technology into athletic injury rehabilitation: a review of the literature. Athl Train Sports Health Care 2009; $1: 79-84$

530. Bányai F, Griffiths MD, Király 0 , et al. The psychology of esports: a systematic literature review. J Gamb/ Stud 2018;doi: 10.1007/s10899-018-9763-1. [Epub ahead of print].

531. Faust KA, Meyer JF, Griffiths MD. Competitive and professional gaming: Discussing potential benefits of scientific study. Int I Cyber Behav Psychol Learn 2013;3:67-77.

532. Griffiths M. The psychosocial impact of professional gambling, professional video gaming and eSports. Casino Gambl Int 2017;28:59-63.

533. Demetrovics Z, Griffiths MD. Behavioral addictions: past, present and future. J Behav Addict 2012;1:1-2.

534. Szabo A, De La Vega R, Ruiz-Barquín $R$, et al. Exercise addiction in Spanish athletes: investigation of the roles of gender, social context and level of involvement. J Behav Addict 2013;2:249-52.

535. Blaydon M, Lindner K. Eating disorders and exercise dependence in triathletes. Eat Disord 2002;10:49-60.

536. Allegre $B$, Therme P, Griffiths M. Individual factors and the context of physical activity in exercise dependence: A prospective study of 'ultra-marathoners'. Int J Ment Health Addict 2007;5:233-43.

537. Szabo A, Griffiths MD, de La Vega Marcos R, et al. Methodological and conceptual limitations in exercise addiction research. Yale J Biol Med 2015:88:303-8.

538. Chen W-J. Frequent exercise: a healthy habit or a behavioral addiction? Chronic Dis Trans/ Med 2016:2:235-40.

539. Plateau CR, Shanmugam V, Duckham RL, et al. Use of the compulsive exercise test with athletes: norms and links with eating psychopathology. J App/ Sport Psychol 2014;26:287-301.

540. Bamber D, Cockerill IM, Carroll D. The pathological status of exercise dependence. $\mathrm{Br}$ J Sports Med 2000;34:125-32

541. Blaydon MJ, Lindner KJ, Kerr JH. Metamotivational characteristics of eatingdisordered and exercise-dependent triathletes: an application of reversal theory. Psychol Sport Exerc 2002;3:223-36
542. Coverley Veale DMW, dependence E. Exercise dependence. Br J Addict 1987:82:735-40.

543. Petry NM. Gambling disorder: The first officially recognized behavioral addiction. In: Petry NM, ed. Behavioral addictions: DSM-5 and beyond. New York, NY: Oxford University Press, 2016: 7-42.

544. Paskus T, Derevensky J. Trends in NCAA Student-Athlete Gambling Behaviors and Attitudes [PowerPoint Presentation. Indianapolis, IN: NCAA, 2017.

545. Alexander K, Stafford A, Lewis R. The experiences of children participating in organised sport in the UK. Edinburgh: The University of Edinburgh/NSPCC Child Protection Research Center, 2011

546. Fasting K, Brackenridge C, Knorre N. Performance level and sexual harassment prevalence among female athletes in the Czech Republic. WSPAJ 2010;19:26-32.

547. Leahy T, Pretty G, Tenenbaum G. Prevalence of sexual abuse in organised competitive sport in Australia. J Sex Aggress 2002;8:16-36.

548. Parent S, Fortier K. Prevalence of interpersonal violence against athletes in the sport context. Curr Opin Psychol 2017;16:165-9.

549. Vertommen T, Schipper-van Veldhoven NHMJ, Hartill MJ, et al. Sexual harassment and abuse in sport: the NOC*NSF helpline. Int Rev Sociol Sport 2015;50:822-39.

550. LSEPS. European Union kids online report. London, UK: Science LSoEaP, 2014.

551. Denison E, Kitchen A. Out on the fields, 2015. Available: http://www. outonthefields. com/wp-content/uploads/2016/04/Out-on-the-Fields-Final-Report.pdf [Accessed 05 May 2019].

552. Vertommen T, Schipper-van Veldhoven N, Wouters K, et al. Interpersonal violence against children in sport in the Netherlands and Belgium. Child Abuse Neglect 2016:51:223-36.

553. Stafford A, Alexander K, Fry D. 'There was something that wasn't right because that was the only place I ever got treated like that': Children and young people's experiences of emotional harm in sport. Childhood 2015;22:121-37.

554. Brackenridge C, Fasting K. Sexual harassment and abuse in sport: the research context. J Sex Aggress 2002;8:3-15.

555. Fasting K, Brackenridge C, Sundgot-Borgen J. Prevalence of sexual harassment among Norwegian female elite athletes inrelation to sport type. Int Rev Sociol Sport 2004:39:373-86

556. Mountjoy M. 'Only by speaking out can we create lasting change': what can we learn from the Dr Larry Nassar tragedy? Br I Sports Med 2019;53:57-60.

557. Sand TS, Fasting K, Chroni S, et al. Coaching behavior: any consequences for the prevalence of sexual harassment? Int I Sports Sci Coach 2011;6:229-41.

558. Fasting K, Huffman D, Sand TS. Gender based violence in Zambian sport: prevalence and protection. Oslo: Norwegian Olympic and Paralympic Committee and Confederations of Sports, 2015.

559. Tofler IR, Morse ED. The interface between sport psychiatry and sports medicine. Clin Sports Med 2005;24:959-71.

560. Gervis M, Dunn N. The emotional abuse of elite child athletes by their coaches. Child Abuse Rev 2004:13:215-23.

561. Yukhymenko-Lescroart MA, Brown ME, Paskus TS. The relationship between ethical and abusive coaching behaviors and student-athlete well-being. Sport Exerc Perform Psychol 2015;4:36-49.

562. Fasting K, Brackenridge C, Walseth K. Consequences of sexual harassment in sport for female athletes. J Sex Aggress 2002;8:37-48.

563. Raakman E, Dorsch K, Rhind D. The development of a typology of abusive coaching behaviours within youth sport. Int I Sports Sci Coach 2010;5:503-15.

564. Fasting K, Brackenridge C, Walseth K. Women athletes' personal responses to sexual harassment in sport. J Appl Sport Psychol 2007;19:419-33.

565. Leahy T. Working with adult athlete survivors of sexual abuse. In: Hanrahan SJ, Anderson MB, eds. Routledge Handbook of applied sport psychology: a comprehensive guide for students and practitioners. London, UK: Routledge, 2010: $303-12$.

566. Marks S, Mountjoy M, Marcus M. Sexual harassment and abuse in sport: the role of the team doctor. Br J Sports Med 2012:46:905-8.

567. NCAA. Interassociation consensus document: understanding and supporting Student-Athlete mental wellness. Mental health best practices, 2018. Available: http://www.ncaa.org/sites/default/files/SSI_MentalHealthBestPractices_Web_ 20170921.pdf [Accessed 18 Feb 2018].

568. Putukian M. How being injured affects mental health. In: Brown GT, Hainline B,

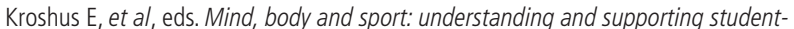
athlete mental wellness. Indianapolis: NCAA Press, 2014: 72-5.

569. Herring SA, Kibler WB, Putukian M. Psychological issues related to illness and injury in athletes and the team physician: a consensus statement-2016 update. Med Sci Sports Exerc 2017:49:1043-54

570. Neal TL, Diamond AB, Goldman S, et al. Inter-Association recommendations for developing a plan to recognize and refer student-athletes with psychological concerns at the collegiate level: an executive summary of a consensus statement. $J$ Athl Train 2013;48:716-20

571. Ivarsson A, Johnson U. Psychological factors as predictors of injuries among senior soccer players. A prospective study. J Sports Sci Med 2010;9:347-52

572. Ivarsson A, Johnson $U$, Andersen MB, et al. Psychosocial factors and sport injuries: meta-analyses for prediction and prevention. Sports Med 2017;47:353-65 
573. Ardern CL, Taylor NF, Feller JA, et al. A systematic review of the psychological factors associated with returning to sport following injury. Br J Sports Med 2013;47:1120-6.

574. Wiese-Bjornstal DM. Psychology and socioculture affect injury risk, response, and recovery in high-intensity athletes: a consensus statement. Scand J Med Sci Sports 2010;20:103-11.

575. Wiese-bjornstal DM, Smith AM, Shaffer SM, et al. An integrated model of response to sport injury: psychological and sociological dynamics. J App/ Sport Psychology 1998;10:46-69.

576. Nippert AH, Smith AM. Psychologic stress related to injury and impact on sport performance. Phys Med Rehabil Clin N Am 2008;19:399-418.

577. Ivarsson A, Johnson U, Lindwall M, et al. Psychosocial stress as a predictor of injury in elite junior soccer: a latent growth curve analysis. J Sci Med Sport 2014; 17:366-70.

578. Forsdyke D, Smith A, Jones M, et al. Psychosocial factors associated with outcomes of sports injury rehabilitation in competitive athletes: a mixed studies systematic review. Br J Sports Med 2016;50:537-44.

579. Timpka T, Janson S, Jacobsson J, et al. Lifetime history of sexual and physical abuse among competitive athletics (track and field) athletes: cross sectional study of associations with sports and non-sports injury. Br J Sports Med 2018.doi: 10.1136/ bjsports-2018-099335. [Epub ahead of print]

580. Fletcher $D$, Hanton $S$. Sources of organizational stress in elite sports performers. Sport Psychol 2003;17:175-95.

581. Pensgaard AM, Ivarsson A, Nilstad A, et al. Psychosocial stress factors, including the relationship with the coach, and their influence on acute and overuse injury risk in elite female football players. BMJ Open Sport Exerc Med 2018;4:e000317.

582. van der Does HTD, Brink MS, Otter RTA, et al. Injury risk is increased by changes in perceived recovery of team sport players. Clin J Sport Med 2017;27:46-51.

583. Steffen K, Pensgaard AM, Bahr R. Self-reported psychological characteristics as risk factors for injuries in female youth football. Scand J Med Sci Sports 2009;19:442-51.

584. Kellmann M. Preventing overtraining in athletes in high-intensity sports and stress/ recovery monitoring. Scand J Med Sci Sports 2010;20:95-102.

585. Staufenbiel SM, Penninx BWJH, Spijker AT, et al. Hair cortisol, stress exposure, and mental health in humans: a systematic review. Psychoneuroendocrinology 2013;38:1220-35

586. Nicholls AR, Levy AR, Grice A, et al. Stress appraisals, coping, and coping effectiveness among international cross-country runners during training and competition. Eur J Sport Sci 2009;9:285-93.

587. Casper D. Psychological predictors of injury among professional soccer players. Sport Science Review 2011;20:5-36.

588. Hainline B, Turner JA, Caneiro JP, et al. Pain in elite athletes-neurophysiological, biomechanical and psychosocial considerations: a narrative review. $\mathrm{Br}$ J Sports Med 2017;51:1259-64.

589. Beals KA, Manore MM. Disorders of the female athlete triad among collegiate athletes. Int J Sport Nutr Exerc Metab 2002;12:281-93.

590. Weigand S, Cohen J, Merenstein D. Susceptibility for depression in current and retired student athletes. Sports Health 2013;5:263-6.

591. Lindqvist A-S, Moberg T, Ehrnborg C, et al. Increased mortality rate and suicide in Swedish former elite male athletes in power sports. Scand J Med Sci Sports 2014;24:1000-5.

592. Armstrong S, Oomen-Early J, connectedness S. Social connectedness, self-esteem, and depression symptomatology among collegiate athletes versus Nonathletes. J of Coll Health 2009;57:521-6.

593. Weinstock J, Whelan JP, Meyers AW, et al. Gambling behavior of student-athletes and a student cohort: what are the odds? J Gamb/ Stud 2007:23:13-24.

594. Kerr ZY, Marshall SW, Harding HP, et al. Nine-year risk of depression diagnosis increases with increasing self-reported concussions in retired professional footbal players. Am J Sports Med 2012;40:2206-12.

595. Smith AM, Milliner EK. Injured athletes and the risk of suicide. J Athl Train 1994;29:337-41.

596. Ardern CL. Anterior cruciate ligament reconstruction-not exactly a one-way ticket back to the preinjury level: a review of contextual factors affecting return to sport after surgery. Sports Health 2015;7:224-30.

597. Czuppon S, Racette BA, Klein SE, et al. Variables associated with return to sport following anterior cruciate ligament reconstruction: a systematic review. Br J Sports Med 2014;48:356-64.

598. Glazer DD. Development and preliminary validation of the injury-psychological readiness to return to sport (I-PRRS) scale. J Ath/ Train 2009:44:185-9.

599. Tripp DA, Stanish W, Ebel-Lam A, et al. Fear of reinjury, negative affect, and catastrophizing predicting return to sport in recreational athletes with anterior cruciate ligament injuries at 1 year postsurgery. Rehabil Psychol 2007;52:74-81.

600. Gignac MAM, Cao X, Ramanathan S, et al. Perceived personal importance of exercise and fears of re-injury: a longitudinal study of psychological factors related to activity after anterior cruciate ligament reconstruction. BMC Sports Sci Med Rehabil 2015;7:4.

601. Flanigan DC, Everhart JS, Glassman AH. Psychological factors affecting rehabilitation and outcomes following elective orthopaedic surgery. J Am Acad Orthop Surg 2015;23:563-70
602. Everhart JS, Best TM, Flanigan DC. Psychological predictors of anterior cruciate ligament reconstruction outcomes: a systematic review. Knee Surg Sports Traumatol Arthroscopy 2015;23:752-62.

603. Podlog L, Banham SM, Wadey R, et al. Psychological readiness to return to competitive sport following Injury: a qualitative study. Sport Psychol 2015;29:1-14.

604. Podlog L, Dimmock J, Miller J. A review of return to sport concerns following injury rehabilitation: practitioner strategies for enhancing recovery outcomes. Phys Ther Sport 2011:12:36-42.

605. Ardern CL, Taylor NF, Feller JA, et al. Sports participation 2 years after anterior cruciate ligament reconstruction in athletes who had not returned to sport at 1 year: a prospective follow-up of physical function and psychological factors in 122 athletes. Am J Sports Med 2015;43:848-56.

606. Hainline B, Derman W, Vernec A, et al. International Olympic Committee consensus statement on pain management in elite athletes. $\mathrm{Br} J$ Sports $\mathrm{Med}$ 2017:51:1245-58.

607. Biggin IJR, Burns JH, Uphill M. An investigation of athletes' and coaches' perceptions of mental ill-health in elite athletes. J Clin Sport Psychol 2017:11:126-47.

608. Page SJ, Martin SB, Wayda VK. Attitudes toward seeking sport psychology consultation among wheelchair basketball athletes. Adapted Phys Activity $Q$ 2001;18:183-92.

609. Wood S, Harrison LK, Kucharska J. Male professional footballers' experiences of mental health difficulties and help-seeking. Phys Sportsmed 2017;45:120-8.

610. Watson JC. College student-athletes' attitudes toward help-seeking behavior and expectations of counseling services. J Coll Stud Dev 2005:46:442-9.

611. Green M, Morgan G, Manley A. Elite rugby League players' attitudes towards sport psychology consulting. Sport Exerc Psychol Rev 2012;8:32-44.

612. MSM L, Bowden-Jones $H$, Salinas M, et al. The experience of gambling problems in British professional footballers: a preliminary qualitative study. Addict Res Theory 2017;25:129-38

613. Kaier $\mathrm{E}$, Cromer LD, Johnson MD, et al. Perceptions of mental illness stigma: comparisons of athletes to nonathlete Peers. J Coll Stud Dev 2015;56:735-9.

614. Bird MD, Chow GM, Meir G, et al. Student-athlete and student non-athletes' stigma and attitudes toward seeking online and face-to-face counseling. J Clin Sport Psychol 2018;12:347-64.

615. Hilliard RC, Redmond LA, Watson JC. Differences in stigma and attitudes toward counseling between college student-athletes and nonathletes. J College Stud Psychother 2018;36:1-8

616. Wahto RS, Swift JK, Whipple JL. The role of stigma and referral source in predictingcollege student-athletes' attitudes toward psychological help-seeking. J Clin Sport Psychol 2016;10:85-98

617. van der Watt ASJ, Nortje G, Kola L, et al. Collaboration between biomedical and complementary and alternative care providers: barriers and pathways. Qual Health Res 2017:27:2177-88.

618. Kpobi LNA, Swartz L. 'The threads in his mind have torn': conceptualization and treatment of mental disorders by neo-prophetic Christian healers in Accra, Ghana. Int J Ment Health Syst 2018;12:40.

619. Bird MD, Chow GM, Cooper BT. Student-athletes' mental health help-seeking experiences: A mixed methodological approach. J College Stud Psychother 2018;40:1-19.

620. Daltry R, Milliner $\mathrm{K}$, James T. Understanding gender differences in collegiate studentathletes' help-seeking behaviors and attitudes toward counseling. Int I Sport Soc 2018:9:11-21.

621. Delenardo S, Terrion JL. Suck it up: opinions and attitudes about mental illness stigma and help-seeking behaviour of male varsity football players. Can J Commun Ment Health 2014:33:43-56.

622. Bapat S, Jorm A, Lawrence K. Evaluation of a mental health literacy training program for junior sporting clubs. Australasian Psychiatry 2009;17:475-9.

623. Gulliver A, Griffiths KM, Christensen H, et al. Internet-based interventions to promote mental health help-seeking in elite athletes: an exploratory randomized controlled trial. J Med Internet Res 2012;14:e69.

624. Pierce D, Liaw S-T, Dobell J, et al. Australian rural football club leaders as mental health advocates: an investigation of the impact of the coach the coach project. Int $J$ Ment Health Syst 2010;4:10-18.

625. Jones T-V. Predictors of perceptions of mental illness and averseness to help: a survey of elite football players. J Ment Health 2016;25:422-7.

626. Beauchemin J. College student-athlete wellness: an integrative outreach model. College Student J 2014;48:268-80.

627. Kern A, Heininger W, Klueh E, et al. Athletes connected: results from a pilot project to address knowledge and attitudes about mental health among college studentathletes. J Clin Sport Psychol 2017:11:324-36.

628. Martin SB, School H. High school and college athletes' attitudes toward sport psychology consulting. J App/ Sport Psychol 2005;17:127-39.

629. Martin SB, Lavallee D, Kellmann M, et al. Attitudes toward sport psychology consulting of adult athletes from the United States, United Kingdom, and Germany. Int J Sport Exerc Psychol 2004;2:146-60.

630. Martin SB, Wrisberg CA, Beitel PA, et al. NCAA division I athletes' attitudes toward seeking sport psychology consultation: The development of an objective instrument. Sport Psychol 1997;11:201-18. 
631. Steinfeldt JA, Steinfeldt MC, England B, et al. Gender role conflict and stigma toward help-seeking among college football players. Psychol Men Masc 2009;10:261-72.

632. NCH O, Harwood C. Attitudes toward sport psychology consulting in athletes: understanding the role of culture and personality. Sport Exerc Performance Psychol 2017;7:46-59.

633. Naoi A, Watson J, Deaner $\mathrm{H}$, et al. Multicultural issues in sport psychology and consultation. Int J Sport Exerc Psychol 2011;9:110-25.

634. López RL, Levy JJ. Student athletes' perceived barriers to and preferences for seeking counseling. J Coll Couns 2013;16:19-31.

635. Roberts C-M, Faull AL, Tod D. Blurred lines: performance enhancement, common mental disorders and referral in the U.K. athletic population. Front Psychol 2016;7:1067.

636. Ponnusamy V, Grove JR. Sport psychology service provision: preferences for consultant characteristics and mode of delivery among elite Malaysian athletes. J Sports Sci Med 2014;13:638-44.

637. Park RJ. Contesting the norm: women and professional sports in late nineteenthcentury America. Int J Hist Sport 2012;29:730-49.

638. Blodgett AT, Ge Y, Schinke RJ, et al. Intersecting identities of elite female boxers: stories of cultural difference and marginalization in sport. Psychol Sport Exerc 2017:32:83-92.

639. Sohal D, Gervis M, Rhind D. Exploration of organizational stressors in Indian elite female athletes. Int J Sport Psychol 2013;44:565-85.

640. Pfister G. Outsiders: Muslim women and Olympic games -barriers and opportunities Int J Hist Sport 2010;27:2925-57.

641. Reardon C. The role of culture in sport. In: Baron DA, ed. Clinical sports psychiatry: an international perspective. Oxford: John Wiley \& Sons, 2013: 179-87

642. Kaskan ER, Ho IK. Microaggressions and female athletes. Sex Roles 2016;74:275-87.

643. Harkness G. Out of bounds: cultural barriers to female sports participation in Qatar. Int J Hist Sport 2012;29:2162-83.

644. Battochio RC, Schinke RJ, McGannon KR, et al. Understanding immigrated professional athletes' support networks during post-relocation adaptation through media data. Int J Sport Exerc Psychol 2013;11:101-16.

645. Hamdi N, Lachheb M, Anderson E. Masculinity, homosexuality and sport in an Islamic state of increasing homohysteria. J Gend Stud 2017;26:688-701.

646. DeFoor MT, Stepleman LM, Mann PC. Improving wellness for LGB collegiate student athletes through sports medicine: a narrative review. Sports Med Open 2018;4:48.

647. Magrath R, Anderson E, Roberts S. On the door-step of equality: attitudes toward gay athletes among academy-level footballers. Int Rev Socio/ Sport 2015;50:804-21.

648. Tagg B. Transgender netballers: ethical issues and lived realities. Socio/ Sport J 2012;29:151-67.

649. World Anti-Doping Agency (WADA). TUE physician guidelines, medical information to support the decisions of TUE committees, transgender athletes, 2017.

650. Murty KS, Roebuck JB. Deviant exploitation of black male student athletes on white campuses. Deviant Behav 2015;36:429-40.

651. Cunningham GB, Miner K, McDonald J. Being different and suffering the consequences: the influence of head coach-player racial dissimilarity on experienced incivility. Int Rev Socio/ Sport 2013;48:689-705.

652. Lee SM, Bernstein MB, Etzel EF, et al. Student-athletes experiences with racial microaggressions in sport: a foucauldian discourse analysis. Qual Rep 2018;23:1016-42.

653. Burdsey D. That joke isn't funny anymore: racial microaggressions, color-blind ideology and the mitigation of racism in English men's first-class cricket. Sociol Sport J 2011;28:261-83.

654. Comeaux E. Unmasking athlete microaggressions: division I studentathletes'engagement with members of the campus community. J Intercollegiate Sport 2012;5:189-98.

655. Lawrence DW. Sociodemographic profile of an olympic team. Public Health 2017;148:149-58.

656. Gouttebarge V, Frings-Dresen MHW, Sluiter JK. Mental and psychosocial health among current and former professional footballers. Occup Med 2015;65:190-6.

657. Gouttebarge V, Aoki H, Kerkhoffs GM. Prevalence and determinants of symptoms related to mental disorders in retired male professional footballers. J Sports Med Phys Fitness 2016;56:648-54.

658. Kilic Özgür, Aoki H, Haagensen R, et al. Symptoms of common mental disorders and related stressors in Danish professional football and handball. Eur J Sport SCi 2017; 17:1328-34.

659. Schwenk TL, Gorenflo DW, Dopp RR, et al. Depression and pain in retired professional football players. Med Sci Sports Exerc 2007;39:599-605.

660. Stephan Y, Bilard J. Repercussions of transition out of elite sport on subjective wellbeing: a one-year study. J App/ Sport Psycho/ 2003;15:354-71.

661. Wippert P-M, Wippert J. Perceived stress and prevalence of traumatic stress symptoms following athletic career termination. J Clin Sport Psychol 2008;2:1-16

662. van Ramele S, Aoki H, Kerkhoffs GMMJ, et al. Mental health in retired professional football players: 12-month incidence, adverse life events and support. Psycho/ Sport Exerc 2017;28:85-90.
663. Wylleman P, Lavallee D. A developmental perspective on transitions faced by athletes. In: Weiss MR, ed. Developmental sport and exercise psychology: a lifespan perspective. Morgantown, WV: Fitness Information Technology, 2004: 503-23.

664. Arvinen-Barrow M, Hurley D, Ruiz MC. Transitioning out of professional sport: the psychosocial impact of career-ending injuries among elite Irish rugby football union players. J Clin Sport Psychol 2017;11:67-84.

665. Sanders G, Stevinson C. Associations between retirement reasons, chronic pain, athletic identity, and depressive symptoms among former professional footballers. Eur J Sport Sci 2017; 17:1311-8.

666. Stoltenburg AL, Kamphoff CS, Bremer KL. Transitioning out of sport: The psychosocial effects of collegiate athletes' career-ending injuries. Athletic Insight J 2011;3.

667. Wippert P-M, Wippert J. The effects of involuntary athletic career termination on psychological distress. J Clin Sport Psychol 2010;4:133-49.

668. Knights S, Sherry E, Ruddock-Hudson M. Investigating elite end-of-athletic-career transition: a systematic review. J App/ Sport Psychol 2016:28:291-308.

669. Esopenko C, Chow TW, Tartaglia MC, et al. Cognitive and psychosocial function in retired professional hockey players. J Neurol Neurosurg Psychiatry 2017;88:512-9.

670. Guskiewicz KM, Marshall SW, Bailes J, et al. Association between recurrent concussion and late-life cognitive impairment in retired professional football players. Neurosurgery 2005;57:719-26.

671. Hart J, Kraut MA, Womack KB, et al. Neuroimaging of cognitive dysfunction and depression in aging retired National Football League players. JAMA Neurol 2013;70:326-35.

672. Strain J, Didehbani N, Cullum CM, et al. Depressive symptoms and white matter dysfunction in retired NFL players with concussion history. Neurology 2013:81:25-32.

673. Gouttebarge V, Aoki H, Verhagen E, et al. Are level of education and employment related to symptoms of common mental disorders in current and retired professional footballers? Asian J Sports Med 2016;7:e28447

674. Schuring $\mathrm{N}$, Aoki H, Gray J, et al. Osteoarthritis is associated with symptoms of common mental disorders among former elite athletes. Knee Surg Sports Traumatol Arthrosc 2017;25:3179-85.

675. Carmody S, Jones C, Malhotra A, et al. Put out to pasture: what is our duty of care to the retiring professional footballer? Promoting the concept of the 'exit health examination' (EHE). Br J Sports Med 2018.doi: 10.1136/bjsports-2017-098392. [Epub ahead of print]

676. Gouttebarge V, Goedhart E, Kerkhoffs G. Empowering the health of retired professional footballers: the systematic development of an after career consultation and Its feasibility. BMJ Open Sport Exerc Med 2018;4:e000466.

677. Sinclair DA, Orlick T. Positive transitions from high-performance sport. Sport Psychol 1993;7:138-50.

678. Newman BM, Ravindranath D. Managing a psychiatric emergency. Psychiatric Times 2010;27:1-5.

679. Patel MX, Sethi FN, Barnes TR, et al. Joint BAP NAPICU evidence-based consensus guidelines for the clinical management of acute disturbance: De-escalation and rapid tranquillisation. J Psychopharmacol 2018;32:601-40.

680. Blakelock DJ, Chen MA, Prescott T. Psychological distress in elite adolescent soccer players following deselection. J Clin Sport Psychol 2016;10:59-77.

681. Galambos SAet al. Psychological predictors of injury among elite athletes * commentary. Br J Sports Med 2005:39:351-4.

682. Baum AL. Suicide in athletes. In: Baron DA, Reardon CL, Baron SH, eds. Clinical sports psychiatry: an international perpsective. 1st edn. Oxford: John Wiley \& Co, 2013: 79-88.

683. Hill A, Á M, Collins D, et al. Examining the role of mental health and clinical issues within talent development. Front Psychol 2042;2015:2042

684. Pagonis TA, Angelopoulos NV, Koukoulis GN, et al. Psychiatric side effects induced by supraphysiological doses of combinations of anabolic steroids correlate to the severity of abuse. Eur Psychiatry 2006;21:551-62.

685. Pope HG, Kouri EM, Hudson Jl. Effects of supraphysiologic doses of testosterone on mood and aggression in normal men: a randomized controlled trial. Arch Gen Psychiatry 2000;57:133-40.

686. Su TP, Pagliaro M, Schmidt PJ, et al. Neuropsychiatric effects of anabolic steroids in male normal volunteers. JAMA 1993;269:2760-4.

687. Thiblin I, Runeson B, Rajs J. Anabolic androgenic steroids and suicide. Ann Clin Psychiatry 1999;11:223-31.

688. Hall KE, Monte AA, Chang T, et al. Mental health-related emergency department visits associated with cannabis in Colorado. Acad Emerg Med 2018:25:526-37.

689. Winstock AR, Barratt MJ. The 12-month prevalence and nature of adverse experiences resulting in emergency medical presentations associated with the use of synthetic cannabinoid products. Hum Psychopharmacol Clin Exp 2013;28:390-3.

690. Weir D, Jackson J, Sonnega A. National Football League player care Foundation Study of retired NFL players. Ann Arbor: University of Michigan Institute for Social Research, 2009.

691. Currie A, Morse ED. Eating disorders in athletes: managing the risks. Clin Sports Med 2005;24:871-83

692. Hendawy HM, Baron DA, Sei-Eldawla A, et al. Prevalence of psychiatric disorders and coping processes in a sample of Egyptian competitive athletes. In: Baron DA, 
ed. Clinical sports psychiatry: an international perspective. Oxford. UK: John Wiley \& Sons, 2012: 53-64.

693. Allen MH, Currier GW, Hughes DH, et al. The expert consensus guideline series. treatment of behavioral emergencies. Postgrad Med 2001;2001:1-88.

694. Currie A, Johnston A. Psychiatric disorders: The psychiatrist's contribution to sport. Int Rev Psychiatry 2016;28:587-94.

695. Suldo SM, Shaffer EJ. Looking beyond psychopathology: the dual-factor model of mental health in youth. School Psych Rev 2008:37:52-68.

696. Keyes CLM, Dhingra SS, Simoes EJ. Change in level of positive mental health as a predictor of future risk of mental illness. Am J Public Health 2010:100:2366-71.

697. Potter M. One coach's X and O: Pay attention, give permission. In: Brown GT, Hainline B, Kroshus E, et al, eds. Mind, body and sport: understanding the supporting student-athlete mental wellness. Indianapolis: NCAA Publications, 2014: 12-13.

698. Kroshus E, Chrisman SPD, Coppel D, et al. Coach support of high school studentathletes struggling with anxiety or depression. J Clin Sport Psychol 2018:1-26.

699. Nixdorf I, Frank R, Beckmann J. An explorative study on major stressors and its connection to depression and chronic stress among German elite athletes. Adv Phys Ed 2015;05:255-62.

700. Armstrong S, Burcin M, Bjerke W, et al. Depression in student athletes: a particularly at-risk group? A systematic review of the literature. Athletic Insight 2015;7:177-93.

701. Lonsdale C, Hodge K, Rose E. Athlete burnout in elite sport: a self-determination perspective. J Sports Sci 2009;27:785-95.

702. Fraser-Thomas JL, Côté J, Deakin J. Youth sport programs: an Avenue to foster positive youth development. Phys Edu Sport Pedagogy 2005;10:19-40.

703. Patel DR, Pratt HD, Greydanus DE. Pediatric neurodevelopment and sports participation. when are children ready to play sports? Pediatr Clin North Am 2002;49:505-31.

704. Bergeron MF, Mountioy M, Armstrong N, et al. International Olympic Committee consensus statement on youth athletic development. Br I Sports Med 2015:49:843-51.

705. Montano DE, Kasprzyk D. Theory of reasoned action, theory of planned behavior, and the integrated behavioral model. In: Glanz K, Rimer BK, Viswanath K, eds. Health behavior: theory, research and practice. San Francisco: Jossey-Bass, 2015: 95-124.

706. Turnnidge J, Côté J. Applying transformational leadership theory to coaching research in youth sport: a systematic literature review. Int I Sport Exerc Psychol 2018;16:327-42

707. Raedeke TD, Smith AL. Coping resources and athlete burnout: an examination of stress mediated and moderation hypotheses. J Sport Exerc Psychol 2004;26:525-41.

708. Wagstaff CRD, Sarkar M, Davidson CL. Resilience in sport: a critical review of psychological processes, sociocultural influences, and organizational dynamics. In: Wagstaff CRD, ed. The organizational psychology of sport: key issues and practical applications. London, UK: Routledge, 2016: 120-49.

709. Kashdan TB, Rottenberg J. Psychological flexibility as a fundamental aspect of health. Clin Psychol Rev 2010;30:865-78.

710. Neff KD, McGehee P. Self-compassion and psychological resilience among adolescents and young adults. Self and Identity 2010;9:225-40.

711. Duda JL, Balaguer I. Coach-created motivational climate. In: Jowette S, Lavallee $D_{\text {, }}$ eds. Social psychology in sport. Champaign, IL: Human Kinetics, 2007: 117-30.

712. Smith RE, Smoll FL, Cumming SP. Effects of a motivational climate intervention for coaches on young athletes' sport performance anxiety. J Sport Exerc Psychol 2007;29:39-59.

713. Keegan RJ, Harwood CG, Spray CM, et al. A qualitative investigation exploring the motivational climate in early career sports participants: coach, parent and peer influences on sport motivation. Psychol Sport Exerc 2009;10:361-72.

714. Bortoli L, Bertollo M, Comani S, et al. Competence, achievement goals, motivational climate, and pleasant psychobiosocial states in youth sport. J Sports Sci 2011;29:171-80.

715. Mazzer KR, Rickwood DJ. Teachers' and coaches' role perceptions for supporting young people's mental health: multiple group path analyses. Aust J Psychol 2015;67:10-19.

716. Sebbens J, Hassmén P, Crisp D, et al. Mental health in sport (MHS): improving the Early intervention knowledge and confidence of elite sport staff. Front Psychol 2016;7:911.
717. Anderson RJ, Pierce D. Assumptions associated with mental health literacy training insights from initiatives in rural Australia. Adv Mental Health 2012;10:258-67.

718. Kitchener BA, Jorm AF. Mental health first aid training for the public: evaluation of effects on knowledge, attitudes and helping behavior. BMC Psychiatry 2002;2:10.

719. Hadlaczky G, Hökby S, Mkrtchian A, et al. Mental health first aid is an effective public health intervention for improving knowledge, attitudes, and behaviour: a meta-analysis. Int Rev Psychiatry 2014;26:467-75.

720. Bean C, Forneris T. Examining the importance of intentionally structuring the youth sport context to facilitate positive youth development. J App/ Sport Psychol 2016;28:410-25

721. McPherson BD, Curtis JE, Loy JW. The social significance of sport: an introduction to the sociology of Sport. Champaign, IIl.: Human Kinetics Books, 1989.

722. Bantjes J, Swartz L. Social inclusion through para sport: a critical reflection on the current state of play. Phys Med Rehabil Clin N Am 2018;29:409-16.

723. Martin JJ, Malone LA, Hilyer JC. Personality and mood in women's paralympic basketball champions. J Clin Sport Psychol 2011;5:197-210.

724. Watson N, Roulstone A, Thomas C. Routledge handbook of disability studies. London, New York: Routledge, 2014.

725. Macdougall H, O'Halloran P, Shields N, et al. Comparing the well-being of para and Olympic sport athletes: a systematic review. Adapted Phys Activity Q2015;32:256-76.

726. Tawse H, Bloom GA, Sabiston CM, et al. The role of coaches of wheelchair rugby in the development of athletes with a spinal cord injury. Qual Res Sport Exerc Health 2012:4:206-25

727. Campbell $E$, Jones $G$, Anxiety P. Precompetition anxiety and self-confidence in wheelchair sport participants. Adapted Physical Activity Quarterly 1997;14:95-107.

728. Campbell E, Jones $G$. Sources of stress experienced by elite male wheelchair Basketball players. Adapt Phys Activ Q 2002;19:82-99.

729. Campbell $E$, Jones $G$. Cognitive appraisal of sources of stress experienced by elite male wheelchair basketball players. Adapted Phys Activity Q2002;19:100-8.

730. Silva A, Queiroz SS, Winckler C, et al. Sleep quality evaluation, chronotype, sleepiness and anxiety of paralympic Brazilian athletes: Beijing 2008 Paralympic Games. Br J Sports Med 2012;46:150-4.

731. Swartz L, Bantjes J, Knight B, et al. "They don't understand that we also exist": South African participants in competitive disability sport and the politics of identity. Disabil Rehabil 2018;40:35-41.

732. Edwards C, Imrie R. Disability and bodies as bearers of value. Sociology 2003;37:239-56

733. Banack HR, Sabiston CM, Bloom GA. Coach autonomy support, basic need satisfaction, and intrinsic motivation of paralympic athletes. Res Q Exerc Sport 2011:82:722-30

734. Bantjes J, Swartz L, Conchar L, et al. Developing programmes to promote participation in sport among adolescents with disabilities: perceptions expressed by a group of South African adolescents with cerebral palsy. Int I Disability Dev Educ 2015;62:288-302.

735. Cheon SH, Reeve J, Lee J, et al. Giving and receiving autonomy support in a highstakes sport context: a field-based experiment during the 2012 London Paralympic Games. Psychol Sport Exerc 2015;19:59-69.

736. Shriver LH, Wollenberg G, Gates GE. Prevalence of disordered eating and its association with emotion regulation in female college athletes. Int I Sport Nutr Exerc Metab 2016;26:240-8

737. Sundgot-Borgen J. Risk and trigger factors for the development of eating disorders in female elite athletes. Med Sci Sports Exerc 1994;26:414-19.

738. Aidman $\mathrm{EV}$, Woollard $\mathrm{S}$. The influence of self-reported exercise addiction on acute emotional and physiological responses to brief exercise deprivation. Psychol Sport Exerc 2003;4:225-36.

739. Allegre B, Souville M, Therme P, et al. Definitions and measures of exercise dependence. Addiction Res Theory 2006;14:631-46.

740. Hausenblas HA, Downs DS. How much is too much? The development and validation of the exercise dependence scale. Psychol Health 2002;17:387-404.

741. Downs DS, Hausenblas HA, Nigg CR. Factorial validity and psychometric examination of the exercise dependence scale-revised. Meas Phys Educ Exerc Sci 2004:8:183-201. 